Vol. 7/No. 1 Jan/Feb 2017

http://jistudents.org/

\section{Journal of International Students}

A Quarterly Publication on International Education

Krishna Bista

Editor-in-Chief/Founder

University of Louisiana at Monroe (USA) 


\section{New Publications on International Student Studies}

\section{Books published by IGI Global:}

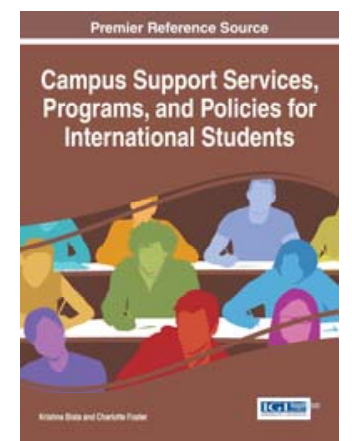

Premier Reference Source

Exploring the Social and Academic Experiences of International Students in Higher Education Institutions

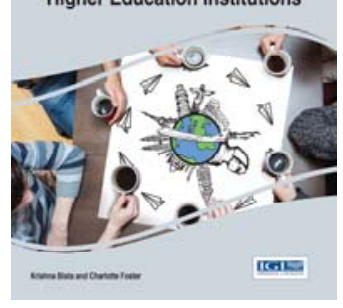

Global Perspectives

and Local Challenges

Surrounding International Student Mobility

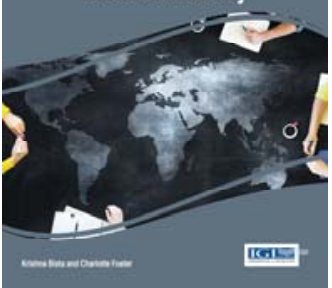

Campus Support Services, Programs, and Policies for International Students Krishna Bista and Charlotte Foster Copyright $\odot 2016.324$ pages

Exploring the Social and Academic Experiences of International Students in Higher Education Institutions Krishna Bista and Charlotte Foster Copyright $\odot 2016.318$ pages

Global Perspectives and Local Challenges Surrounding International Student Mobility Krishna Bista and Charlotte Foster Copyright $\odot 2016.354$ pages 
ISSN: 2162-3104 Print/ ISSN: 2166-3750 Online

Volume 6 Number 4 Oct/Nov 2016

(C) Journal of International Students

http://jistudents.org/

\section{EDITORIAL TEAM}

Founder/Editor-in-Chief: Dr. Krishna Bista, U. of Louisiana at Monroe, USA

\section{Associate Editors:}

Dr. Chris R. Glass, Old Dominion University, USA

Dr. Charlotte Foster, Missouri Western State University, USA

Dr. Danilo M. Baylen, University of West Georgia, USA

Dr. Diana B. Carlin, Saint Louis University, USA

Dr. Keri Dutkiewicz, Davenport University, USA

Dr. Sandria Officer, University of Toronto, Canada

Dr. Shyam Sharma, Stony Brook University, USA

Dr. Rai Farrelly, American University of Armenia, Armenia

Dr. Rosalind L. Raby, California Colleges for International Education, USA

Dr. Vera V. Chapman, Colgate University, USA

\section{Assistant Editors/Copy Editors}

Dr. Barry Fass-Holmes, University of California, San Diego, USA

Dr. Charles R. Harris, Stony Brook University, USA

Dr. Christina W. Yao, University of Nebraska- Lincoln, USA

Dr. David Comp, University of Chicago Booth School of Business, USA

Ms. Dorota Silber-Furman, Tennessee Tech University, USA

Dr. Hugo Garcia, Texas Tech University, USA

Dr. Jiaqi Li, Wichita State University, USA

Dr. Lisa Kahle-Piasecki, Tiffin Univesity, USA

Dr. Ji Zhou, USC Marshall School of Business, USA

Dr. Luchen Li, University of New Hampshire, USA

Dr. Miguel H. López, California State University, San Bernardino, USA

Dr. Mingsheng Li, Massey University, Wellington, New Zealand

Dr. Nicholas D. Hartlep, Illinois State University, USA

\section{Book Review \& Reflection Editors}

Dr. Yi Luo, University of Illinois at Urbana-Champaign, USA

Ms. Joy Bancroft, Daytona State Collage, USA

Ms. Kerri Bennett, Arkansas State University, USA

Dr. Misato Yamaguchi, Georgia Regents University, USA

Dr. Paige E. Sindt, The Middlebury Institute of Intl Studies at Monterey, USA

\section{BOARD OF DIRECTORS}

Cattriona Gribble, Deakin University, Australia; Amany Saleh, Arkansas State

University, USA; Howard Wang, Duke Kunshan University, China; Amy

Dagley, University of Alabama at Birmingham, USA; Charlotte Foster,

Missouri Western State University, USA; Don Jones, Belhaven University, USA;

Krishna Bista, University of Louisiana at Monroe, USA; Rahul

Choudaha, DrEducation.org, USA; Russ Hannah, Arkansas State University, USA;

Janet B. Ilieva, Education Insight, UK

For more information: http://jistudents.org/board 
ISSN: 2162-3104 Print/ ISSN: 2166-3750 Online

Volume 7 Number 1 Jan/Feb 2017

(C) Journal of International Students http://jistudents.org/

\section{Contributors}

1. Cheryl O. DuBose, Arkansas State University, Jonesboro, USA

2. Chia-Fang (Sandy) Hsu, University of Wyoming, USA

3. Daniel Moglen, University of California, Davis, USA

4. Dorothy N. Ugwu, Tarrant County Community College District, USA

5. I-Ting (Joyce) Huang, Synnix Industries Inc., Taiwan

6. Janet H. Bagby, Baylor University, USA

7. Janet Sheets, Baylor University, USA

8. Ju Seong Lee, University of Illinois at Urbana-Champaign, USA

9. Jun Mian Chen, Brock University, Canada

10. Karla Perez-Velez, University of Northern Colorado, USA

11. LaNette W. Thompson, Baylor University, USA

12. Maria Adamuti-Trache, University of Texas Arlington, USA

13. Nisreen Alsahafi, University of New South Wales, Australia

14. Seong-Chul Shin, University of New South Wales, Australia

15. Sherrie Lee, University of Waikato, New Zealand

16. Tamara Yakaboski, University of Northern Colorado, USA

17. Tonya M. Trepinski, Texas A\&M International University, USA

18. Tracey N. Sulak, Baylor University, USA

19. Yousef Almutairi, University of Northern Colorado, USA

\section{Founder/Editor-In-Chief}

Krishna Bista, University of Louisiana at Monroe (USA)

\section{BOARD OF DIRECTORS}

Cattriona Gribble, Deakin University, Australia; Amany Saleh, Arkansas State University, USA; Howard Wang, Duke Kunshan University, China; Amy Dagley, University of Alabama at Birmingham, USA; Charlotte Foster, Missouri Western State University, USA; Don Jones, Belhaven University, USA; Krishna Bista, University of Louisiana at Monroe, USA; Rahul Choudaha, DrEducation.org, USA; Russ Hannah, Arkansas State University, USA; Janet B. Ilieva, Education Insight, UK

For more information: http://jistudents.org/board/ 
Copyright (C) 2017 by Journal of International Students

All rights reserved. This book or any portion thereof may not be reproduced or used in any manner whatsoever without the express written permission of the publisher/editor except for the use of brief quotations in a book review or scholarly journal.

First Printing: 2017

Print ISSN 2162-3104

Online ISSN 2166-3750

Journal of International Students

230 Walker Hall, School of Education

University of Louisiana at Monroe

Monroe, LA 71209 USA

http://jistudents.org/

\section{Disclaimer}

Facts and opinions published in Journal of International Students (JIS) express solely the opinions of the respective authors. Authors are responsible for their citing of sources and the accuracy of their references and bibliographies. The editors cannot be held responsible for any lacks or possible violations of third parties' rights. 


\section{Journal of International Students}

\section{Jan/Feb 2017 | Volume 7 | Number 1}

An interdisciplinary, peer reviewed publication, Journal of International Students (Print ISSN 2162-3104 \& Online ISSN 2166-3750) is a professional journal that publishes narrative, theoretical and empiricallybased research articles, student reflections, and book reviews relevant to international students and their cross cultural experiences and understanding. Published quarterly, the Journal encourages the submission of manuscripts from around the world, and from a wide range of academic fields, including comparative education, international education, student affairs, linguistics, psychology, religion, sociology, business, social work, philosophy, and culture studies.

All articles published in the Journal of International Students are indexed and listed in major databases and sources:

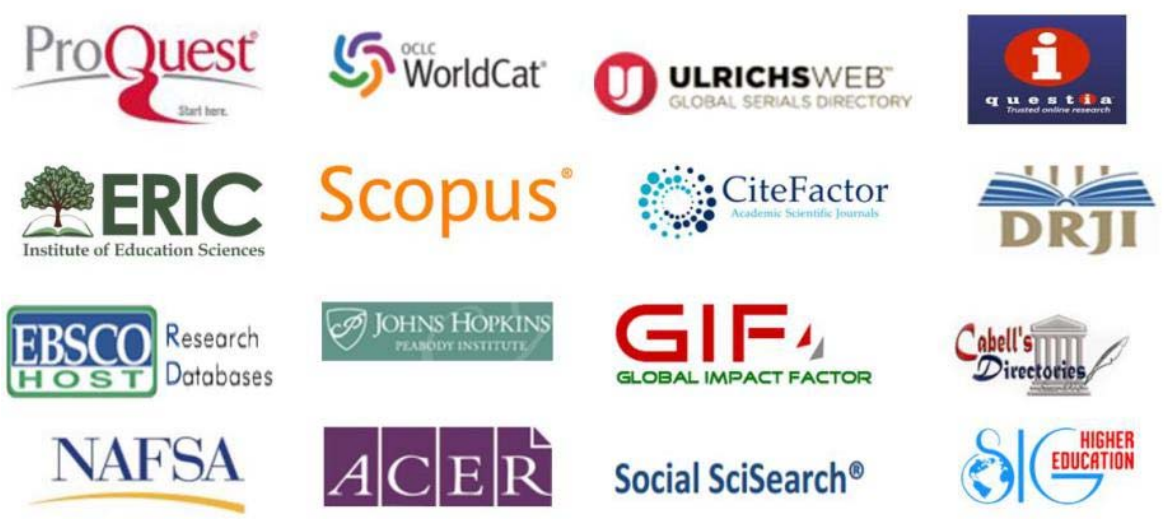

\section{Authors and Submissions}

The Journal audience includes international and domestic students, faculty, administrators, and educators engaged in research and practice in international students in colleges and universities.

a) Peer-reviewed Article - includes manuscripts that focus on the interpretation, implication, or significance of research work related to international students and scholars from various disciplines (between 4,500 to 7,500 words).

b) Research in Brief - includes manuscripts that focus a specific topic or question using new data or conceptual framework that does not require a full-length manuscript; up to two figures/tables, and maximum 5-8 references (1,500-2,000 words). 
c) Study Abroad/Reflection - includes descriptions and perceptions from students and scholars concerning another culture, language, people and society from an insider or outsider perspective (between 1,000 to 2,500 words).

d) Book/Dissertation/Flim Review - includes reviews and critiques of the written work of scholars from a number of disciplines related to international students (between 750 to 1,200 words).

Please e-mail your manuscript to the Editor, Dr. Krishna Bista at contact@jistudnets.org. Include your full address with email and telephone number. Follow APA 6th edition in your citation and references. Double space. Times New Roman with 12 font size.

This Journal is a non-profit publication and has been operating through the voluntary services of editors, copy editors, reviewers and guest editors. All positions in the Journal are unpaid. There is no fee for submission or publication.

\section{For further information}

Krishna Bista

Editor-in-Chief/Founder - Journal of International Students

http:/ /jistudents.org/

E-mail: contact@jistudents.org 
ISSN: 2162-3104 Print/ ISSN: 2166-3750 Online

Volume 7, Number $1 \mathrm{Jan} / \mathrm{Feb}$ (2017)

(C) Journal of International Students

http://jistudents.org

\section{Table of Contents}

Institutional Policies and Practices for Admitting, Assessing, and

I-VI

Tracking International Students (Editorial)

Maureen Snow Andrade, Utah Valley University, USA

1. Post-Graduation Plans of International Science and Engineering

Doctoral Students Attending U.S. Universities. ...

Dorothy N. Ugwu,Tarrant County Comm. College District, USA

Maria Adamuti-Trache, University of Texas Arlington, USA

2. International Graduate Students: Social Networks and Language

Use

Daniel Moglen, University of California, Davis, USA

3. Are International Students Quiet in Class? The Influence of

Teacher Confirmation on Classroom Apprehension and

Willingness to Talk in Class. ...

Chia-Fang (Sandy) Hsu, University of Wyoming, USA

I-Ting (Joyce) Huang, Synnix Industries Inc., Taiwan

4. Factors Affecting the Academic and Cultural Adjustment of

Saudi International Students in Australian Universities............

Nisreen Alsahafi, University of New South Wales, Australia

Seong-Chul Shin, University of New South Wales, Australia

5. Challenges of International Students in a Japanese University:

Ethnographic Perspectives for the First Semester..............

Ju Seong Lee, University of Illinois at Urbana-Champaign, USA

6. Collectivists' decision-making: Saudi Arabian graduate students' study abroad choices............................................

Tamara Yakaboski, Karla Perez-Velez and Yousef Almutairi, University of Northern Colorado, USA

7. Three Levels of Push-Pull Dynamics among Chinese International Students' Decision to Study Abroad in the Canadian Context...

Jun Mian Chen, Brock University, Canada

8. The Cultural Elements of Academic Honesty....

$136-153$

LaNette W. Thompson, Janet H. Bagby, Tracey N. Sulak, and Janet Sheets, Baylor University, USA

Tonya M. Trepinski, Texas A\&M International University, USA

9. But I Don't Understand You: One Faculty's Observations of the Challenges Facing International Healthcare Students. ...

Cheryl O. DuBose, Arkansas State University, Jonesboro, USA

Exploring the Social and Academic Experiences of International

Students in Higher Education Institutions. ...

Sherrie Lee, University of Waikato, New Zealand 
ISSN: 2162-3104 Print/ ISSN: 2166-3750 Online Volume 7, Number 1 Jan/Feb (2017) pp. I-VI

(C) Journal of International Students http://jistudents.org/

\title{
Institutional Policies and Practices for Admitting, Assessing, and Tracking International Students
}

\author{
Maureen Snow Andrade \\ Utah Valley University
}

The United States has the largest market share of international students at $22 \%$, followed by the United Kingdom at $11 \%$ (Project Atlas, 2015). The U.S. share has decreased from $28 \%$ in 2001 although total numbers of international students are increasing (Project Atlas, 2015). Decreased market share may be due to targeted national strategies in other countries to attract international students. These include immigration policies that not only expedite obtaining a student visa, but provide opportunities to work while studying and permanent jobs and residency after graduation (e.g., Canada, the Netherlands, Germany, Sweden) (Lane, 2015). Nations are also actively recruiting, providing databases with comprehensive information about studying in the country, (e.g., the Netherlands), and offering financial incentives (e.g., Germany)(Lane, 2015). In some cases, countries that once sent students to study abroad (United Arab Emirates, Singapore, Malaysia) are now actively recruiting to host students from their regions (Lane, 2015).

An important distinction in comparing the United States with other host countries is that only $4.8 \%$ of the total U.S. higher education enrollment is comprised of international students (Institute of International Research, 2015; Project Atlas, 2015) in contrast with approximately 22\% in the United Kingdom and $21 \%$ in Australia. This has significant implications for institutional practice in terms of English proficiency levels in particular. If international students represent only $1-2 \%$ of enrollments at an institution, for instance, the needs of these students can go largely unnoticed. Even in these situations, however, some programs of study may attract significant numbers of English language learners in which cases additional resources and strategies may be implemented. 
The overall percentage of students in U.S. higher education institutions may explain, in part, why the Department of Education or regional accrediting bodies do not provide centralized guidance for international student support. In contrast, Australia has addressed the needs of its large percentage of international students who speak English as an Additional Language by implementing 10 Good Practice Principles (Australian Universities Quality Agency, 2009). These include adequate resourcing for English language development, ensuring students' competency for study, determining appropriate entry requirements, understanding the need for well-developed communication skills at the time of graduation, advising students of their responsibility for proficiency improvement, embedding linguistic development into the curriculum, diagnosing needs early, supporting sociocultural adjustment, enhancing linguistic development through social interaction, and monitoring improvement. In all cases, whether guidelines are established or not, strategies need to be context-specific and may vary within institutions.

Prospective international students indicate that their primary motivation for studying abroad is to learn to speak English fluently followed by achieving a degree, obtaining a satisfying job, living in another country, and making a difference in the world (ICEF Monitor, 2016). Are U.S. institutions of higher education enabling students to achieve their top goal? Are they collecting sufficient data to make this determination? A series of national studies addressed these and related questions (Andrade, Evans, \& Hartshorn, 2014, 2015, 2016). The first study included a survey of staff directly responsible for international students, such as admissions officers, international student center directors, and ESL program directors, at the top hosting institutions in the U.S. Questions focused on institutional policies and practices for admitting, assessing, and tracking international students.

Findings indicated the following:

$>$ Institutions determine if prospective students are native or nonnative English speakers based on country of origin and citizenship (e.g., if they are from countries where English is predominantly spoken or which has English as an official language, the applicant is considered to be a native English speaker and is excused from admissions testing).

$>$ Students are admitted on a single standardized proficiency test. Few institutions require additional post-admissions testing such as further examination of writing or speaking skills, diagnostic testing, or as a best practice (e.g., using multiple measures). When testing 
occurs, writing skills assessment is the most common, particularly at the undergraduate level.

$>$ Undergraduate students are more likely than graduate students to be required to further their English language skills. The most common method for doing so is coursework.

$>$ Courses, skill centers, and tutoring are the most common means of support with courses generally being required and the other two types of support being optional.

$>$ No institutions track English language learners' proficiency development; about half track grade point averages, $40 \%$ track retention, and 30\% monitor graduation rates; this lack of tracking is primarily due to it not being required or to not having the resources to do so.

$>$ Participants had a range of perspectives about their policies and practices with some having full confidence in their admission processes and others recognizing that test scores do not always demonstrate actual ability or that they were making subjective assumptions about student success.

A follow-up study of these same institutions, but which solicited input from chief academic officers regarding the importance of international students to their strategic planning and the likelihood of adopting practices different from those established resulted in the following conclusions.

$>$ International students are critical to institutional strategic planning; institutions are committed to supporting the development of students' academic English skills.

$>$ Faculty/staff tend to lack of knowledge of language acquisition factors (e.g., general v. academic English) as well as the need for continued skill development.

$>$ International students who speak English as an additional language perform as well academically as native English speakers, yet faculty are likely not satisfied with students' skill levels.

$>$ Existing support focuses primarily on developing students' general academic English skills rather than on discipline-specific needs or preparing students with the linguistic skills needed for future professions.

$>$ Strategies beyond improving students' English language skills in ways other than required ESL coursework and optional tutoring or learning center attendance are generally not under consideration.

$>$ Institutions are most interested in conducting a needs analysis or changing testing approaches as opposed to additional tracking of 
learning outcomes, discipline-based approaches for English development, faculty training, or senior year English assessments.

$>$ Lack of resources and time to graduation, as opposed to faculty and student resistance, are perceived as the most significant barriers to implementing additional opportunities for English language development.

These studies establish that the institutions hosting the most international students in the U.S. follow fairly standard and consistent practices, which, for the most part, are quite practical. However, institutional decision-makers have not given much consideration to alternative ways of assessing and developing students' English language skills in spite of a strong commitment to this and an acknowledgement that students' skills could be better.

One way of framing the discussion of English language proficiency in order to change current paradigms is to shift the focus from an emphasis on support to a focus on English language development (Arkoudis, Baik, \& Richardson, 2012). Support implies simply helping students get through their degree requirements while development acknowledges a commitment to assisting students in achieving higher level skills and preparing them for future contexts in which they will use English. Given the variations in institutions, as indicated earlier, the framework in Figure 1 could serve as a guide to the development of institution-specific approaches.

Institutions must first determine stakeholder views and beliefs about the role of English language learning, how it develops, and expectations for levels of proficiency. They can then determine and develop pedagogical approaches most beneficial in helping students further develop their skills. They need to weigh the advantages and disadvantages of various approaches - for example, how would a collaborative model in which faculty partner with TESOL professionals to develop a discipline-based approach to proficiency development work as opposed to required generic stand-alone ESL course work or optional tutoring? Which model best supports learners and furthers their skills? What are the financial and human resource issues and what are the implications for organizational structure or policy? Are some approaches more appropriate than others in a given situation (e.g., many English learners in a major v. very few)? The same is true of the various assessment points in the Table. How feasible are they are which have the most benefits? How can an institution measure success in terms of advancing students' English proficiency? Should additional assessment points be identified or post-graduation information be collected from employers? 


\section{optional v. required \\ generic $v$. discipline \\ pedagogy collaborative \\ Views \& \\ situational beliefs \\ pre-admission \\ diagnostic \& on-going \\ a ssessment successmeasures \\ completion \& post}

Figure 1. Framework for English language development (adapted from Andrade et al. 2014, 2016).

U.S. institutions of higher education have enormous potential to develop models for furthering students' English language skills postadmission so that these learners can achieve their top goal for studying in an English-speaking country-fluent use of the language. Opportunities exist for innovations that will set institutions apart from their competitors in terms of their approach to English language development. This involves campuswide discussions and reflection of these results in institutional strategic plans. The proposed framework can serve as a guide.

\section{References}

Andrade, M. S., Evans, N. W., \& Hartshorn, J. (2016). Internationalizing higher education: English language policy and practice. In B. Krishna, \& C. Foster (Eds.), Campus support services, programs, and policies for international students (pp. 188-208). Hershey, PA: IGI Global.

Andrade, M. S., Evans, N. W., \& Hartshorn, J. (2015). Perceptions and realities of ESL students in higher education: An overview of institutional practices. In N. W. Evans, N. J. Anderson, \& W. G Eggington (Eds.), ESL readers and writers in higher education: Understanding challenges, providing support (pp. 18-35). New York, NY: Routledge.

Andrade, M. S., Evans, N. W., \& Hartshorn, K. J. (2014). Linguistic support for non-native English speakers: Higher education practices in the United States. Journal of Student Affairs Research and Practice, 51(2), 207-221. http://dx.doi.org/10.1515/jsarp-2014-0020 
Australian Universities Quality Agency. (2009). Good practice principles for English language proficiency for international students in Australian universities. Report to the Department of Education, Employment and Workplace Relations, Canberra. Retrieved from http://www.teqsa.gov.au

Evans, N. W., \& Andrade, M. S. (2015). Understanding challenges, providing support-ESL readers and writers in higher education. In N. W. Evans, N. J. Anderson, \& W. G Eggington (Eds.), ESL readers and writers in higher education: Understanding challenges, providing support (pp. 3-17). New York, NY: Routledge.

ICEF Monitor. (2016, February 12). New report tracks key influencers for international students. Retrieved from http://monitor.icef.com/2016/02/new-report-tracks-keyinfluencers-for-international-students/

Institute of International Education. (2015). International students. Enrollment trends. Retrieved from http://www.iie.org/Research-andPublications/Open-Doors/Data/International-Students/EnrollmentTrends/1948-2015

Lane, J. (2015, October 23). US losing its dominance in global higher education market.Retrieved from https://www.higheredjobs.com/ articles/articleDisplay.cfm?ID $=751$

MAUREEN SNOW ANDRADE is Associate Vice President of Academic Affairs for Academic Programs at Utah Valley University. Her responsibilities include flexible learning, student learning assessment, program review, faculty development, academic advisement, curriculum development, degree completion, general education, and graduate studies. Dr. Andrade is a professor in the field of education, specializing in teaching English as a second language. She is a former ESL program director, department chair, and journal editor. Her professional interests include global higher education, distance language learning, self-regulated learning, international student transition and success, language assessment, teaching writing, and the scholarship of teaching and learning. E-mail: Maureen.Andrade@uvu.edu 
Peer-Reviewed Article

ISSN: 2162-3104 Print/ ISSN: 2166-3750 Online

Volume 7 Number 1 (2017), pp. 1-21

(C) Journal of International Students

http://jistudents.org/

\title{
Post-Graduation Plans of International Science and Engineering Doctoral Students Attending U.S. Universities
}

\author{
Dorothy N. Ugwu \\ Tarrant County Community College District, USA \\ Maria Adamuti-Trache \\ University of Texas Arlington, USA
}

\begin{abstract}
This study examines the post-graduation plans of international science and engineering doctoral students at a public research-intensive university, and the extent to which graduate school experiences influence post-graduation plans. The study is grounded in Tinto's Integration Model as well as Berry's Acculturation Model. Study findings highlight the variety of challenges international doctoral students go through such as adapting to a new culture, experiencing English language difficulties, and cultural, social, and academic adjustment barriers. Using survey data collected in 2013-2014, this study reveals the complexity of factors that affect post-graduation plans and need for institutional initiatives to provide socio-cultural and academic support, and recommends changes in immigration policies to sustain the retention of talented international scientists and engineers upon degree completion.
\end{abstract}

Keywords: doctoral students; science and engineering; graduate school experiences; post-graduation plans

The Institute of International Education (IIE) reported that the number of international students in the United States increased by 8\% in 2013/2014 compared to the previous year to a record high of 886,052 (IIE, 2014). According to several studies, in 2025 this number will rise to 8 million (Altbach \& Bassett, 2004; Eustace, 2007; Fischer, 2009). Meanwhile, the 
number of international graduate students attending U.S. universities in 2014 reached 329,854 representing 37\% of all international students in the country (IIE, 2014), and continued to increase through fall 2010, with all of the increase occurring in Science and Engineering (S\&E) fields. For instance, about $60 \%$ of all international graduate students in the United States in 2010 were enrolled in S\&E fields, while only 32\% of all international students enrolled in undergraduate programs were in S\&E fields (National Science Board, 2012). There is a clear trend to attract large numbers of international students for the graduate $S \& E$ programs in the United States.

As more international doctoral students flow into American universities, a marked shift in the demographic composition of the doctoral student population in S\&E has also been witnessed. Foreign students on temporary visas earned high proportions of S\&E doctorates and dominated in fields like engineering, physics, computer science, and economics. In 2009, they received $57 \%$ of doctorates in engineering, 54\% in computer science, and 51\% in physics (National Science Board, 2012). These statistics have been extremely stable; in 2011, foreign students earned $56 \%$ of doctorates in engineering, $51 \%$ in computer science, and $44 \%$ in physics (National Science Board, 2014).

As described in Allum's (2014) report based on the annual Survey of Graduate Enrollment and Degrees, in the fall of 2013, 56.2\% of all foreign graduate students were in engineering, mathematics and computer science, physical and earth sciences, or biological and agricultural sciences. Meanwhile, only $17.6 \%$ of U.S. citizen and permanent resident graduate students were enrolled in these fields. This trend has continued unabated showing that the United States receives a considerable number of international graduate students, who are preferentially enrolled in S\&E programs.

The flow of scientists and engineers to the developed countries is not surprising. The United States' economic growth and its leading position in the global markets depend heavily on advancements in science, technology, engineering, and mathematics (STEM) fields (Machi, McNeill, Lips, Marshall \& Carafano, 2009; National Academy of Sciences, 2006). The growing demand for scientists and engineers is a worldwide phenomenon and many developed countries that cannot meet this increased demand locally, recruit international students and foreign-born highly educated workers who are likely to bring a significant contribution to the higher education system and workplaces. Despite the magnitude of the international S\&E doctoral students population, the investment that U.S. higher education institutions make in preparing them, and the potential contributions that these individuals can make to the United States, S\&E doctoral students' graduate school experiences and the impact on their post- 
graduation plans have been understudied (Ren \& Hagedorn, 2012; Mori, 2000). By gaining an understanding of these issues, American higher education institutions could proactively formulate appropriate policies and programs that would benefit international students and in long term would contribute to recruit, train, and retain talented specialists in science and engineering fields.

This paper examines the relationship between post-graduation plans and the graduate school experiences of S\&E doctoral students when controlling for demographic factors (age, sex), culture-specific characteristics (race/ethnicity as a proxy for region of origin), field of study, and English language proficiency. Tinto's Integration Model (1993) and Berry's Acculturation Model (1997) offer an appropriate theoretical framework to interpret the challenges faced by international doctoral students in S\&E such as adapting to a new culture, experiencing English language difficulties, and adjusting to cultural, social, and academic barriers. The study addresses several research questions:

1. What are the graduate school experiences (i.e., academic, social, cultural) of doctoral students enrolled in S\&E programs? Do these experiences vary by demographic factors, culture-specific factors, field of study and English language proficiency?

2. What are students' post-graduation plans and how do they differ by demographic factors, culture-specific factors, and field of study?

3. What is the relationship between post-graduation plans and the graduate school experiences of S\&E doctoral students when controlling for demographic factors, culture-specific factors, field of study and English language proficiency?

\section{LITERATURE REVIEW}

\section{Social and Culture Adjustment}

Research indicates that multiple factors are associated with students' graduate school experience. For international doctoral students, these factors include, but are not limited to age, sex, race/ethnicity, field of study, and English language skills (Duru, 2008; Lee, Park, \& Kim, 2009; McClure, 2007; Poyrazli \& Lopez, 2007; Poyrazli, Kavanaugh, Baker, \& Al-Timimi, 2004). Olaniran (1996) reported that older international students who were less proficient in English appear to have more problems acquiring social skills. Yet another study indicated that younger international doctoral students were much more social and independent (Moffett, 2006). Poyrazli and Lopez (2007) discovered that while older foreign students reported a higher level of perceived discrimination, younger students reported a greater amount of homesickness. 
The literature also suggests significant gender differences in international students' sojourn experiences (Fong \& Peskin, 1969; Lee, et al., 2009). An early study found that female foreign students reported a greater number of adjustment problems compared with male foreign students (Fong \& Peskin, 1969). Contrary to earlier gender research on international students, Ying and Han (2006) more recently found that females were more adaptable than males.

Empirical studies have consistently demonstrated that international students from particular areas of the world have uniquely differing experiences in their adjustment to the United States. For example, students from regions such as Asia, Africa, and Latin America are more likely to face adjustment difficulties in the U.S. due to cultural dissimilarity, and more likely to report racism and discrimination (Yeh \& Inose 2003). Trice (2004) also found that international students from African and Middle Eastern countries tended to interact less often with their American peers than those from other world regions.

Many studies point out that language proficiency affects the academic performance of international students (Andrade, 2006; McClure, 2007; Mori, 2000; Yeh \& Inose, 2003). Ying (2003) reported that students who had stronger English writing skills had higher academic achievement. Yet another study (Poyrazli, Arbona, Bullington \& Pisecco, 2001) reported that graduate students with higher English proficiency experienced fewer academic adjustment problems.

A review of previous literature indicates that international students frequently face challenges in adjusting socially to the university environment in the United States (Duru, 2008; Olivas \& Li, 2006). AlSharideh and Goe (1998) added that social support is therefore important in ensuring that international students succeed in their new environment. Like other authors, McClure (2007) explained that foreign students often feel lonely in their new environment because they lack family, friends and social network. Further research emphasized that developing social networks that include American students helps international students make successful social adjustment (Lee, 2010).

Other studies suggest that language deficiency affects the social adjustment of international students (Andrade, 2006; Kwon, 2009; Mori, 2000; Poyrazli \& Kavanaugh, 2006; Yeh \& Inose, 2003). Trice (2007) discovered that international students who reported English language difficulties also experienced poor social adjustment. She also found that students who had difficulties forming relationships with American students were more likely to feel isolated. Although her study used teachers' rather than students' perspectives, her findings were similar to other studies which showed that language proficiency was crucial to the social experience of international students. In addition, Sherry, Thomas, and Wing Hong (2009) 
revealed that students who socialized only with other foreign students tended to experience poorer social adjustment.

In addition to demographic and culture-specific adjustment issues, international students go through a significant culture shock (Oberg, 1960). Since then the role of culture has long been studied in relation to acculturation problems. According to Cohen (1968), culture is one of the most important factors influencing the adaptation of individuals. Likewise, international students who come to the U.S. for higher education find themselves in a new cultural environment and experience the overwhelming task of organizing their life to meet the needs and requirements imposed upon them by the new society.

When foreign students move to a new culture for a period of intensive education abroad, they are exposed to a new environment in which they must adapt in order to function effectively (Hechanova-Alampay, Beehr, Christiansen, \& Van Horn, 2002). English language proficiency is certainly a first impediment as they may struggle understanding class lectures, completing class assignments, speaking in class or expressing their feelings, and making friends with their American classmates. Zhai (2002) adds that helping international students to successfully adjust to the U.S. culture and higher education system should not be overlooked. Many recognize that the culture shock symptoms add to the challenges experienced by international students coming to study in the United States (Baier, 2005; Poyrazli, Kavanaugh, Baker, \& Al-Timimi, 2004; Yeh \& Inose (2003).

\section{Post-Graduation Plans}

As stated previously, international students encounter some adjustment difficulties during their educational journeys in American universities. It may not be surprising to find that these students could also face difficulties when deciding on their future careers and place of residence (e.g., whether or not they should stay in the United States or go back to their countries after graduation). Despite the significant implications of the stay or leave decision for international graduate students, only a few studies have investigated post-graduation issues and the factors that may influence students’ decisions (Finn, 2005; Kim, Bankart, \& Isdell, 2010; Shen \& Herr, 2004). There have been however, discussions in the literature about the stay rate of international students after graduation from American universities. Many researchers found that the stay rate of foreign-born doctorates varied by country of origin (Finn, 2003) and by field of study (Finn, 2005). For instance, according to Finn (2003), students from Egypt, South Africa, and other African countries have higher stay rates than those from other countries. 
Although limited, other studies investigated the career plans of graduate international students. Shen and Herr (2004) investigated the career placement concerns and the needs of international graduate students leaving the U.S. or staying in the country after graduating. They found that although many international students wanted to stay in the U.S. after graduation for greater chances of career advancement, others expressed the intention to return to their country of origin because they recognized the needs for qualified people in the home country. On the other hand, Shen and Herr (2004), and Saravia and Miranda (2004) reported that about half of internationally-born graduate students studying in the U.S. stayed behind even upon completion of their doctoral degree programs.

Contrary to Shen and Herr (2004), and Saravia and Miranda (2004), Finn's (2014) study specifically focused on international doctorate students and not graduate students in general. Finn's (2014) study looked at doctorate recipients since 1991 and revealed high stay rates of doctorate recipients. For instance, the 2011 stay rate for foreign doctorate recipients, including both permanent and temporary visas at graduation, was $68 \%$ for those graduating in 2006, and 65\% for those graduating in 2001. When only temporary resident visas were included, the stay rates dropped to $66 \%$ for those graduating in 2006, and 62\% for those graduating in 2001, but were still high. Stay rates depend on discipline and country of citizenship. Finn (2014) concluded that doctorate recipients from disciplines such as economics, agricultural sciences, and social sciences have significantly lower stay rates than those in S\&E fields.

\section{THEORETICAL FRAMEWORK}

Tinto's (1993) Student Integration Model (SIM) and Berry's (1997) acculturation model serve as the theoretical framework for this study. Given the absence of a comprehensive theory to describe the international doctoral students' experiences and post-graduation plans, using existing undergraduate models of student integration and acculturation as a starting point to frame this study proved to be useful. This study expands the work of Tinto's SIM and contributes to the literature concerning the effects of higher education experiences on post-graduation plans by examining an understudied population: international doctoral students enrolled in S\&E fields at a public university.

In his theory, Tinto (1993) posits that the social and academic integration into a higher education institution is the foundation for students' academic success. One of the criticisms of Tinto's theory is that it does not apply to non-traditional students or those underrepresented in higher education (e.g., African-American), so one can question whether it should apply to international students who also experience challenges on campus. 
However, Tinto recognized that a student comes to school with an individual background, motivation, academic preparation, study skills, goals and intentions that influence his or her ability to integrate academically and socially into the campus environment. Academic integration concerns the degree to which students interact with faculty, in and outside of the classroom, and the degree to which they become part of the campus' culture. Social integration represents student's interaction with peers (Pascarella \& Terenzini, 1991). As Tinto himself suggested, students who do not sufficiently integrate, socially and academically, into the college environment run the risk of being isolated within the campus environment. We argue that tenets of Tinto's theory can be extended to the academic and social experiences of international graduate students.

Likewise, Berry's acculturation model (1997) provides a useful framework to examine the cultural adjustment of international students in the United States. Berry defined acculturation as the social and psychological exchanges that take place when there is continuous interaction between individuals from different cultures. According to Berry (1994), international students who are not fully integrated into the new culture might experience culture shock. Berry explored what happened to individuals when they attempted to adapt to a new culture. He explained that individuals either continued to act in the new culture as they did in the previous one, or tried to change their behavior, values, and beliefs. Berry (2003) noted in his later work that a person exposed to a new culture would undergo a process of change and could adopt various coping strategies. Berry's notion of cultural integration is similar to Tinto's notions of academic and social integration. A person using the integration coping strategy shows an interest in learning and participating in the host culture even if maintaining ties with the native culture. We argue that Tinto's Student Integration Model (1993) and Berry's Acculturation Model (1997) provide a useful framework to study how international doctoral students present on American campuses experience and respond to various academic, social and cultural challenges.

\section{RESEARCH METHOD}

\section{Data Collection}

This is an empirical study that employs quantitative methods to analyze survey data collected by researchers in 2013-2014. The data were gathered at a large public research university located in the Dallas-Fort Worth Metroplex. The university serves about 35,000 students who attend more than 180 degree programs in 12 different schools and colleges. This university offers 71 masters and 30 doctoral degrees in nine different academic areas that include science and engineering. 
In Fall 2013, the university enrolled about 7,500 graduate students (both international and domestic) with almost 2,000 students in the S\&E fields. Of these 2,000 S\&E graduate students, $74 \%$ were in engineering while $26 \%$ in science. In engineering, international graduate students ranked first place with over 1,000 students comprising $69 \%$ of the total graduate engineering student population. Although the number of international graduate students in science (about 150) is not as high as in engineering, they comprised $27 \%$ of the graduate science students, ranking the second largest. Overall, the international graduate students combined to make up more than half $(58 \%)$ of the entire graduate student population in science and engineering at this university. About 500 of the 1,150 international graduate students in S\&E were enrolled in a doctoral program, and they represented the target population for this study.

After examining numerous empirical and theoretical studies on international students and graduate school experience, the authors developed a survey instrument for online administration (Ugwu, 2014). In order to ensure content validity of the questionnaire, the researchers asked a colleague to review and comment on the survey construction, wording format, clarity and question flow as to capture international graduate students' experiences and post-graduation plans. A face-to-face pilot study was then conducted with a few international doctoral students to ensure that the participants were able to understand the questions and complete the survey.

The survey was conducted online. Three sets of emails were sent to the international doctoral students through the Office of International Education and the S\&E departments. Emails included an introduction to the study, information about the survey, confidentiality policy, estimated survey completion time, and the online survey's web link. The survey instrument included an informed consent on the first page. Only those who agreed to participate were able to access the survey. IRB approval was received from the university prior to conducting the data collection, research, and reporting.

\section{Participants}

An invitation was sent to about 500 international doctoral students at the university in October 2013 and 129 responded by December 2013(a response rate of about 26\%). Of the 129 respondents, about 91 students answered the survey and provided relevant information. Of the 129 respondents, 75 students completed answers on the main variables and had valid data for inclusion in the study. Therefore, the study's sample size was $N=75$. The final response rate of $15 \%$ was consistent with recent research showing that response rates tend to be lower in online than paper surveys (in their study, Sax, Gilmartin, and Bryant (2003) found online response rates 
ranging from $17.1 \%$ to $19.8 \%$ while paper response rates ranged from $22 \%$ to $24 \%$ ). The research sample consisted of 53.3\% Asian, non-Hispanic, 32\% White, non-Hispanic, and $14.7 \%$ other races. Males accounted for $68 \%$ and females $32 \%$ of the sample. It included $50.7 \%$ and $49.3 \%$ of the S\&E programs' international students, respectively.

\section{Variables and data analysis}

Table 1 presents the study's variables. The main outcomes were students' post-graduation plans and graduate school experiences. We conducted an exploratory factor analysis that served to uncover the relationships between survey items and identify the three hypothesized dimensions of graduate school experience: academic experiences, social involvement, and cultural global values. For each of them, we checked the scale's reliability and obtained high Cronbach's alpha (Table 1) as a measure of internal consistency.

\section{Table 1: Data Variables}

\begin{tabular}{|c|c|}
\hline Variable & Categories/Variables \\
\hline Age & 3-category variable: $20-25 ; 26-30$; Over 30 \\
\hline Sex & 2-category variable: male; female \\
\hline Race/Ethnicity & $\begin{array}{l}\text { 3-category variable: White, non-Hispanic; Asian, non- } \\
\text { Hispanic; Other -- under-represented minorities (URM) }\end{array}$ \\
\hline $\begin{array}{l}\text { English language } \\
\text { skills }\end{array}$ & $\begin{array}{l}\text { 2-category variable: Some difficulties; No difficulties } \\
\text { (Overall English skills are computed as an average of } \\
\text { speaking, writing, reading scores ranging from } 1 \text { to } 4 \text {. No } \\
\text { difficulties category include only those whose overall score } \\
\text { equals } 4 \text {, meaning very good skills) }\end{array}$ \\
\hline Field of study & $\begin{array}{c}\text { 2-category variable: science; engineering } \\
\text { Outcomes }\end{array}$ \\
\hline $\begin{array}{l}\text { Graduate School } \\
\text { experiences }\end{array}$ & $\begin{array}{l}\text { Composite scores (range 1-5) corresponding to the } 3 \\
\text { dimensions: }\end{array}$ \\
\hline Academic experiences & Academic (10 items, Cronbach’s alpha=.859) \\
\hline $\begin{array}{l}\text { Social involvement } \\
\text { Cultural global values }\end{array}$ & Social (13 items, Cronbach’s alpha=.941) \\
\hline & Cultural (17 items, Cronbach’s alpha=.934) \\
\hline $\begin{array}{l}\text { Post-graduation } \\
\text { plans }\end{array}$ & $\begin{array}{l}\text { 3-category variable: Stay in U.S. to find a job or continue } \\
\text { education; Go back to own country- immediately/after } \\
\text { working in U.S.; Not sure/ work anywhere in the world }\end{array}$ \\
\hline
\end{tabular}

The composite scores of academic, social, and cultural experiences represented new variables employed in the analysis. We also included demographic factors (i.e., age, sex), culture-specific factors (race/ethnicity), English language proficiency, and field of study as independent variables.

The study employed descriptive statistics, bivariate, and multivariate data analyses. Chi-square tests were used to determine the 
association among categorical variables and ANOVA tests were used to determine whether cultural, social, and academic experiences differed by the predictive factors. Finally, a Multinomial Logistic Regression (MLR) was conducted to examine the relationship between the main dependent variable (post-graduation plans) and a set of eight predictors (i.e., age, sex, race /ethnicity, field of study, English language skills, and cultural, social, and academic graduate school experiences). The sample size of 75 closely satisfied the MLR's sample size requirement (Schwab, 2002).

\section{RESULTS}

\section{Graduate School Experiences}

We identified three dimensions of graduate school experiences by following the proposed conceptual framework combining Tinto's Student Integration Model (1993) and Berry's Acculturation Model (1997). As shown in Table 2, descriptive statistics and ANOVA F-tests were used to compare the three scale scores by various individual factors.

Table 2: Graduate school experiences -- Comparative analysis (ANOVA)

\begin{tabular}{|c|c|c|c|c|c|c|c|}
\hline \multirow[t]{2}{*}{ Factors } & \multirow[t]{2}{*}{$N$} & \multicolumn{2}{|c|}{$\begin{array}{l}\text { Academic } \\
\text { experiences }\end{array}$} & \multicolumn{2}{|c|}{$\begin{array}{l}\text { Social } \\
\text { involvement }\end{array}$} & \multicolumn{2}{|c|}{$\begin{array}{l}\text { Cultural global } \\
\text { values }\end{array}$} \\
\hline & & $M$ & $p$-value & $M$ & $p$-value & $M$ & $p$-value \\
\hline \multicolumn{8}{|l|}{ Age } \\
\hline $20-25$ & 20 & 4.3 & .548 & 2.4 & .138 & 4.5 & $.022 *$ \\
\hline $26-30$ & 36 & 4.1 & & 2.0 & & 4.2 & \\
\hline Over 30 & 19 & 4.2 & & 2.3 & & 4.1 & \\
\hline \multicolumn{8}{|l|}{ Sex } \\
\hline Male & 51 & 4.2 & .480 & 2.2 & .975 & 4.2 & .813 \\
\hline Female & 24 & 4.1 & & 2.2 & & 4.3 & \\
\hline \multicolumn{8}{|l|}{ Race/Ethnicity } \\
\hline Asian, non-Hispanic & 40 & 4.2 & .238 & 2.3 & .157 & 4.2 & .433 \\
\hline White, non-Hispanic & 24 & 4.1 & & 2.1 & & 4.3 & \\
\hline Other & 11 & 3.9 & & 1.8 & & 4.4 & \\
\hline \multicolumn{8}{|l|}{ Field of Study } \\
\hline Science & 38 & 4.1 & .578 & 2.1 & .588 & 4.4 & $.094^{+}$ \\
\hline Engineering & 37 & 4.2 & & 2.4 & & 4.2 & \\
\hline English language skills & & & & & & & \\
\hline No difficulties & 32 & 4.3 & .131 & 2.1 & .230 & 4.4 & $.014^{*}$ \\
\hline Some difficulties & 43 & 4.1 & & 2.3 & & 4.1 & \\
\hline ALL & 75 & 4.2 & & 2.2 & & 4.3 & \\
\hline
\end{tabular}

${ }^{*} p<0.05^{+} p<0.1$

First, the overall score for the social involvement dimension (mean=2.2) was low compared to academic experiences (mean=4.2) and cultural values $($ mean=4.3) dimensions; this showed that international 
doctoral students were not interested in campus activities other than ones related to their academic programs. They scored high in terms of cultural global values, broad cultural understanding skills useful to integration in the host country.

Second, there was little variability in the experience scores by the selected factors. Academic experience scores varied from a minimum of 3.9 (Other race) to a maximum of 4.3 (age 20-25; those with very good English skills). Greater variability occurred among the social involvement scores that varied from 1.8 (Other race) to 2.4 (age 20-25; engineering students). Finally, the cultural global values scores varied from 4.1 (age over 30; those experiencing some language difficulties) to 4.5 (age 20-25). ANOVA tests indicated statistically significant differences only for the cultural global value scores by age and English language skills, and to some extent by field of study. The research sample was quite homogeneous in terms of student perceptions of graduate school experiences.

\section{Post-graduation Plans}

An association between post-graduation plans and the factors considered in this study is shown in this section through a series of chisquare tests. Table 3 presents the percentages of students with various characteristics within each 'post-graduation plan' category which are compared to the marginal percentages (first column) to identify whether some groups are more or less represented within the respective 'postgraduation plan' category. For instance, although age does not appear to be significantly associated with post-graduation plans, $68 \%$ compared to $48 \%$ in the sample of the age group 26-30 were among those who either had uncertain plans or intended to go after graduation anywhere in the world. Meanwhile, the older students were more likely to intend to return to their home country after graduation.

Table 3 also shows that men were more likely to plan to return to their country as compared to women who were uncertain or wanted to work anywhere in the world. Similarly, engineering students were likely to plan to return to their country as compared to science students who were uncertain or wanted to go anywhere in the world. The only statistically significant associations with post-graduation plans were obtained for race/ethnicity and English proficiency. Asian students planned to return to their home countries while White students planned to stay in the U.S. and find jobs or continue education. Other race groups had uncertain plans or wanted to go anywhere in the world. Finally, the data show the importance of English proficiency in making post-graduation plans. Planning to stay in the U.S. is clearly determined by having higher levels of English proficiency. Two thirds of those who had no difficulty with English intended to stay after graduation although they represented only $43 \%$ of the sample. Meanwhile, 
$79 \%$ and $68 \%$ of those who experienced language difficulties planned to either return to their countries or go elsewhere.

Table 3: Post-graduation plans (column \%)

\begin{tabular}{|c|c|c|c|c|c|}
\hline & ALL & $\begin{array}{l}\text { Stay in U.S. } \\
\text { and find a job } \\
\text { or continue } \\
\text { education }\end{array}$ & $\begin{array}{l}\text { Go back to } \\
\text { own country } \\
\text { immediately/af } \\
\text { ter working in } \\
\text { U.S. }\end{array}$ & $\begin{array}{l}\text { Not } \\
\text { sure/work } \\
\text { anywhere in } \\
\text { the world }\end{array}$ & $\begin{array}{l}\text { Sig. test } \\
p \text {-value }\end{array}$ \\
\hline \multicolumn{6}{|l|}{ Age } \\
\hline $20-25$ & 27 & 28 & 25 & 26 & .142 \\
\hline $26-30$ & 48 & 44 & 38 & 68 & \\
\hline Over 30 & 25 & 28 & 38 & 5 & \\
\hline \multicolumn{6}{|l|}{ Sex } \\
\hline Male & 68 & 69 & 75 & 58 & .487 \\
\hline Female & 32 & 31 & 25 & 42 & \\
\hline \multicolumn{6}{|l|}{ Race/Ethnicity } \\
\hline $\begin{array}{l}\text { Asian, non- } \\
\text { Hispanic }\end{array}$ & 53 & 41 & 79 & 42 & $.006 * *$ \\
\hline $\begin{array}{l}\text { White, Non- } \\
\text { Hispanic }\end{array}$ & 32 & 50 & 8 & 32 & \\
\hline Other & 15 & 9 & 13 & 26 & \\
\hline \multicolumn{6}{|l|}{ Field of Study } \\
\hline Science & 51 & 56 & 33 & 63 & .107 \\
\hline Engineering & 49 & 44 & 67 & 37 & \\
\hline $\begin{array}{l}\text { English language } \\
\text { skills }\end{array}$ & & & & & $.002 * *$ \\
\hline No difficulties & 43 & 66 & 21 & 32 & \\
\hline Some difficulties & 57 & 34 & 79 & 68 & \\
\hline $\mathbf{N}$ & 75 & 32 & 24 & 19 & \\
\hline
\end{tabular}

\section{Modeling post-graduation plans}

Table 4 contains the results of a multinomial regression model for post-graduation plans when all variables are included. This table includes odds ratios indicating the likelihood of 'going back to the home country' or 'being not sure/going anywhere in the world' as compared to 'stay in the U.S.' (reference category). As indicated by Nagelkerke's $\mathrm{R}^{2}$ coefficient, the set of variables used in the model explains $46 \%$ of the outcome's variability.

The strongest predictor of the model is English proficiency. As compared to students who had no language problems, those who did have language difficulties were almost 5 times and 7 times more likely to plan to go back to their country or anywhere in the world rather than staying in the U.S. As compared to Asian students, White non-Hispanic students were very unlikely to plan to return to their country rather than stay in the U.S. 
Table 4. Multinomial Logistic Regression ('Stay in U.S.’=reference group)

\begin{tabular}{|c|c|c|c|}
\hline \multirow{2}{*}{$\begin{array}{c}\text { Variables } \\
\text { (Reference categories) }\end{array}$} & \multirow{2}{*}{ Levels } & \multicolumn{2}{|r|}{ Odds Ratios } \\
\hline & & $\begin{array}{l}\text { Go back } \\
\text { to home } \\
\text { country }\end{array}$ & $\begin{array}{l}\text { Not sure / work } \\
\text { anywhere in the } \\
\text { world }\end{array}$ \\
\hline \multirow{2}{*}{ Age (20-25=ref) } & Age $26-30$ & 1.1 & 2.0 \\
\hline & Age over 30 & 1.6 & .2 \\
\hline Sex (Male=ref) & Female & 1.5 & 2.9 \\
\hline Race (Asian, non- & White, non- & $.1^{*}$ & 1.0 \\
\hline Hispanics=ref) & $\begin{array}{l}\text { Hispanics } \\
\text { Other race }\end{array}$ & 1.1 & 2.8 \\
\hline $\begin{array}{l}\text { Field of study } \\
\text { (Engineering=ref) }\end{array}$ & Science & .6 & .8 \\
\hline $\begin{array}{l}\text { English Skills (No } \\
\text { difficulties = ref) }\end{array}$ & Some difficulties & $4.5^{*}$ & $7.3^{*}$ \\
\hline $\begin{array}{l}\text { Graduate school } \\
\text { experience }\end{array}$ & Ordinal variable & 1.1 & 1.1 \\
\hline Academic experiences & Ordinal variable & 1.2 & .6 \\
\hline \multirow{2}{*}{$\begin{array}{l}\text { Social involvement } \\
\text { Cultural global values }\end{array}$} & Ordinal variable & .8 & 4.0 \\
\hline & $\begin{array}{l}\text { Likelihood ratio tes } \\
\text { Nagelkerke } R^{2}\end{array}$ & Chi-Square & $\begin{array}{l}39.463 * \\
.46\end{array}$ \\
\hline
\end{tabular}

${ }^{*} p<0.05{ }^{* *} p<0.001$

This study is exploratory, so the following brief discussion of the direction of some relationships does not have statistical evidence for their strengths. Female as compared to male students were more likely to plan either to return to their country of origin or go anywhere in the world rather than stay in the U.S. Science doctoral students were more likely to plan to stay in the U.S. compared to engineering students. Higher levels of cultural values increased by a factor of 4.0 for the likelihood of students planning to go anywhere in the world after graduation rather than staying in the U.S. These observations suggest that academic and social graduate school experiences are not crucial to post-graduation plans.

\section{DISCUSSION AND CONCLUSIONS}

Similar to what the literature suggests, the present study also has shown that language is a major problem in the adjustment of international students at this public university. The present study's results indicated that more than half (57\%) of the respondents reported some English language problems. Those who were not native English speakers may experience some difficulties in the classrooms or establishing relationships with their American classmates (Galloway \& Jenkins, 2005; Lee, 2010; Mori, 2000; 
Poyrazli \& Grahame 2008; Sherry et al., 2009; Yeh \& Inose, 2003). Invariably, these scholars assert that language inadequacies and the lack of close friendships make it difficult, if not impossible, for international students to adapt culturally, academically, and socially.

Researchers have drawn attention to the need to create positive campus climates that support international student adjustment to the academic and social demands of college life (Schweitzer, Morson, \& Mather, 2011). International students face a plethora of challenges, including navigating different social and cultural norms, and building friendships, especially when their home cultures and host culture are very distant (Mori, 2000). The present findings have also demonstrated that the international doctoral students shared most of the similar challenges highlighted in the literature, including social and cultural challenges, and language-related difficulties. The presence of challenges is somehow surprising since the doctoral students in this study have acquired academic knowledge and have already spent several years of their lives in school in or out of the United States.

Challenges are not the same for all students. Moffett (2006) found that older international students are less social than younger ones. Poyrazli et al. (2001) suggested that younger international students face less social difficulty and adjust more quickly than older students. This age group may be socially more mobile and interactive than their older peers, thus increasing their potential to integrate and assimilate. The present findings are in agreement with earlier ones showing that age may play a role in cultural experiences. For example, our data revealed that younger international students reported higher cultural values than the older students. Since these students are younger, and still in the exploratory stage of their careers, they are more open to meet with people from different cultures. Although students in this study were not asked to rate their social interactions with American students, one can infer that younger foreign students had more extensive social interactions with the American students. As a result, they are likely to acquire tenets of the new culture. This interaction may help them overcome cultural difficulties or literally break cultural boundaries than these other students, who may be held down by age-acquired change resistance (Huntley, 1993).

The present study's sample was composed of twice as many males as females. Previous research showed that females are underrepresented in the S\&E fields (Smart Richman, VanDellen, \& Wood, 2011). Women in the U.S. and other developed countries are increasingly entering the traditionally male-dominated fields of study like S\&E. For example, the National Science Foundation (2008) reported that the percentage of women in the U.S. who earned doctorates in engineering increased from less than $1 \%$ in 1958 to $20 \%$ in 2006 . The same report also claimed that women are 
finally assuming faculty positions in engineering in many universities. Although women still face challenges in S\&E, they are coping effectively with their minority status in these fields (Smart Richman, et al., 2011).

The present findings seem to support the statement in the literature (Finn, 2014) that more international students, especially those in S\&E, report that they would stay in the U.S. upon graduation instead of returning to their home countries. Finn (2014) concluded that doctorate recipients from other disciplines (such as economics, agricultural sciences, and other social sciences) have significantly lower stay rates than do students in S\&E. Not only does this study support prior research showing that $43 \%$ of S\&E doctorate recipients intend to stay in the U.S., but it also uncovered that race/ethnicity and language skills affect their intent.

Results from multivariate statistical analysis in the present study revealed that White, non-Hispanics students were the least likely to plan returning to their home countries upon degree completion than the other racial groups. A study by Klomegah (2006) strengthens the above assertion. He found that students from the European countries and geographic areas similar to that of the U.S. in terms of language and culture reported less adjustment difficulties than students from other regions. With less adjustment issues as reported by Klomegah (2006), it becomes easier for White, non-Hispanic students to plan to stay in the U.S. after graduation. Lee (2010) similarly believes that individuals from non-Western countries face greater challenges due to the need to negotiate cultural and linguistic differences, so they may prefer to return to their home countries upon graduation.

Other researchers (Trice, 2004; Yeh \& Inose, 2003) reported that students from African and Asian countries evidently were more likely to be unsatisfied with their educational experiences, mainly due to issues related to language proficiency and adaptability. The above report is congruent with the findings in this study inferring that Asian, non-Hispanic students were more likely to plan to return to their countries than stay in the U.S. One can also speculate that students who want to stay in the U.S. after graduation may do so because they want to gain employment and improve their economic status and that of their families. Some may want to stay for better job opportunities here in the U.S. especially if an employer is willing to sponsor them to get their permanent resident card.

On the other hand, some international students intentionally expressed their desires to return to their countries after completing their studies. Amongst these students were ones who indicated that they had some language challenges, and thus communication difficulties might have interfered with their studies or their social, academic or cultural adjustment. In line with the preceding argument, Andrade (2006) also identified English language proficiency, culture, support services, and educational background 
as influential toward the academic achievement of international students. Additionally, many researchers have investigated how students' English proficiency affects their adjustment (Poyrazli, Arbona, Nora, McPherson, \& Pisecco, 2002). Our findings suggest the importance of either recruiting students who already have good English skills or offering them professional support to improve their language proficiency.

With respect to gender, it is likely that more males than females said they would return because of the societal role expected of men as the head of family in their native countries. They might want to find employment to support their families or return to a previous position in their country to fulfill professional obligations after graduation. Some students may have been sponsored financially to travel abroad and study, and they may be obligated to return for contractual obligations. Others may be doing so because of their strong family ties and attachment to their countries (Singaravelu, White, \& Bringaze, 2005).

\section{IMPLICATIONS}

First, this research study is relevant to higher education policy and practice because it adds to a growing body of research on the graduate school experiences and post-graduation plans for international doctoral students who are enrolled in science and engineering fields of study. Though the generalizability of this study is limited by the small sample size, the findings reinforce the multidimensional aspect of graduate students' experiences. More studies are needed to focus on this population and to understand their challenges, in part so that post-secondary educators can effectively and carefully consider where to invest resources to provide meaningful social, cultural, and academic experiences for international students on their campuses. The present findings complement and extend prior research on social and cultural adjustment (Yeh \& Inose, 2003), social integration (Tinto, 1997), and language proficiency (Andrade, 2006; Trice, 2007).

Second, this study is informative for immigration policy makers by showing that about $43 \%$ of the international doctoral students in science and engineering would like to stay in the United States after graduation. This draws attention to changes in immigration policies to ensure not just the recruitment but also retention of highly qualified international individuals. For instance, a desirable change in U.S. academic visa issuance policy would be to make our country more accessible and H-1B visas easier to obtain for scientists and engineers who want to work in the U.S. (Douglas \& Edelstein, 2009).

Third, this study is relevant to policies and practices that deal with the recruitment, training, and retention of the S\&E workforce. American higher education institutions make a laudable effort to recruit international 
students in S\&E. However, there should be a coordinated effort by government, higher education institutions, and business/industry to retain highly qualified graduates so they can contribute to the American economy (National Association of Foreign Student Advisors, 2010-2011).

\section{REFERENCES}

Al-Sharideh, K. A. \& Goe, W. R. (1998). Ethnic communities within the university: An examination of factors influencing the personal adjustment of international students. Research in Higher Education, 39(6), 699-725.

Altbach, P., \& Bassett, R. M. (2004). The brain trade. Foreign Policy, 144, 30-32.

Allum, J. (2014). Graduate enrollment and degrees: 2003 to 2013. Washington, D.C.: Council of Graduate Schools.

Andrade, M. S. (2006). International students in English-speaking universities: Adjustment factors. Journal of Research in International Education, 59(2), 131-154.

Baier, S. T. (2005). International students: Culture shock and adaptation to the U.S. culture. (Master's Thesis). Retrieved from http://commons.emich.edu/ theses/523/

Berry, J. W. (2003). Conceptual approaches to acculturation. In K. M. Chun, P. Balls Organista, \& G. Marín (Eds.), Acculturation: Advances in Theory, Measurement, and Applied Research (pp. 17-37). Washington, D.C.: American Psychological Association.

Berry, J. W. (1997). Immigration, acculturation, and adaptation. Applied Psychology, 46, 5-34.

Berry, J. W. (1994). Acculturation and psychological adaptation: An overview. In A-M. Bouvy, F. van de Vijver, P. Boski, \& P. Schmitz (Eds.), Journeys Into Cross-Cultural Psychology (pp.129-141). Amsterdam: Swets \& Zeitlinger.

Cohen, Y. A. (1968). Culture as adaptation. In Y. Cohen (Ed.), Man In Adaptation: The Cultural Present (pp. 40-60). New York: Aldine de Gruyter.

Douglas, J. A. \& Edelstein, R. (2009). THE GLOBAL COMPETITION FOR TALENT: The rapidly changing market for international students and the need for a strategic approach in the US. Center for Studies in Higher Education.

Duru, E. (2008). The predictive analysis of adjustment difficulties from loneliness, social support, and social connectedness. Educational Sciences: Theories \& Practice, 8(3), 849-856.

Eustace, R. W. (2007). Factors influencing acculturative stress among international students in the United States. (Doctoral Dissertation). Retrieved from krex.k-state.edu/dspace/handle/2097/452

Finn, M. G. (2014). Stay rates of foreign doctorate recipients from U.S. Universities, 2011. Oak Ridge, TN: Oak Ridge Institute for Science and Education.

Finn, M. G. (2005). Stay rates of foreign doctorate recipients from U.S. Universities, 2003. Oak Ridge, TN: Oak Ridge Institute for Science and Education. 
Finn, M. G. (2003). Stay rates of foreign doctorate recipients from U.S. Universities, 2001. Oak Ridge, TN: Oak Ridge Institute for Science and Education.

Fischer, K. (2009). The booming business of international education. Retrieved from http://chronicle.com/article/the-booming-business-of-int/44244

Fong, S. K., \& Peskin, H. (1969). Sex-role strain and personality in adjustment. Journal of Abnormal Psychology, 74, 563-568.

Galloway, F. J. \& Jenkins, J. R. (2005). The adjustment problems faced by International students in the United States: A comparison of international students and administrative perceptions at two private, religiously affiliated universities. NASPA Journal, 42, 175-187.

Hechanova-Alampay, R., Beehr, T. A., Christiansen, N. D., \& Van Horn, R. K. (2002). Adjustment and strain among domestic and international student sojourners. School Psychology International, 23(4), 458-474.

Huntley, H. S. (1993). Adult International Students: Problems of Adjustment. Retrieved from http://eric.ed.gov/?id=ED355886

Institute of International Education (2014). Open Doors 2014 data/ International Student/ Enrollment Trends. Washington, D.C.: Institute of International Education.

Kim, D., Bankart, C. A. S., \& Isdell, L. (2011). International doctorates: Trends analysis on their decision to stay in US. Higher Education, 62(2), 141-161.

Klomegah, R. Y. (2006). Social factors relating to alienation experienced by international students in the United States. College Student Journal, 40(2), 303-315.

Kwon, Y. (2009). Factors affecting international students' transition to higher education institutions in the United States from the perspective of office of international students. College Student Journal, 43(4), 1020-1036.

Lee, S. A., Park, H. S., \& Kim, W. (2009). Gender differences in international students' adjustment. College Student Journal, 43(4), 1217-1227.

Lee, J. J. (2010). International students' experiences and attitudes at a US host institution: Self reports and future recommendation. Journal of Research in International Education, 9 (66), 67-84.

Machi, E., McNeill, J.B., Lips, D., Marshall, J. A., \& Carafano, J. J. (2009). Improving U.S. competitiveness with K-12 STEM education and training (Report No.SR-57).Washington, D.C.: Heritage Foundation.

McClure, J. W. (2007). International graduates' cross-cultural adjustment: Experiences, coping strategies, and suggested programmatic responses. Teaching in Higher Education, 12(2), 199-217.

Moffett, D. W. (2006). A phenomenological study of international students in a Florida University Ph.D. program. Paper presented at the meeting of Florida Educational Research Association (FERA) Annual Meeting, Jacksonville, FL.

Mori, S. (2000). Addressing the mental health concerns of international students. Journal of Counseling and Development, 78, 137-144.

National Association of Foreign Student Advisors. (2010-2011). The economic benefits of international education to the United States: A statistical analysis, 2010-2011. Retrieved from http://www.nafsa.org/_/File/_/eis2011/USA.pdf 
National Academy of Sciences (2006). Rising Above the Gathering Storm: Energizing and Employing America for a Better Economic Future. Washington, D.C.: National Academy Press.

National Science Board (2014). Science and Engineering Indicators 2014. (NSB 14-01), Arlington, VA: National Science Foundation.

National Science Board (2012). Science and Engineering Indicators 2012. (NSB 12-01), Arlington, VA: National Science Foundation.

National Science Foundation (2008). Thirty-Three Years of Women in S\&E Faculty Positions. Arlington, VA: National Science Foundation.

Oberg, K. (1960). Cultural shock: Adjustment to new cultural environment. Practical Anthropology, 7, 197-182.

Olaniran, B. A. (1996). Social skills acquisition: A closer look at foreign students on college campuses and factor influencing their level of social difficulty in social situations. Communication Studies, 47, 72-88.

Olivas, M., \& Li, C. S. (2006). Understanding stressors of international students in higher education: What college counselors and personnel need to know. Journal of Instructional Psychology, 33(3), 217-222.

Pascarella, E. T., \& Terenzini, P. T. (1991). How College Affects Students: Findings and Insights from Twenty Years of Research. San Francisco: Jossey-Bass.

Poyrazli, S., Arbona, C., Nora, A., McPherson, R., \& Pisecco, S. (2002). Relation between assertiveness, academic self-efficacy, and social adjustment among international graduate students. Journal of College Student Development, 43,632-641.

Poyrazli, S., Arbona, C., Bullington, R., \& Pisecco, S. (2001). Adjustment issues of Turkish college students studying in the United States. College Student Journal, 35(1), 52-62.

Poyrazli, S., Kavanaugh, P. R., Baker, A., \& Al-Timimi, N. (2004). Social support and demographic correlates of acculturative stress in international students. Journal of College Counseling, 7, 73-82.

Poyrazli, S., \& Kavanaugh, P. R. (2006). Marital status, ethnicity, academic achievement, and adjustment strains: The case of graduate international students. College Student Journal, 40(4), 767-781

Poyrazli, S., \& Lopez, M. D. (2007). An exploratory study of perceived discrimination and homesickness: A comparison of international students and American students. The Journal of Psychology, 141, 263-280.

Poyrazli, S., \& Grahame, K. M. (2008). Barriers to adjustment: Needs of international students within a semi-urban campus community. Journal of Instructional Psychology, 34(1), 28-45.

Ren, J., \& Hagedorn, L. S. (2012). International graduate students' academic performance: What are the influencing factors? Journal of International Students, 2(1), 135-143.

Saravia, N.G., \& Miranda, F. (2004). Plumbing the brain drain. Bulletin of World Health Organization 8, 559-636.

Sax, L. J., Gilmartin, S. K., \& Bryant, A. N. (2003). Assessing response rates and nonresponse bias in Web and paper surveys. Research in Higher Education 44(4), 409-32. 
Schwab, J.A. (2002). Multinomial logistic regression: Basic relationships and complete problems. Retrieved from http://www.utexas.edu/courses/schwab/sw388r7/SolvingProblems/

Shen, Y., \& Herr, E. (2004). Career placement concerns of international graduate students: A qualitative study. Journal of Career Development, 31(1), 1529.

Sherry, M., Thomas, P., \& Wing Hong, C. (2009). International students: A vulnerable student population. Higher Education, 60(1), 33-46.

Schweitzer, B., Morson, G., \& Mather, P. (2011). Understanding the International Student Experience. Baltimore, MD: American College Personnel Association.

Singaravelu, H. D., White, L. J., \& Bringaze, T. B. (2005). Factors influencing international students' career choice: A comparative study. Journal of Career Development, 32, 46-59.

Smart Richman, L., vanDellen, M., \& Wood, W. (2011). How women cope: Being a numerical minority in a male-dominated profession. Journal of Social Issues, 67(3), 492-509.

Tinto,V. (1993). Leaving College, Rethinking the Causes of Student Attrition. Chicago: University of Chicago Press.

Trice, A. G. (2007). Faculty perspectives regarding graduate international students' isolation from host national students. International Education Journal, 8(1), 108-117.

Trice, A. G. (2004). Mixing it up: International graduate students' social interactions with American students. Journal of College Student Development, 45(6), 671-687.

Ugwu, D. (2014). Graduate school experiences and post-graduation plans of international science and engineering doctoral students at a public university. Unpublished dissertation. University of Texas at Arlington.

Yeh, C. J., \& Inose, M. (2003). International students' reported English fluency, social support satisfaction, and social connectedness as predictors of acculturative stress. Counseling Psychology Quarterly, 16(1), 15-28.

Ying, Y. W. (2003). Academic achievement and quality of overseas study among Taiwanese students in the United States. College Student Journal, 37(3), 470-480.

Ying, Y. W., \& Han, M. (2006). The contribution of personality, acculturative stressors, and social affiliation to adjustment: A longitudinal study of Taiwanese students in the United States. International Journal of Intercultural Relations, 30, 623-635.

Zhai, L. (2002). Studying international students: Adjustment issues and social support. Journal of International Agricultural and Extension Education, 11(1), 97-104.

DOROTHY UGWU received her PhD from the University of Texas at Arlington. She is currently a Special Educator Teacher at the Mansfield Independent School District. She is also an Adjunct Faculty in the Speech Department at Tarrant County Community College District. Her research 
interests include educational experience and academic success of international students.

Email: dorothy.ugwu@my.tccd.edu or dorothyugwu@misdmail.org

MARIA ADAMUTI-TRACHE is an Associate Professor in the Department of Educational Leadership and Policy Studies at the University of Texas at Arlington. She has a $\mathrm{PhD}$ in higher education and extensive experience in quantitative research. Her research areas include higher education, sociology of education, economics of education, science education, and immigration studies with focus on social inequity generated by gender, race/ethnicity, social class, disability. Email: mtrache@uta.edu.

Manuscript submitted: November 15, 2015 Manuscript revised: January 15, 2016 Accepted for publication: October 30, 2016 
ISSN: 2162-3104 Print/ ISSN: 2166-3750 Online

Volume 7 Number 1 (2017), pp. 22-37

(C) Journal of International Students

http://jistudents.org/

\title{
International Graduate Students: Social Networks and Language Use
}

\author{
Daniel Moglen \\ University of California, Davis, USA
}

\begin{abstract}
The campus climate for international graduate students (IGSs) has been gaining attention in recent years as the number of IGSs in the United States continues to rise. IGSs bring diversity to the campus community and enrich the academic community, but also come to the table with distinct needs, concerns, and experiences. The current study is primarily concerned with how early social and academic experiences affect English learning and academic success. Social networks outside of the student's cultural background may be difficult to develop, and, therefore, it is not uncommon to see students gravitate towards others who share their cultural and language background. In order to obtain perspective on what early social and linguistic experiences are for newly matriculated IGSs, I conducted interviews with first-year IGSs, asking them about their language use in academic and social settings. Results from the interviews suggest that while English-oriented networks may provide more opportunities to speak in English, co-national networks are easier to join and provide much needed social and academic support.
\end{abstract}

Keywords: International Graduate Students, Second Language Learners, Social Networks, Second Language Acquisition

Brian, a first-year international graduate student from China, presented in the first-quarter ESL class in a clear, well-organized manner, and exuded confidence while he spoke. By all measures, his presentation combined with the other academic work that he produced indicated that he was on the track to academic success. I came to realize that, as the instructor of the class, it was not entirely clear to me how the presentation skills learned in my class would transfer to other academic classes, and in which ways this 
class would contribute to the overall language development of my students. Additionally, I later found out in an interview with Brian that he was socially isolated and not integrating easily into the local culture. Studies have suggested that international students ought to make more native English speaking (NES) friends (see Liu 2011); however, there are other viable social strategies, as this study will show. Brian was just one of the approximately one hundred international graduate students that were enrolled in this ESL class. What were the students' social and academic experiences outside of this class? How were the academic writing and presentation skills that they learned in this class being applied in their other academic classes? These were some of the questions that drove this research project.

There is a growing trend in American universities of recruiting and admitting an increasing number of international students, both at the undergraduate and graduate level. In fact, according to Open Doors (2012), there are over 700,000 international students in the United States, and about half of them are at the graduate level. At the university where the current research project was conducted, international students make up over $20 \%$ of the entire graduate student population, where in some fields, such as Statistics and Computer Science, the majority of graduate students are now international. The trend seems to show that STEM fields (science, technology, engineering, math) tend to host the highest amount of international students, followed by social sciences, and lastly humanities, which attracts the fewest number of IGSs (Open Doors 2012). This means that the STEM fields have a distinctly high concentration of IGSs, many of which singularly come from China, which inevitably leads to an increase in opportunities to communicate in their first language (L1) and a decrease in incentive to communicate in English.

The aim of this paper is to shed light on the choices that international graduate students make in terms of developing their social network, which in turn will provide insights regarding factors that influence language learning for this particular group of people. Particularly of importance are these early experiences, from which ultimately may account for not only the wellbeing of the student, but also the likelihood of academic success. I argue that while the social experience of the IGSs will have a great influence on their academic experience and success, it is not necessarily the case that more interactions with NESs is the optimal situation, as some of the literature has suggested.

The research questions for the current study are as follows:

1. How often are first year international graduate students using English in academic and social settings?

2. What kinds of social networks do IGSs form? 
3. What are the advantages and disadvantages of the different types of social networks?

\section{LITERATURE REVIEW}

While there are numerous studies that examine the social and academic experiences of international undergraduate students, fewer are concerned with international graduate students. The studies that solely look at undergraduate international student issues may have implications for IGSs, but the lack of literature surrounding IGSs suggests that more research needs to be done for this growing population. Of those studies that focus on IGSs, many look at acculturative stress (Constantine, Okazaki, \& Utsey, 2004; Lee, Koeske, \& Sales, 2004; Mori, 2000; Sandhu \& Asrabadi, 1994; Yeh \& Inose, 2010), and come from a psychological/counseling perspective rather than a linguistic one. These studies have identified causes for this stress, such as perceived discrimination (Dao, Lee, \& Chang, 2007; Lee \& Rice, 2007), language deficiencies (Fletcher \& Stren, 1989; Lee, Abd-ella, \& Burks, 1981), social connectedness (Yeh \& Inose 2010), and financial stress (Mori 2000), but little has been done to track and analyze language development through the critical transitional period that occurs in the first quarter of graduate school.

Constantine, Okazaki, and Utsey (2004) found that language proficiency negatively correlated with acculturative stress, and Lee, Koeske, \& Sales (2004) found that social support helped mitigate the effects of acculturative stress. In earlier studies, Selltiz, Chirst, Havel, and Cook (1963) and Heikinheimo and Shute (1986) reported that more interaction with NES students led to better social adjustment and there was a positive link between contact and adaptation. As would be expected, more advanced English skills, especially speaking skills, corresponded to both social and overall satisfaction (Fletcher \& Stren, 1989; Lee, Abd-ella, \& Burks, 1981; Yeh \& Inose, 2010). Selltiz and team (1963) found that the subjective level of confidence was the most important predictor of academic achievement; that is, how confident the student perceived him/herself to be with communicating in English. Language ability did not necessarily lead to problems with academic work, but did lead to non-academic problems.

The overall adjustment period is more complex for international students when compared to NES counterparts. Cheng, Myles, and Curtis (2004) found that the most difficult skills included leading class discussions (speaking), understanding instructions from professors (listening), and understanding the main points of a text (reading comprehension). The least important and least difficult skills identified in the survey included everyday English, for example, reading/writing emails. Andrade (2006) noted that language proficiency and cultural knowledge are two primary obstacles that 
international students face, but in the case of language proficiency, studies were inconclusive regarding its impact, or lack of impact, on academic achievement.

In regards to social experiences outside of the academic realm, language proficiency can play a major role in determining the quality and satisfaction of one's interactions with NESs (Fletcher \& Stren 1989; Lee, Abd-ella, \& Burks, 1981); however, as international communities on campus continue to gain prominence, IGSs may be more likely to seek companionship among co-nationals, either because of convenience, ease and comfort of interaction, or other factors. That said, how this will impact the student's socio-cultural adjustment and language development is rarely examined. A number of studies (Liu, 2011; Myles \& Cheng, 2003) suggested that increased interaction with NESs outside of class will improve acculturation, yet at the same time, IGSs responded with mixed feelings regarding social events such as BBQs and campus clubs, of which IGSs tend to feel like cultural outsiders and unable to fit in, thereby often avoiding such events altogether. Above all, factors such as marital status and home life of the IGS had a major impact on which people the IGS is spending time with. Andrade (2006) noted that for international students, interactions with NESs remain challenging, yet have been proven to help with overall adjustment even though gravitation towards co-nationals happens to be the more natural social approach. By using a self-reflective technique, Liu (2011), as an international student, was able to describe her own barriers and subsequently, her strategies in overcoming them. For her, the barriers to language development were reduced to a common theme: not enough interactions with NES outside of the classroom. Liu (2011) reaffirmed that being proactive is a key part of becoming an autonomous English learner; that is, someone who takes charge by creating opportunities to learn and speak English outside of the classroom. The resulting recommendation was to broaden one's NES social network as a means to maximize learning potential through increasing opportunities to speak.

Not all IGSs are able to create or join NES social networks, or even any social network, as Sawir, Marginson, Deumert, Nyland, and Ramia (2008) found that two-thirds of their 200 interviewees experienced loneliness and/or isolation during their early experiences at a university in Australia. These authors suggested that more interaction with local students will help decrease loneliness/isolation for international students, and while co-nationals can play a crucial role in the life of an international student, they cannot fully replace the student's network in the home country. Social isolation was characterized by "boredom and a sense of exclusion" (p.152), which stemmed from the need to belong to a social group. Sherry, Thomas, and Chui (2010) corroborated the findings from Sawir et al. (2008), noting that in their survey of 161 international students at the University of Toledo, 
a major theme was lack of NES friends, with only 35\% of the respondents indicating that they had successfully made friends with their American colleagues. The participants in the Robertson et al. (2000) study expressed concerns about isolation in their university life, which provided more evidence that this was a prevalent experience among international students. One of many factors for creating a successful social experience may be the willingness to communicate (WTC), defined by Gallagher (2013) as "the likelihood to initiate communication in the L2 given the opportunity" (p.56), where the WTC increases or decreases depending on the situation and is less stable than one's WTC in the L1. MacIntyre et al. (2001) describe WTC as "trait-like" (p.372), similar to other personality traits stays stable and consistent over time and across a variety of situations. However, if IGSs could develop their WTC in social situations, it would likely lead to more positive social outcomes.

The literature has acknowledged the socially isolated international student as well as the international student's inclination towards conationals, and generally recommends that international students build friendships with the local people - specifically NESs; however, what has been less discussed are the benefits of having a strong network in general, which may consist of co-nationals and other international students. Conationals who have lived in the US for a longer time can help immensely with the transition to graduate school, including help with finding housing and navigating through the local culture; in fact, co-nationals may be better equipped to help scaffold the academic experience for the newcomers, something that will be highlighted in the experiences of some of the interviewees. This help can come in many forms, for example, providing general academic advice, helping the newcomer maneuver through the academic bureaucracy, and more directly by partaking in discussion groups and discussing homework assignments.

\section{RESEARCH METHOD}

In designing my interview protocol, my goal was to maintain a certain level of informality. The intention behind this was to create a safe space for the students to talk about their experiences. I chose to conduct a semistructured interview (Meriam, 2009), which is one that has pre-written questions, but also remains open and flexible. I presumed this to be the best fit since I wanted to give the interviewee plenty of opportunities to elaborate on their experiences. In the interview process, I had to take into consideration the fact that the students were adjusting to a new setting, culture, and academic environment, while also encountering linguistic challenges. The openness and flexibility of the interview allowed me to document and detail these personal experiences. 
I divided the interview protocol into three sections: 1) questions about the student's educational background, 2) questions about language resources and opportunities on campus, and 3) questions about their social and academic experience. In reality, however, these questions and topics were not separate, but overlapping and intertwined. I first asked about the interviewee's academic background because these types of questions tend to elicit narratives and are more easily answered. In this way, the interviewee would be gently brought into the interview. The other topics in the interview were designed to be more thought-provoking in order to get the interviewee to detail the complexity of his/her experience.

\section{Participants}

Participants in the current study were recruited from the first quarter ESL class, offered to IGSs every fall, which focuses on academic writing and speaking. Students in this class had been placed in this introductory ESL class based on either by a low TOEFL score or a no-pass score on the internally administered placement exam. The three interviewees in the current study are with Brian, Amber, and Frank (pseudonyms). Brian, from China, is working on a Masters degree in Civil and Environmental Engineering. He uses English frequently in academic settings, but infrequently in non-academic settings. At the time of this study, Brian had not yet developed a social network, and remained mostly socially isolated. Amber, from Taiwan, is working on a Masters degree in Veterinary Medicine. She uses English frequently, in not exclusively, in both academic and non-academic environments. Her social network consists of international students and NESs. Frank, from Chile, is in a PhD program in Plant Sciences. He uses English infrequently in both academic and nonacademic environments. His social network consists of almost exclusively co-nationals.

I chose the interviewees based on their willingness to be interviewed as well as their different language/cultural background. The resultant interviews show a variety of experiences within the IGS community, and are representative of some of the major trends in the literature, but because of the sample size, the results from this study are not generalizable. Instead, the major themes ought to be considered as a point for future research.

\section{RESULTS}

\section{Brian (Chinese IGS)}

So in a way don't have too much chance to practice, so for the international student speaking is a big problem, seldom speak to Americans, native speakers. 
Brian, a first-year Masters student in Civil and Environmental Engineering, was a student of mine in the introductory ESL class, and one of the reasons for pursuing this project. During the interview, Brian gave an honest account of his experience as an IGS, including his perspective on what IGSs go through in their transition to graduate school, in particular with regards to social experiences. Brian did not integrate easily, and gave an account of the loneliness and isolation that he felt as an international graduate student, particularly upon arrival, being far away from family and familiar settings. In addition, Brian's talked about his difficulty to befriend American students, as in the following excerpt:

Brian: For international student, actually it is hard to make friends with native Americans, so most of the time they just group together with other international students, so we don't have the surrounding or atmosphere of the language, but you know, we can understand each other, but not so good, just understand.

As a result of not integrating easily into the host culture, Brian endured an isolating transition. Of the interactions that he had with others, he mentions that most of these interactions were with international students, largely because they can understand each other more easily. As a corollary to gravitating towards other NNESs, Brian implies that he seeks situations where making mistakes is acceptable. Perhaps, in this way, he is able to interact with others, using English, and still feel like it is a safe or nonjudgmental setting. In the next excerpt, Brian talks about the social importance of the ESL class for new international graduate students:

Brian: Yeah, when you come here, you know nobody, so you are pretty lonely, just live by yourself, if you have something uncomfortable or sad, you don't have nobody to communicate with, everybody has a hard time just come to [this university].

Daniel: Yeah, at first.

Brian: So, I think for the new students, I suggest that, for [the ESL class], they should like have the contact information of everybody, or make a group, make friends with each other, because they are the first group of people you meet here, they can support each other.

Brian reinforces the idea of the ESL class as an opportunity to make friends with other international students, and the importance of making connections early on, especially since graduate students, like Brian, often live on their own. He seems to be especially keen on finding support, as the support network was lacking in his early experiences. In addition to the lack of 
support, the social isolation correlates with a lack of meaningful opportunities to speak in English, and impacted Brian's speaking confidence.

Difficulties with speaking and confidence were brought up and expounded on throughout the interview, and, unsurprisingly, Brian reported using English in academic settings $60-79 \%$ of the time, but only $20-39 \%$ of the time in non-academic setting, demonstrating that the majority of his social interactions took place in his L1.

In the realm of academic experiences, Brian mentioned having to present in his major course, something that he felt extremely nervous about doing, which contrasted to his experience in the ESL class, where he felt comfortable presenting. The ESL class was a safer space for Brian to present and he excelled; by contrast, he struggled with his presentation in his major course not because of the content, but more because of the inevitable question/answer period that would come afterwards, as shown in the following exchange:

Brian: In [the ESL class] everyone is from a different major, you just have a general idea of your research, but in a major course, they understand what you see and maybe they can point out why you are wrong.

Daniel: Tell me about that experience, presenting in class.

Brian: It is like we are doing a research based on computer calculation to get the best design for material, I think the report I did was pretty good, pretty nice, and the presentation was based on the report, I tried to make everything in the report on the slides, I think I relied too much on the slides, we have a lot of data, I don't think I need to talk too much before the data, but the truth is I tried to talk to about datas, I failed to describe the data, why it's the best, sometimes people ask why? What is something? Oh, you didn't prepare for it, so it's stuck.

Daniel: Was that your first presentation?

Brian: Yeah, first academic presentation

In this excerpt, Brian is talking about feeling stuck during the question-andanswer sections of the presentation. Brian knew the material, and even practiced and prepared, but there wasn't any clear way to prepare for the Q \& A session, and quite probably his nervousness negatively affected his performance. Unsurprisingly, Brian felt like speaking was his biggest weakness.

What emerges from these interview excerpts is the link between opportunities to speak and speaking confidence. Brian has started his graduate program with a weak social network, and when there were 
interactions with other, Chinese was used. Whether or not Brian is able to successfully acclimate to, or at the very least cope with, the local culture may be crucial to his overall experience in graduate school. In order to find out, more interviews over time with Brian will need to be conducted.

\section{Amber (Taiwanese IGS)}

Study hard, don't think you are here for your life, you are here for your education, you are not here to have a life, you are here to study, don't be afraid to talk to people.

At the time of the study, Amber was a first year Masters student in Public Health and Veterinary Medicine. She spent the vast majority of her upbringing and adult life in Taiwan, where she graduated from university. She seemed to be the most culturally adjusted of all the interviewees, which may be accounted for by the fact that she already had some extended family in Southern California. Amber represents a socially successful IGS with a strong support network who has acculturated and formed a network of friends. Possibly her already existing familial network gave her confidence, and the fact that she had spent a year in the states beforehand made the cultural transition less of a shock. Amber has an international social network consisting of people from her country (Taiwan) and other countries, and sees the benefit of having co-nationals in one's social network. Even though she has a network of international people, Amber is primarily using English in her day-to-day interactions. Among the interviewees, Amber had the most strategic approach to finding friends, as expanded on in the following excerpt:

Daniel: I want to ask about your transition, socially and academically, first socially.

Amber: I think common in Asia, most people stick together all the time because a class stays together for the whole year, so you know everyone well, but here some of those people don't really talk to each other, people find a small group and stick together forever, sometimes it's hard for people to get in these small groups. But I found my small group anyways.

Daniel: Was that your strategy?

Amber: Well I have been here before for one year and I was shy, waiting for people to talk to me, but people didn't talk to me, okay, so I need to talk this time, so I try to talk more, and my classmates are amazing to me, so that's good.

This is an example of how Amber was able to adapt easily to her new surrounding, and as a result of her flexibility she was able to achieve social 
success. She talked about how she spent most of her time with international students from other countries, which provided her with ample opportunities to speak and interact in English in a safe environment. Given that Amber creates these opportunities for herself, she would be considered an autonomous English user in the eyes of Liu (2011), and her high WTC (Gallagher 2013) justifies her experience of being able to adapt easily to the host culture.

Amber even had the wherewithal to recognize that the new social environment required interaction in new settings, perhaps even in settings that are looked down upon in her home culture. In this next interview excerpt, Amber talks about hoe she goes to bars in the United States as a place of interaction and socializing even though bars are places where bad students go in her culture.

Daniel: You feel like you found your group?

Amber: Yeah, most people cannot really find their group

Daniel: In one year, you are halfway done

Amber: I know, it's fast. I think people here like to hang out in the bar, which is pretty different in Asia, because bar is only like for bad student, someone will hang out late in the night, my parents wouldn't like me to go to a bar, but here I see why people go, they don't have anywhere else to go.

Amber shows her ability to not only recognize the cultural differences, but she chooses to go beyond the boundaries of her own cultural norms in order to achieve her goals of creating a viable social network.

In these interview excerpts, Amber shows her outgoing demeanor and her drive to be social, which led to many successful friendship with other international students. This international social network has provided Amber with unending opportunities to speak in English and the support needed for her to be successful in her program.

\section{Frank (Chilean IGS)}

I try to talk to American people, because here we are too many

Chilean. I feel like, not always, I talk too much in Spanish.

Frank is a first-year international graduate student from Chile studying plant sciences. He never imagined coming to the United States for a graduate program. Recognizing his weaknesses in speaking, he arrived early for an intensive English program that lasted three quarters, during which time he made some connections with professors on campus. He then took TOEFL a few times, and ultimately scored high enough to be a competitive candidate; his success on TOEFL, coupled with his connection 
with a professor on campus, led to the acceptance to his graduate program.

Frank reported using English rarely in academic settings, and almost never in non-academic settings. Overall, he uses English the least out of all of the interviewees. As a testament to his low frequency of English use, Frank shared the fact that in the majority of his time spent in social situations, he communicates in his native language, Spanish. He justified this by noting the fact that the university has a tight-knit community of people from Chile, leading him to interact in that social circle easily. In this excerpt, Frank shares his early experiences, interacting with his Chilean roommate, which sets him on his social path.

Daniel: So you arrive in California, and what is that like?

Frank: Okay I come [to this university] to live with Chilean friend and okay, was a family and for me was easy because I can speak with him in Spanish and he help me with so many [things], and I arrive for study in the extension.

Daniel: Yeah

Frank: And I spend three quarter there and at this time I begin to apply for the scholarship and in there I contact with a professor here and okay finally he gave me the possibility for working here in the university and I have to leave extension for that but I don't know my level I think that I got tools but finally my grammar is no good, my speaking is no good but I can communicate my ideas, but not so good, but usually the people can understand.

This early experience of socializing with a co-national roommate led to an opportunity to join the larger Chilean community, where Frank found comfort and cultural familiarity. As a result, Frank gained enough friends to satisfy his social needs, and did not feel the need to make friends with NESs. However, the fact that all of his friends were co-nationals, sharing the same language, meant that almost all of his interactions were in Spanish and his English speaking skills were slower to develop.

In this next excerpt, the lack of interaction in English culminates in the feeling of uncomfortable in a social situation that requires him to use English. In fact, he feels even more uncomfortable in a social situation compared to an academic one. In this excerpt, Frank addresses his experience in social and academic settings. In the first part, he is referring to making a quick comeback to someone in a social situation:

Frank: Yeah, here the something happen I don't feel too much confidence say something or I don't know I'm always looking but no doing something.

Daniel: Okay, yeah, sure. 
Frank: I don't know for me it's more difficult, I don't know.

Daniel: Like you might want to say a silly comment, but...

Frank: I'm not sure if it would be good or not and also sometimes on the street I can no understand all the people and my listening in the social area is no the best I think in the academics is good because the people speak very clear and they try to give you an idea but on the street if someone say something that I didn't pick up or didn't pay attention and I didn't hear I don't know.

In the interview, Frank gave as an example a hypothetical situation of something happening abruptly, like a glass falling from a table, where he would automatically know how to respond in Spanish, perhaps even with a witty or quirky comment. In English, however, the time that it would take to process something to say would diminish the content of the remark, since timing is an important aspect of spoken interactions.

Frank is representative of IGSs who choose to primarily, if not exclusively, socialize with co-nationals, and the reason is that of ease and convenience. A network of co-nationals can be strengthening and supportive, and for many IGSs having such a network trumps the need to seek out opportunities to speak in English. Frank, as a result, seemed happy and well-adjusted to his life as a graduate student, although perhaps he will find himself lacking the culturally acceptable remark in certain social situations.

\section{DISCUSSION AND CONCLUSIONS}

The three interviewees in the present study show a snapshot of the variety of social networks that IGSs may form early on, and motivate further research as to the impact of social experiences on language learning and academic achievement. Each IGS detailed in this study had a different social experience, including Brian, who felt isolated, but had some interaction with foreign students, Amber, who used English frequently with other NNESs, and Frank, who interacted predominantly in Spanish with co-nationals. Each of these social experiences is unique, and there are characteristics of each one that will impact language learning in unique ways.

As educators, researchers, and administrators, we would be concerned about students like Brian who have not yet developed a support network. We should be cognizant that the transition period to graduate school in another country presents many challenges, and without support from peers, these challenges are even more pronounced. ESL classes are helpful for introducing students to each other, but more programming and campus event many be needed to promote social success in the IGS community. 
Amber was successful in achieving social support through her own willpower and proactive demeanor. As a result, she became a part of a strong social network, one that provided her with lots of speaking opportunities. The literature (e.g., Liu 2011) may still recommend that Amber interact more with NESs; however, her international network has led to a sense of ease and ability to acculturate, evidence that seeking out NESs is not necessarily the best strategy.

In the case of Frank, who had immersed himself in a strong conational community, he was able to build his social network easily, but because the vast majority of his interactions take place in his L1, it is unclear how his long-term language development will be affected. Still, for someone who is joining a new cultural environment, the strategy of befriending co-nationals may be a wise choice, especially in places where strong co-national communities exists. These preexisting communities are valuable sources of support for new students, and they are likely to have an increasing importance as more international students matriculate. Because co-national communities tend to be easy to join, more research needs to be done on the impact of being immersed in such a community on English language development.

The current study considers the social experiences of three IGSs, which is not enough to attain generalizable results. The IGSs profiled in this study are representative of larger trends, but do not represent every social experience. That said, it is important to take notice in these trends, measure their impacts, and continue to research how they change over time.

\section{IMPLICATIONS}

The data and analyses within this paper represent a starting point for a greater project that seeks to identify and explore salient issues that international graduate students face in the first year of their graduate program. The interview portion contributed to understanding some of the experiences of international graduate students by giving them a voice. The interviewees' accounts shed light on the complexity of their experiences by giving concrete examples and instantiations of the struggles that IGSs face in garnering healthy social networks. Further research on this topic would include first and foremost interviewing more international graduate students, and not only first-year students, but also students who are further along in their program. By interviewing those who have been around for a longer period of time, it would be possible to see what the social and academic experience looks like in more developed stages, and as they proceed through critical, gatekeeping stages in their program (becoming a TA, writing qualifying papers, taking the qualifying exam, etc.). Also, of interest would be to observe IGSs in their field specific classes, as well as situations where 
IGSs interact with colleagues and professors outside of the 'safe' space that ESL classes often provide; in other words, shadow students in both academic and non-academic settings. Finally, I think that it would be crucial to collect more data regarding the social networks of IGSs to better understand the role of social networks in language learning. Although this initial study is limited in scope, it has raised more questions for future studies.

\section{Appendix - Interview questions}

\section{Topic 1: Background Information and English Language}

1. Please tell me about your educational background and how you came to study at this university.

2. What were the hardest and easiest parts about transitioning to life at this university socially?

3. What were the hardest and easiest parts about transitioning to life at this university academically?

4. I'd like to ask about how you doing in terms of language. First, in speaking, reading, writing, and listening in the academic setting, and also in the social setting.

5. And in which skill area have you improved the most, and how do you account for that?

\section{Topic 2: Opportunities and Resources}

6. What resources has your department offered you in terms of English support? This can be in the form of tutoring, meetings, etc.

7. What else would you like to see available at your campus in terms of English resources?

8. In what ways was this class helpful, and in what ways do you think that this class could be improved to better suit your needs?

\section{Topic 3: Academic experience}

9. What are some challenges that international students face that American born students may not?

10. Regarding your expectations of your academic program, what was the most surprising thing about your program? In what ways has your program met your expectations?

11. What do you wish you knew before coming to university (about life, academics, your program)?

12. If you have been a TA, please tell me about that experience. If you haven't, what would you look forward to, and what would concern you about being a TA?

13. Tell me about your experience in your classes (note-taking, listening comprehension, opportunities to participate).

14. Tell me about your experience doing research.

15. If you were struggling with an assignment/paper, what would you do? Who would you see, how would you handle this situation?

16. Now that you have completed a quarter here, what advice do you have for international graduate students who will be starting next year? 


\section{REFERENCES}

Andrade, M. S. (2006). International students in English-speaking universities. Journal of Research in International Education, 5, 131-154.

Berg B.L., \& Lune, H. (2004). Qualitative Research Methods for the Social Sciences. Needham Heights, MA: Pearson.

Cheng, Y., Myles, J., \& Curtis, A. (2004). Targeting language support for non-native English-speaking graduate students at a Canadian university. TESOL Canada Journal, 21(2), 50-71.

Constantine, M. G., Okazaki, S., \& Utsey, S. O. (2004). Self-concealment, social self-efficacy, acculturative stress, and depression in African, Asian, and Latin American international college students. American Journal of Orthopsychiatry, 74, 230-241.

Coxhead, A. (2000). A New Academic Word List. TESOL Quarterly, 34(2), 213238.

Dao, T. K., Lee, D., \& Chang, H. L. (2007). Acculturation level, perceived English fluency, perceived social support level, and depression among Taiwanese international students. College Student Journal, 41(2), 287-295.

Fletcher, J., \& Stren, R. (1989). Language skills and adaptation: A study of foreign students in a Canadian university. Curriculum Inquiry, 19(3), 293-308.

Heikinheimo, P. S., \& Shute, J. C. (1986). The adaptation of foreign students: Student views and Institutional Implications. Journal of College Student Personnel, 27(5), 399-406.

Gallagher, H. C. (2013). Willingness to communicate and cross-cultural adaptation: L2 communication and acculturative stress as transaction. Applied Linguistics, 34(1), 53-73.

Lee, J., Koeske, G. F., \& Sales, E. (2004). Social support buffering of acculturative stress: A study of mental health symptoms among Korean international students. International Journal of Intercultural Relations, 28(5), 399-414.

Lee, J. J., \& Rice, C. (2007). Welcome to America? International student perceptions of discrimination. Higher Education, 53, 381-409.

Lee, M. E., Abd-ella, M., \& Burks, L. (1981). Needs of foreign students from developing nations at U.S. colleges and universities. National Association for Foreign Student Affairs, Washington, DC.

Li, L., Mazer, J. P., \& Ju, R. (2011). Resolving international teaching assistant language inadequacy through dialogue: Challenges and opportunities for clarity and credibility. Communication Education, 60(4), 461-478.

Liu, L. (2011). An international graduate student's ESL learning experience beyond the classroom. TESL Canada Journal, 29(1), 77-92.

MacIntyre, P. D., Baker, S. C., Clement, R., \& Conrod, S. (2001). Willingness to communicate, social support, and language-learning orientations of immersion students. SSLA, 23(3), 369-388.

Manese, J. E., Sedlacek, W. E., \& Leong, F. T.L. (1988). Needs and perceptions of female and male international undergraduate students. Journal of Multicultural Counseling \& Development, 16(1), 24-29.

Meriam, S. B. (2009). Qualitative research. San Francisco, CA: Jossey-Bass.

Mitchell, R., \& Myles, F. (2004). Second language learning theories $2^{\text {nd }}$ Edition. London: Hodder Education. 
Myles, J., \& Cheng, L (2003). The social and cultural life of non-native English speaking international graduate students at a Canadian university. Journal of English for Academic Purposes, 2, 247-263.

Open Doors (2012). Fast Facts. Retrieved from http://www.iie.org.

Perrucci, R., \& Hu, H. (1995). Satisfaction with social and educational experiences among international graduate students. Research in Higher Education, 36(4), 491-508.

Robertson, R, Line, M, Jones, S., \& Thomas, S (2000). International students, learning environments and perceptions: A case study using the Delphi technique. Higher Education Research \& Development 19(1), 89-102.

Sandhu, D. S., \& Asrabadi, B. R. (1994). Development of an acculturative stress scale for international students: Preliminary findings. Psychological Reports, 75(1), 435-448.

Sawir, E., Marginson, S., Deumert, A., Nyland, C., \& Ramia, G. (2008). Loneliness and international students: An Australian study. Journal of Studies in International Education, 12(2), 148-180.

Sawir, E. (2005). Language difficulties of international students in Australia: The effects of prior learning experience. International Education Journal, 6(5), 567-580.

Scheider, M., \& Fujishima, N. (1995). When practice doesn't make perfect: The case of a graduate ESL student. In Academic Writing in a Second Language: Essays on Research and Pedagogy (pp. xx-xxx). Norwood, NJ: Ablex Publishing Corporation.

Selltiz, C., Chirst, J. R., Havel, J., \& Cook, S. W (1963). Attitudes and social relations of foreign students in the United States. Minneapolis, MN: University of Minnesota Press.

Sherry, M., Thomas, P., \& Chui, W. International students: A vulnerable population. Higher Education, 60, 33-46.

Yeh, C. J., \& Inose, M. (2010). International students’ reported English fluency, social support satisfaction, and social connectedness as predictors of acculturative stress. Counseling Psychology Quarterly, 16(1), 15-28.

DANIEL MOGLEN, M.A., is a PhD candidate in Linguistics. His research interests include language assessment, placement tests, and second language writing. Email: djmoglen@ucdavis.edu

Manuscript submitted: February 15, 2015

Manuscript Revised: November 30, 2015 Accepted for publication: February 21, 2016 
Peer-Reviewed Article

ISSN: 2162-3104 Print/ ISSN: 2166-3750 Online

Volume 7 Number 1 (2017), pp. 38-52

(C) Journal of International Students

http://jistudents.org/

\title{
Are International Students Quiet in Class? The Influence of Teacher Confirmation on Classroom Apprehension and Willingness to Talk in Class
}

\author{
Chia-Fang (Sandy) Hsu \\ University of Wyoming, USA \\ I-Ting (Joyce) Huang \\ Synnix Industries Inc., Taiwan
}

\begin{abstract}
This study investigated the influence of teacher confirmation (TC) on classroom apprehension (CCA) and willingness to talk in class (WTT) among international students in the United States. The participants $(N=121)$ completed a battery of self-report instruments online. Results confirmed a path model that TC positively predicts classroom connectedness, which in turn, positively influences self-perceived language competence, which subsequently reduces CCA and increases WTT. The influences of length of stay in the U.S. and class size were controlled in the model, while culture of origin and class type did not influence CCA and WTT. Implications of these findings were further discussed.
\end{abstract}

Keywords: teacher confirmation, classroom connectedness, classroom apprehension, willingness to talk, language competence, international students

There were 4.3 million international students worldwide in 2011, and the number was projected to reach 8 million in 2025 (Organisation for Economic Co-operation and Development [OECD], 2013). The United States hosted more international students than any other country, and the enrollment rose steadily with an $8.1 \%$ growth in 2013/14 to a record high of 886,052 international students (Institute of International Education, 2014).

Although studying abroad has become a trend, the majority of faculty (77\%) in the College of Business at two southeastern universities 
reported that class participation is the top issue among international students in the U.S. (Tompson \& Tompson, 1996). Most international students in the U.S. (82\%) are from non-English-speaking nations (OECD, 2014). Many international students attributed their difficulty to fear or anxiety associated with speaking in English (Liu, 2007; Lu \& Hsu, 2008). The differences in the cultural values and school environments might also explain why international students experience communication anxiety during class discussion. For example, the collectivistic cultural orientation, which emphasizes group harmony, may make Asian students more hesitant to assert themselves in a meeting than American students with individualistic cultural values that presume the uniqueness of individuals (Hsu, 2007). The teacher-centered and authoritarian teaching style in Asian countries also encourages students to be quiet in the classroom (Hsu, 2002; Myers, Zhong, \& Guan, 1998; Zhang, 2005).

Given that class participation results in better grades and learning outcomes in American colleges and universities (Sidelinger \& BoothButterfield, 2010), it is important to illuminate how teachers can help international students overcome communication anxiety and improve class participation. Although previous studies (Tompson \& Tompson, 1996; Liu, 2007) have recommended strategies, such as improving students' language skills, little research has investigated instructional practices and classroom environment that can facilitate class participation among international students. According to Sidelinger and Booth-Butterfield (2010), both teacher-student and student-student relationships are important to student involvement in and out of class. Teacher confirmation behaviors, which emphasize teachers' relating behaviors with students, have been found to reduce students' listening apprehension and improve learning outcomes (Ellis, 2004; Hsu 2012). Classroom connectedness, which refers to a cooperative and supportive climate among students (Dwyer, Bingham, Carlson, Prisbell, Cruz, \& Fus, 2004), is another significant factor contributing to student involvement (Sidelinger \& Booth-Butterfield, 2010). Furthermore, research (Clément, Baker, \& MacIntyre, 2003) on second language (L2) learning indicated that a positive intergroup climate improves students' communicative confidence in L2, which in turn increases their desire to communicate with the L2 group. Teachers' confirmation behaviors and supportive classroom climate should help international students participate in American classroom. However, research has not investigated these possibilities. Therefore, the purpose of this study was to examine whether teacher confirmation and classroom connectedness could increase self-perceived language competence, which in turn reduces classroom apprehension and increases willingness to talk in class among international students in the U.S. 


\section{LITERATURE REVIEW}

\section{Classroom Apprehension and Willingness to Talk in Class}

McCroskey (1977) originally defined Communication apprehension as fear or anxiety associated with either real or anticipated communication with other people. Neer (1987) studied apprehension experienced in the classroom setting and defined classroom apprehension (CCA) as evaluation apprehension or expectation of negative outcomes associated with class participation. Students felt more comfortable in discussion when they perceived the class as a less formal, more familiar and more accepting environment (Neer \& Kircher, 1989).

Willingness to communicate (WTC) refers to the probability of initiating communication with others when the opportunity arises (McCroskey \& Richmond, 1987). Menzel and Carrell (1999) studied willingness to talk in class focusing on students' likelihood to talk in class in several situations: interest in class or topic, motivation, similarity to the rest of the students, similarity to the instructors, and seating arrangement. MacIntyre, Clément, Dörnyei, and Noels (1998) further developed a theoretical model to explain WTC in a second language. The model follows hierarchical layers of variables. The first layer of variables are communicative self-confidence and desire to communicate in a specific situation. The second layer of variables are interpersonal motivation, intergroup motivation, and L2 self-confidence. The final layers, which include intergroup attitudes, communicative competence, intergroup climate and personality traits, represent enduring influences on the process. Based on this WTC model, enduring influences are presumed to influence L2 selfconfidence, self-perceived communication competence, and motivational propensities, which in turn influence desire to communicate, WTC, and other communication behaviors in L2. Thus, international students may be less apprehensive and more willing to communicate in class when they experience positive intergroup climate and attitudes, and feel confident about communicating in L2.

\section{The Influence of Teacher Confirmation on CCA and WTT}

Ellis (2000) defined teacher confirmation (TC) as "the transactional processes by which teachers communicate to students that they are endorsed, recognized, and acknowledged as valuable, significant individuals" (p. 266). Teacher confirmation consisted of three elements: (a) teachers' responses to students' questions and comments, (b) interest in students or their learning, and (c) an interactive teaching style (Ellis, 2000). Teacher confirmation behaviors have been found to reduce students' fear of not being able to comprehend class material, and improve students' 
perceived learning (Ellis 2004; Hsu, 2012) and class involvement (Sidelinger \& Booth-Butterfield, 2010). When a teacher shows interest in students by using praise, smiles, and eye contact, students will feel more encouraged expressing their thoughts in class. When a teacher communicates messages that support and confirm international students' learning effort, students will feel valued and confident in class, which in turn they may experience less fear in participation and are more likely to initiate communication in class. Thus, the following hypotheses were derived (see Figure 1):

H1: Teacher confirmation is negatively related to classroom apprehension. H2: Teacher confirmation is positively related to willingness to talk in class.

\section{The Mediating Role of Classroom Connectedness and Language Competence}

Classroom connectedness (CC) refers to "student-to-student perception of a supportive and cooperative communication environment in the classroom” (Dwyer et al, 2004, p. 269). The relationships between teacher confirmation, classroom apprehension and willingness to talk in class among international students may depend on student-to-student relationships in class. Students in courses with high participation perceived having more supportive and cooperative relationships with fellow students than those in courses with low participation (Fassinger, 2000; Neer \& Kircher, 1989). Similarly, Frisby and Martin (2010) found that good student-to-student relationships facilitate class participation. It can be expected that international students would experience less anxiety in discussion when they feel welcome and accepted by their peers. Thus, the following hypotheses were derived (see Figure 1):

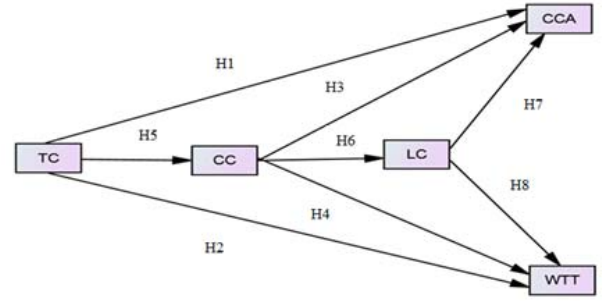

Figure 1.

The hypothetical model of the relationships between Teacher Confirmation (TC), Classroom Connectedness (CC), Language Competence (LC), Classroom Apprehension (CCA), and Willingness to Talk (WTT) in Class

H3: Classroom connectedness is negatively related to classroom apprehension.

H4: Classroom connectedness is positively related to willingness to talk in class. 
Furthermore, classroom connectedness has been found to mediate the relationship between teacher confirmation and student involvement (Sidelinger \& Booth-Butterfield, 2010). Teacher confirmation behaviors not only build up a supportive teacher-student relationship, but also facilitated a participatory learning environment in class. That is, teachers' confirming behaviors help improve student-to-student relationships, which in turn make students more comfortable participating in class. Thus, the following hypothesis was derived (see Figure 1):

H5:Teacher confirmation is positively related to classroom connectedness.

Another factor that may influence the relationships from teacher confirmation and classroom connectedness to CCA and WTT is selfperceived language competence (LC) among international students. LC refers to one's perceptions of his or her own ability of communicating in English in this study. According to MacIntyre et al. (1998), one's degree of L2 proficiency has a significant effect on WTC in L2. Most international students do not speak English as their first language. Because people tend to pay extra attention on a foreign accent and other differences, international students may become very sensitive to others' evaluations and doubt their own ability to communicate clearly; as a result, they may feel uncomfortable when speaking up in class.

In addition, research on WTC theory in L2 indicated that a positive intergroup climate and quality of contact with the $\mathrm{L} 2$ group lead to greater L2 communication confidence (Clément, Baker, \& MacIntyre, 2003). That is, a supportive communication climate in the classroom should make international students feel more confident speaking in L2, and less fearful asserting their points of view in class. Thus, the following hypotheses were derived (see Figure 1):

H6: Classroom connectedness is positively related to self-perceived language competence.

H7: Self-perceived language competence is negatively related to classroom apprehension.

H8: Self-perceived language competence is positively related to willingness to talk in class.

In sum, this study integrated the teacher confirmation model of learning and WTC theory in L2 to explain international students' classroom apprehension and willingness to talk in class in the U.S. Teacher confirmation influences student involvement through building a participatory learning environment in class (Sidelinger \& Booth-Butterfield, 2010). WTC theory (MacIntyre et al., 1998) argued that intergroup climate 
influences communicative self-confidence, which in turn, influences desire to communicate, WTC and other communication behaviors in L2. As applied to the classroom setting, both teacher confirmation and classroom connectedness contribute to intergroup climate between the teacher, domestic and international students, while communicative self-confidence is indicated by self-perceived ability in speaking English. Thus, this study proposed a hypothetical model that teacher confirmation predicts classroom connectedness, which in turn, influences students' language confidence, which subsequently influences students' classroom apprehension and willingness to talk in class (see Figure 1). In addition, the hypothetical model included several control variables, including culture of origin, length of stay in America, class size and class type. Previous research (e.g., Lu \& Hsu, 2008) suggested that these variables might also influence willingness to communicate among international students.

\section{RESEARCH METHOD}

\section{Participants and Procedure}

One hundred and twenty-one $(N=121)$ international students voluntarily completed the questionnaire online at a small-size western university in the United States. The link to the online questionnaire was distributed to international students' school email addresses via the International Student and Scholar Office. The university enrolled approximately 600 international students. The sample size is large enough for detecting significance given the population size (Krejcie \& Morgan, 1970).

The participants' average age was 26 years $(S D=5.84)$, ranging from 18 to 45 years. Of the participants, $46.3 \%$ were men and $51.2 \%$ were women. Eighty-one percent of the participants did not use English as an official language in their native country. The average time of staying in the United States was 21 months $(S D=23.61)$. The participants came from 36 countries (two participants did not clarify their nationality, but identified themselves as Asian and African). The 10 largest groups were as follows: 20.66\% from China, $7.44 \%$ from India, $4.96 \%$ from Nepal, $4.13 \%$ from Canada and Iran, and $1.65 \%$ from Saudi Arabia, South Korea, Sri Lanka, and Vietnam. The demographic characteristics resemble the population of international students in the university mostly.

Participants consisted of 55 different majors across six colleges of the university (all colleges except the college of law). In order to include various types of courses, at the beginning of the questionnaire, participants were asked to identify one class that they just attended right before they filled out this survey. The subjects of the courses they chose to evaluate 
varied from basic required courses (such as political science) to graduatelevel courses. The average class size was 34.93 students. As for class type, $38.8 \%$ of the chosen courses were a discussion-oriented class and $56.2 \%$ of the chosen courses were a lecture-oriented class. Furthermore, $9.9 \%$ of respondents were freshmen, $9.1 \%$ of respondents were sophomore, $9.1 \%$ of respondents were juniors, $7.44 \%$ of respondents were seniors, $26.45 \%$ of respondents were master's students, $30.6 \%$ of respondents were doctoral students, $7.44 \%$ of respondents were exchange students, and $5.8 \%$ of respondents were transfers (participants were asked to check all applied options).

\section{Instruments}

Teacher Confirmation. Teacher confirmation was measured using Ellis' (2000) Teacher Confirmation Scale (TCS). The TCS consists of 16 items and measures behaviors across three dimensions: (a) teachers' responses to students' questions or comments, (b) demonstrated interest in students and in their learning, and (c) teaching styles. Participants evaluated the instructor's confirming behaviors on a five-point Likert scale ranging from "strongly agree" to "strongly disagree." Sample items include "this instructor takes time to answer students' questions fully," and "this instructor makes an effort to get to know students." The scale had good reliability with alpha coefficients ranging from .85 to .95 , and its construct validity was demonstrated in several studies (e.g., Ellis, 2004; Hsu, 2012). Cronbach's alpha reliability was .93 in this study.

Classroom Connectedness. The Connected Classroom Climate Inventory (CCCI), developed by Dwyer et al. (2004), was used to measure students' connectedness with their classmates. The CCCI is an 18-item Likert-type scale with one dimension. Participants evaluated their classroom connectedness from "strongly agree" to "strongly disagree." Sample items include "the students in my class are friendly with one another," and "I feel a strong bond with my classmates." The scale had high alpha reliability of .94 and construct validity (Sidelinger \& Booth-Butterfield, 2010). The reliability in this study was .96.

Classroom Apprehension. The Class Apprehension about Participation Scale (CAPS), developed by Neer (1987), was used to measure the degree of classroom participation apprehension among students during classes. This study adopted the 20-item, 5-point Likert scale with response categories ranging from "strongly agree" to "strongly disagree." Ten items of the scale measure the dimension of communication participation defined as "predisposition to communicate during class discussion" (Neer, 1987, p.157), and the other 10 items measure the dimension of communication confidence referring to "general nervousness or fear of being evaluated by others during discussion" (p. 157). Sample items include "I worry that 
instructor will call on me during class," and "I usually do not speak in class unless called on by the instructor." The scale had high alpha reliability of .94 and construct validity (Neer \& Kircher, 1989). The current reliability in this study was .95 .

Willingness to Talk in Class. Willingness to Talk in Class Scale (Menzel \& Carrell, 1999) was used to measure students' likelihood to talk in class. This 19-item Likert scale was adapted from Willingness to Communicate scale (McCroskey, 1992). The scale involved several situations: Interest in class or topic, motivation, similarity to the rest of the students, similarity to the instructors, and seating arrangement (Menzel \& Carrell, 1999). The response categories were changed to "always," "often," "sometimes," "seldom," and "never." Sample items include "when the class is engaged in an open discussion, how likely will you talk in class?" and "when the professor asks for a response from the class, how likely will you talk in class?” The scale had high alpha reliability of .92 (Menzel \& Carrell, 1999). The current reliability in this study was .96 .

Language Competence. A scale adapted from the Self-Perceived Communication Competence scale (SPCC) (McCroskey \& McCroskey, 1988), was used to measure students' perceptions of their own ability when speaking in English. The SPCC is a 12-item scale, including four types of communication settings: Public, large group, small group, and dyad, with three types of receivers: Strangers, acquaintances, and friends. In the original scale, respondents evaluate their degree of competence from $0 \%$ (incompetent) to $100 \%$ (competent) in each setting. The scale had high reliability of .92 and good construct validity (Lu \& Hsu, 2008). In this study, only six items regarding large and small group settings were included because this study focused on class discussion. The response categories were also modified into a Likert-type scale: "Very easy," "easy," "neutral," "difficult," and "very difficult." Two words, "in English," were added to the end of each item in order to measure English competence. The current reliability in this study was .91.

Demographic Items. Participants were asked about their gender, age, nationality, major, educational status, first language, and number of months living in the United States. Participants were also asked to provide the information about the class they chose to evaluate. Class type was measured by asking whether the class is a lecture-oriented or discussionoriented class. Class size was measured by indicating an approximate number of students enrolled in class.

\section{RESULTS}

Table 1 shows all relevant means, standard deviations, and Pearson's correlations. Structural equation modeling (SEM) with maximum likelihood 
estimation, by SPSS Amos 21, was used to test all hypotheses. In order to test the direct and indirect effects of teacher confirmation, hypotheses testing was completed using three structural equation models (see Table 2). Only length of stay and class size were included as control variables because they were significantly related to classroom apprehension and willingness to talk in class (see Table 1).

Table 1. Pearson Correlation Matrix of Variables, Means, Standard Deviations, and Reliabilities

\begin{tabular}{lccccccccc} 
Variables & M & SD & 1 & 2 & 3 & 4 & 5 & 6 & alpha \\
\hline & & & & & & & & & \\
(1) TC & 67.68 & 10.76 & - & - & - & - & - & - & .93 \\
(2) CC & 66.20 & 14.72 & $.60^{* *}$ & - & - & - & - & - & .96 \\
(3) LC & 23.21 & 5.05 & $.20^{*}$ & $.29 * *$ & - & - & - & - & .91 \\
(4) CCA & 56.21 & 17.70 & $-.23^{* *}$ & $-.31^{* *}$ & $-.51^{* *}$ & - & - & - & .95 \\
(5) WTT & 63.34 & 16.49 & $.32^{* *}$ & $.34^{* *}$ & $.42^{* *}$ & $-.83^{* *}$ & - & - & .96 \\
(6) LS & 21.48 & 23.61 & .08 & $.17^{*}$ & .08 & $-.17^{*}$ & $.16^{*}$ & - & - \\
(7) CS & 34.93 & 36.14 & $-.19 *$ & $-.20^{*}$ & .06 & $.18^{*}$ & $-.22^{* *}$ & -.06 & -
\end{tabular}

Note. $* p<.05 . * * p<.01$. (1) TC $=$ Teacher Confirmation. (2) $\mathrm{CC}=$ Classroom Connectedness. (3) $\mathrm{LC}=$ Self-perceived Language Competence. (4) CCA= Classroom Apprehension. (5) WTT= Willingness to Talk in Class. (6) LS= Length of Stay (in months). (7) CS= Class Size (number of students).

Table 2. Results of Hypothesis Testing: Goodness-of-Fit Indices, Regression Coefficients, and R-Squared

\begin{tabular}{|c|c|c|c|c|c|c|c|c|}
\hline Models & Hypotheses & $\chi^{2}$ & Df & GFI & RMS & AGFI & $\beta$ & $r^{2}$ \\
\hline \multirow[t]{2}{*}{1} & $\mathrm{H} 1: \mathrm{TC} \rightarrow \mathrm{CCA}$ & 4.77 & 3 & .99 & .07 & .92 & $-.29 * *$ & .11 \\
\hline & $\mathrm{H} 2: \mathrm{TC} \rightarrow \mathrm{WTT}$ & & & & & & $.21 *$ & .07 \\
\hline \multirow[t]{5}{*}{2} & $\mathrm{H} 1: \mathrm{TC} \rightarrow \mathrm{CCA}$ & 7.77 & 5 & .98 & .07 & .91 & -.07 & .10 \\
\hline & $\mathrm{H} 2: \mathrm{TC} \rightarrow$ WTT & & & & & & .17 & .13 \\
\hline & $\mathrm{H} 3: \mathrm{CC} \rightarrow \mathrm{CCA}$ & & & & & & $-.25 * *$ & \\
\hline & $\mathrm{H} 4: \mathrm{CC} \rightarrow \mathrm{WTT}$ & & & & & & $.22 *$ & \\
\hline & $\mathrm{H} 5: \mathrm{TC} \rightarrow \mathrm{CC}$ & & & & & & $.59 * * *$ & \\
\hline \multirow[t]{8}{*}{3} & $\mathrm{H} 1: \mathrm{TC} \rightarrow \mathrm{CCA}$ & 10.77 & 8 & .98 & .05 & .92 & -.04 & .25 \\
\hline & $\mathrm{H} 2: \mathrm{TC} \rightarrow$ WTT & & & & & & .15 & .29 \\
\hline & $\mathrm{H} 3: \mathrm{CC} \rightarrow \mathrm{CCA}$ & & & & & & -.13 & \\
\hline & $\mathrm{H} 4: \mathrm{CC} \rightarrow \mathrm{WTT}$ & & & & & & .12 & \\
\hline & $\mathrm{H} 5: \mathrm{TC} \rightarrow \mathrm{CC}$ & & & & & & $.59 * * *$ & \\
\hline & $\mathrm{H} 6: \mathrm{CC} \rightarrow \mathrm{LC}$ & & & & & & $.29 * *$ & \\
\hline & $\mathrm{H} 7: \mathrm{LC} \rightarrow \mathrm{CCA}$ & & & & & & $-.45 * * *$ & \\
\hline & H8: LC $\rightarrow$ WTT & & & & & & $.36 * * *$ & \\
\hline
\end{tabular}

Note. $* \mathrm{p}<.05 . * * \mathrm{p}<.01 .^{* * *} \mathrm{p}<.001$. GFI $=$ Goodness of Fit Index; RMS = Root-Mean-Square; AGFI $=$ Adjusted Goodness of Fit Index. TC $=$ Teacher Confirmation. $\mathrm{CC}=$ Classroom

Connectedness. $\mathrm{LC}=$ Self-perceived Language Competence. $\mathrm{CCA}=$ Classroom Apprehension. WTT= Willingness to Talk in Class. 
Cultural backgrounds (individualistic vs. collectivistic nations by Hofstede's [2001] cultural index) and class types (lecture vs. discussion) were not included in the models because they did not significantly influence classroom apprehension and willingness to talk in class. In addition, the results of initial testing revealed poor fits between the specified models and the data. After allowing the correlated errors between CCA and WTT, the goodness-of fit indices, including $\chi^{2}$, GFI, RMS, and AGFI, all demonstrated good fits between the models and the data (see Table 2).

As shown in Table 2, the first SEM tested the direct effects of TC on CCA and WTT. Results indicated that teacher confirmation was negatively related to classroom apprehension (H1), and positively related to willingness to talk in class (H2). Thus, both $\mathrm{H} 1$ and $\mathrm{H} 2$ were supported. TC explained $11 \%$ and $7 \%$ of the variance in CCA and WTT, respectively.

The second SEM tested the indirect effect of TC on CCA and WTT via CC. Results indicated that classroom connectedness was negatively related to classroom apprehension (H3), and positively related to willingness to talk in class (H4). Teacher confirmation was positively related to classroom connectedness (H5). Thus, H3, H4, and $\mathrm{H} 5$ were supported. In addition, the regression coefficients from TC to CCA and WTT became insignificant after adding CC as the intervening variable. Thus, classroom connectedness mediated the relationships from teacher confirmation to classroom apprehension and willingness to talk in class among international students. A combination of TC and CC explained $10 \%$ and $13 \%$ of the variance in CCA and WTT, respectively.

The third SEM tested the indirect effects of TC via CC and subsequently LC. Classroom connectedness was positively related to selfperceived language competence (H6). Language competence was negatively related to classroom apprehension (H7) and positively related to willingness to talk in class among international students (H8). Thus, H6, H7, and H8 were supported. In addition, the regression coefficients from TC to CC and WTT were further reduced and remained insignificant, while the coefficients from CC to CCA and WTT decreased substantially and became insignificant. Thus, self-perceived language competence mediated the relationships from TC and CC to CCA and WTC. Overall international students' ratings of teacher confirmation, classroom connectedness, and self-perceived language competence explained $25 \%$ and $29 \%$ of the variance in classroom apprehension and willingness to talk in class, respectively.

\section{DISCUSSION}

This study investigated international students' perceptions of teacher behaviors, classroom environment, and class participation. The results indicated that teacher confirmation behaviors influence classroom 
apprehension and willingness to talk in class directly, as well as indirectly through classroom connectedness and self-perceived language competence. Regardless of length of stay in the U.S. and class size, the more positive relationships international students have with their teacher and classmates, the more confident they feel when speaking in English. As a result of these relationships, international students will experience less fear or anxiety, and they are more likely to express ideas or opinions in class. These findings further support WTC theory in a second language (MacIntyre et al., 1998; Clement et al., 2003) positing that students are less apprehensive and more willing to communicate in class when they experience positive intergroup climate and attitudes, and feel confident about communicating in L2. These findings also extend previous research (Sidelinger \& Booth-Butterfield, 2010) indicating that teacher confirmation helps build supportive student-tostudent relationships, which in turn, improve students' learning outcomes and class involvement.

Furthermore, self-perceived language competence appears to be the most significant factor predicting international students' classroom apprehension and willingness to talk in class. This result is consistent with the previous finding that student confidence is the major explanation for class participation (Fassinger, 2000; Neer, 1987). While previous research indicated that international students' confidence levels and class participation are influenced by their language skills and cultural backgrounds (Liu, 1997; Lu \& Hsu, 2008; Tompson \& Tompson, 1996), this study further discovered that student-to-student relationships play an important role in building international students' confidence when participating in class. When fellow students are not showing interest or support to each other's comments, international students might think negatively, such as "my ideas are not welcome," and "my accent is difficult to understand." Such negative thoughts may further increase students' communication anxiety or fear, which in turn, decreases their likelihood to speak up in class.

Previous researchers (Neer 1987; Neer \& Kircher, 1989) recommended some instructional practices for building supportive interpersonal climate and reducing classroom apprehension, such as allowing students sufficient time to offer response, promoting personal interest in discussion, avoiding producing stress, circular seating, and small group interaction. Compared to these recommendations, the findings of the current study offer practical implications targeting international students. To make international students feel more comfortable participating in class, it is important for instructors to give out assignments, hold activities, and establish norms that allow students developing strong bonds and support with each other in the classroom. International students often feel isolated from domestic students or only interact with other international students 
(Tompson \& Tompson, 1996). Small group activities or assignments that involve coordination between domestic and international students in completing a specific task may help students develop supportive relationships and create a positive communication climate in class.

In addition, class discussion tends to be dominated by a few outspoken, talkative students. Given the language and cultural constraints, it could be hard for international students to get their speaking turns and thus they remain quiet. Instructors should try to equalize speaking opportunities for students. For example, in a seminar class, instead of having an open discussion during the entire class period, each student can give a short oral report on the progress of his or her research project and the rest of the class can provide feedback afterwards. Each student can also take turns leading discussion over the assigned readings. The more opportunities international students have for participating in class, the more they feel they are parts of the class group, and the more comfortable they should feel when speaking up in class.

Several limitations need to be acknowledged in this study. First, this study was conducted in a small town where the majority of students are Caucasian Americans. The results might be different if data were collected from international students in large urban universities. To increase generalizability of these findings, a larger sample size with participants from different geographical areas should be used. Second, this study focused on international students' perceptions of teacher behaviors, classroom environment, and class participation. Given the importance of peer relationships in the classroom, future study may also investigate domestic students' attitudes toward international students, and survey instructors about effective ways to improve connectedness between international and domestic students. Third, this study did not find significant differences between students from individualistic and collectivistic cultures. Perhaps some international students choose to study in the U.S. because they identify more with American culture than their culture of origin. Future research should measure individual cultural orientation rather than classifying cultures based on nations. Fourth, this study used a cross-sectional survey research design. A longitudinal research design would allow observing the changes in participants' classroom participation over time. In addition, different data collection procedures, such as conducting interviews, observing classroom participation, or using experiments, may increase our understanding about the relationships between teacher behaviors, classroom connectedness, and classroom participation among international students in American classrooms.

In conclusion, international students bring global perspectives into U.S. classrooms and enhance the intellectual environment of domestic students. However, they often have difficulties in class participation due to 
the feeling of social isolation and low confidence in speaking English. For better idea-exchange outcomes, international students need to feel welcome and accepted not only by their teacher, but also fellow students. More research is needed to investigate ways to improve international students' connectedness with domestic students in the classroom, which should further help them to get involved in the larger academic community.

\section{REFERENCES}

Clément, R., Baker, S. C., \& MacIntyre, P. D. (2003). Willingness to communicate in a second language: The effects of context, norms, and vitality. Journal of Language and Social Psychology, 22, 190-209.

Dwyer, K. K., Bingham, S. G., Carlson, R. E., Prisbell, M., Cruz, A.M., \& Fus, D. A. (2004).Communication and connectedness in the classroom: Development of the connected classroom climate inventory. Communication Research Reports, 21, 264-272. doi: 10.1080/08824090409359988

Ellis, K. (2000). Perceived teacher confirmation. Human Communication Research, 26, 264-291.

Ellis, K. (2004). The Impact of Perceived Teacher Confirmation on Receiver Apprehension,Motivation, and Learning. Communication Education, 53, 120. doi:10.10/0363452032000135742

Fassinger, P. A. (2000). How classes influence students' participation in college classroom. Journal of Classroom Interaction, 35, 38-47.

Frisby, B. N., \& Martin, M. M. (2010). Instructor-student and student-student rapport in the classroom. Communication Education, 59, 146-164. doi: $10.1080 / 03634520903564362$

Hofestede, G. (2001). Culture's consequences: Comparing values, behaviors, institutions, organizations across nations $\left(2^{\text {nd }}\right.$ ed.). Thousand Oaks, CA: Sage.

Hsu, C-F. (2002). The influence of self-construal, family and teacher communication patternson communication apprehension among college students in Taiwan. Communication Reports, 15, 123-132. doi: 10.1080/08934210209367759

Hsu, C-F. (2007). A cross-cultural comparison of communication orientations betweenAmericans and Taiwanese. Communication Quarterly, 55, 359374. doi:10.1080/01463370701497831

Hsu, C-F. (2012). The influence of vocal qualities and confirmation of nonnative English-speaking teachers on student receiver apprehension, affective learning, and cognitive learning. Communication Education, 61, 4-16. doi: $10.1080 / 03634523.2011 .615410$

Institute of International Education. (2014). Open doors report on international educational exchange. Retrieved from http://www.iie.org/en/Research-andPublications/Open-Doors

Krejcie, R. V., \& Morgan, D. W. (1970). Determining sample size for research activities. Educational and Psychological Measurement, 30, 607-610.

Liu, L. (2007). International students' perceptions of intercultural communication 
apprehension. (Master's thesis). Retrieved from http://scholarworks.sjsu.edu/etd_theses/3425

Lu, Y., \& Hsu, C-F. (2008). Willingness to communicate in intercultural interactions betweenChinese and Americans. Journal of Intercultural Communication Research, 37, 75-88. doi: 10.1080/17475750802533356

MacIntyre, P. D. (1994). Variables underlying willingness to communicate: Causal analysis. Communication Research Reports, 11, 135-142.

MacIntyre, P. D., Babin, P. A., \& Clement, R. (1999). Willingness to communicate: Antecedents and consequences. Communication Quarterly, 47, 215-229.

MacIntyre, P. D., Baker, S. C., \& Clément, R. (2003). Willingness to communicate in a second language: the effects of context, norms, and vitality. Journal of Language and Social Psychology, 22. 190-209.

MacIntyre, P. D., Clement, R., Dornyei, Z., \& Noels, K. A. (1998). Conceptualizing willingness to communicate in a L2: A situational model of L2 confidence and affiliation. The Modern Language Journal, 82, 545-562.

McCroskey, J. C. (1977). Oral communication apprehension: A summary of recent theory and research. Human Communication Research, 4, 78-96.

McCroskey, J. C., \& McCroskey, L. L. (1988). Self-report as an approach to measuring communication competence. Communication Research Reports, 5, 108-113.

McCroskey, J. C. (1992). Reliability and validity of the willingness to communicate scale. Communication Quarterly, 40, 16-25.

McCroskey, J. C., \& Richmond, V. P. (1987). Willingness to communicate and interpersonal communication. In J. C. McCroskey \& J. A. Daly (Eds.), Personality and interpersonal communication (pp. 129-156). Beverly Hills, CA: Sage.

Menzel, K. E., \& Carrell, L. J. (1999). The impact of gender and immediacy on willingness to talk and perceived learning. Communication Education, 48, 31-40.

Myers, S. A., Zhong, M., \& Guan, S. (1998). Instructor immediacy in the Chinese college classroom. Communication Studies, 49, 240-255.

Neer, M. R. (1987). The development of an instrument to measure classroom apprehension. Communication Education, 36, 154-166.

Neer, M. R., \& Kircher, W. F. (1989). Apprehensives’ perception of classroom factors influencing their class participation. Communication Research Reports, 6, 70-77.

Organization for Economic Co-operation and Development. (2013). Education at a glance 2013: OECD indicators. Retrieved from http://dx.doi.org/10.1787/eag-2013-en

Organization for Economic Co-operation and Development. (2014). Indicator C4: Who studies abroad and where. Education at a Glance 2014: OECD Indicators. Retrieved from http:/www.oecd.org/edu/EAG2014Indicator\%20C4\%20\%28eng\%29.pdf

Sidelinger, R. J. \& Booth-Butterfield, M. (2010). Co-constructing student involvement: An examination of teacher confirmation and student-tostudent connectedness in the college classroom. Communication Education, 59, 165-184. doi: 10.1080/03634520903390867

Tompson, H. B., \& Tompson, G. H. (1996). Confronting diversity issues in the 
classroom with strategies improves satisfaction and retention of international students. Journal of Education for Business, 72, 53-57.

Zhang, Q. (2005). Immediacy, humor, power distance, and classroom communication apprehension in Chinese college classrooms. Communication Quarterly, 53, 109-124. doi:10.1080/01463370500056150

CHIA-FANG (SANDY) HSU, PhD., is an associate professor of communication and journalism. Her research interests include communication anxiety, cultural adaptation, and interpersonal relationships. She teaches research methods, nonverbal communication, and group communication. Email: hsus@uwyo.edu

I-TING (JOYCE) HUANG, MS., is a sales representative. Portions of this paper are based on her master's thesis under the first author's supervision. She presented this paper at the annual convention of the International Communication Association in London, UK, 2013. Email: alllightup@hotmail.com 
Peer-Reviewed Article

ISSN: 2162-3104 Print / ISSN: 2166-3750 Online Volume 7 Number 1 (2017), pp. 53-72 (C) Journal of International Students http://jistudents.org/

\title{
Factors Affecting the Academic and Cultural Adjustment of Saudi International Students in Australian Universities
}

\author{
Nisreen Alsahafi \\ University of New South Wales, Australia \\ Seong-Chul Shin \\ University of New South Wales, Australia
}

\begin{abstract}
The authors investigate factors affecting Saudi students' educational experiences in Australian universities and their adjustment issues. The data comes from the survey of 100 Saudi international students in Sydney and subsequent interviews. The analysis revealed that language proficiency is the main barrier to Saudi students' academic and social adjustment, with some academic factors such as classroom activities and assessment methods, and social factors such as homesickness and loneliness also affecting their study. The analysis has also identified Saudi students' coping strategies such as improvement of language competence, time management and mixing with others. It then discusses differences in perceived level of difficulty with respect to gender, age, educational level and length of residence, as well as some implications of the findings.
\end{abstract}

Keywords: Affecting factors, Australian universities, International education, Saudi students

International education is a great experience, which provides students with the opportunity to gain a number of valuable benefits. However, the literature demonstrates that international students experience the differences between their home culture and the new culture, which may have a great impact on their study. International students face a new learning environment, a foreign language, difficulties related to finance and 
accommodation, as well as different cultural aspects and norms (Borland \& Pearce, 2002; Poyrazli \& Grahame, 2007; Trice, 2007). These challenges tend to be more complex if the students' home culture is markedly different from the new culture. Although adjustment to a new learning environment is not an easy process, previous research shows that international students generally take a positive approach to overcome all the difficulties and they have the ability to adjust to the new environment (Vole \& Renshaw, 1996; $\mathrm{Wu}, 2011)$.

With the establishment of the King Abdullah Scholarships Program in 2005, there has been a significant increase in the number of Saudi students enrolled in Australian universities over the last few years, with about 10,000 Saudi government-sponsored students in 2011 (Ministry of Higher Education, 2012). Being supported financially by the government, Saudi students may not struggle with financial burdens but they face a new environment, which is vastly different from their home country, which may have a significant impact on their study.

Despite the significant increase in the number of Saudi students enrolled in Australian universities, very little research has been done to understand their experiences and how they bridge the cultural differences. Thus, this study sought to investigate the language and cultural difficulties facing Saudi students and the strategies they use to cope with the new environment. The findings of this study will greatly enhance the educational experiences of international students in general and Saudi international students, in particular. The findings will also assist education providers in Australia to make a better plan for international education.

\section{LITERATURE REVIEW}

\section{Language Issues Affecting International Students}

Studying in a non-native language is one of the main difficulties facing international students. Proficiency in the target language is a fundamental factor that enhances their academic achievement and cultural adjustment. Stoynoff (1997) examines the main factors affecting international students' academic performance and found that there is a correlation between their academic achievement and language proficiency. Based on another study by Lewthwaite (1996), lack of confidence in the language of instruction is one of the main frustrations that may face international students and their contribution inside the classroom. Many aspects of academic language barriers facing international students have been identified in previous studies (Robertson, Line, Jones, \& Thomas, 2000; Shin, 2011; Wong, 2004; Wu, 2011). For example, Wu (2011) investigates the difficulties faced by Taiwanese students enrolled in an 
American university and found that the main problems were related to written assignments, tests, the use of language, second language comprehension, note-taking, oral presentation and participation in class discussions. In her case study, Bifuh-Ambe (2009) summarizes the main difficulties faced by international students into four domains: the receptive and expressive language, written language such as written assignments and note-taking, comprehension such as understanding texts, and difficulties related to the methods of teaching and assessment in the host country.

Language barriers also affect international students in the social settings as they contribute to their socio-cultural adjustment. Besides the academic language, international students need to acquire the social language as well. They need to have competence in the language used in academic contexts as well as in informal, non-academic, contexts. Some international students may have sufficient level of language proficiency, which enhances their success academically, but they may avoid social interaction as a result of the lack of social language (Lewthwaite, 1996). Likewise, Trice (2007) attributes international students' isolation from domestic people to their weakness in language skills. Furthermore, lack of social language may also affect international students even inside classrooms. As Robertson et al. (2000) reported, one of the difficulties facing international students is the difficulty of understanding colloquial language, idioms, slang and the different accents used by their lecturers.

\section{Cultural Issues Affecting International Students}

Besides language proficiency, international students need to acquire cultural competence. Differences between cultures have a great impact on international students' academic and social lives. Borland and Pearce (2002) reported that international students' language knowledge without cultural competence is not sufficient to achieve success in both the academic and the social settings. One aspect of cultural differences is related to the differences in learning and teaching approaches, which hinder most of international students' adaptation to the new academic setting. The lack of familiarity with the learning approaches in the host country resulted in great challenges amongst international students in the academic context (Borland \& Pearce, 2002; Shin, 2011).

Loneliness has been reported as one of the problems that are most likely to impact international students' adaptation. Sawir, Marginson, Deumert, Nyland, and Ramia (2008) attribute cultural loneliness to being away from the familiar environment. According to Berry (1997), those who separate themselves from the new culture are more likely to experience a high level of cultural stress. When the home culture and the new one are vastly different, cultural stress becomes a big challenge (Thomson, Rosenthal, \& Russell, 2006). Making friends with students from the host 
culture is a difficulty that most international students encounter (Sawir et al., 2008; Sun \& Chen, 1999). Difficulty in making friends may lead to the feeling of homesickness, which is considered as one of the frequent concerns among international students (Kegel, 2009).

\section{Adaptation to the New Culture}

In order to gain their goals, international students do need to overcome the language and cultural challenges and to adjust to the new environment. Adaptation to the new culture may take five stages as suggested by Adler (1975): (a) contact with the new culture; (b) disintegration; (c) reintegration; (d) autonomy; and (e) interdependence. Different factors that enhance the adaptation process have been identified: self-efficacy and social support (Hechanova-Alampay, Beehr, Christiansen, \& Horn, 2002), familial support (Mittal \& Wieling, 2006; Poyrazli \& Kavanaugh, 2006), understanding the similarities and differences between the two cultures (Tseng \& Newton, 2002). Research shows that international students generally take a positive approach to overcome all the difficulties (Vole \& Renshaw, 1996).

International students' demographic characteristics may have an impact on their adaptation process, though there are no consistent findings. For example, in some studies, female students showed a higher level of stress (Kwon, 2009). Poyrazli and Lopez (2007) found that male students had a higher level of language difficulties. In contrast, some other studies revealed that gender had no impact on the adjustment process (Poyrazli, Arbona, Bullington, \& Pisecco, 2001; Yan \& Berliner, 2011). Age has also presented to have an effect on the adjustment process. Sumer, Poyrazli, and Grahame (2008) reported that younger students adapt to the new culture more easily, compared to older students. However, a study by Yan and Berliner (2011) revealed that younger students are more likely to experience cultural difficulties. Hofmann (2010) found that younger undergraduate students experience a higher level of language difficulties and cultural stress. It was also found that respondents who resided in the host country for two years had more cultural stress than those who resided for longer or shorter periods of time.

\section{Saudi International Students}

Saudi students' learning and culture backgrounds cannot contribute more to their academic success in Western universities. Shabeeb (1996) found that English language was the main difficulty affecting Saudi and Arabian Gulf students' adjustment process. Furthermore, Saudi students are accustomed to teaching and learning styles, which are different from the common teaching approaches in Western culture (Kampman, 2011). Another cultural aspect, which may have a great impact on Saudi 
international students, is the gender segregation aspect of Saudi culture. Male and female are segregated in schooling and universities. They attend separate schools and institutions and are taught by teachers from the same gender. Being in a non-segregated culture is considered as a new experience that Saudi students need to adapt to. A study by Shaw (2009) revealed that Saudi students in the US experience a different culture and unfamiliar learning styles. The major differences reported were: the mixed gender classes, the negotiation atmosphere of American classrooms, and the availability of different resources, and to bridge these differences, they use strategies such as setting their goals, developing study skills, study in groups and time management. Abdel Razek (2012) identified different factors that limit Saudi students' participation in the social life in America including religion, the mixed gender aspect of American culture and dietary restrictions. Al-Hazmi's study (2010) focused on the impact of Saudi gender segregation culture upon Saudi students in Australia. The study revealed that being in a mixed gender culture has an impact on Saudi students' cultural identity. The study is directed by the following research questions:

1. What are the language-associated activities that Saudi students experience difficulties with in Australian universities?

2. What are the cultural issues affecting Saudi students' in Australian universities?

3. Are there differences in the perceived level of language and cultural difficulties based on demographic factors among Saudi students in Australian universities?

4. What strategies do Saudi students use to overcome the language and cultural challenges they face?

\section{RESEARCH METHOD}

Mixed method research is defined as "research in which the investigator collects and analyzes data, integrates the findings, and draw inferences using both qualitative and quantitative approaches or methods in a single study or program of inquiry” (Tashakkori \& Creswell, 2007, p. 4). The rationale for integrating both quantitative and qualitative methods in this study is that using a single method is insufficient to address the complex issue of Saudi student experiences in Australia. Using the mixed method approach offers a better understanding of the research problem and provides richer data from the participants as the two methods complement each other (Creswell \& Clark, 2011; Valadez \& Bamberger, 1994).

The fieldwork for data collection was conducted in 2012, in a four-

month period. It was designed in two phases. In the first phase, a survey was developed and administered to a large sample to measure a number of 
language and cultural affecting factors and coping strategies considered important in the relevant literature. The second phase was a qualitative exploration of Saudi students' personal educational experiences in Australian universities using semi-structured interviews to gain more insight into the quantitative data. The results of the quantitative and qualitative data were integrated when discussing the findings of the study. 100 Saudi students enrolled in 17 different Australian universities participated in this study (See Table 1 for participants' backgrounds). Those who were still undertaking English as a second language courses were not included in this study as they did not have full academic experiences outside the ESL program.

\section{Table 1: Description of the participants' background}

\begin{tabular}{llc}
\hline \multicolumn{1}{c}{ Characteristics } & & No. \& \% (out of 100) \\
\hline \multirow{2}{*}{ Gender* } & $\mathrm{M}$ & 78 \\
& $\mathrm{~F}$ & 22 \\
\cline { 2 - 3 } Age & $18-23$ & 20 \\
& $24-26$ & 76 \\
Level of Education** & $27<$ & 22 \\
& $\mathrm{UG}$ & 78 \\
\hline \multirow{2}{*}{ Length of Residence (Years) } & $\mathrm{PG}$ & 24 \\
& $<2$ & 55 \\
& $2-4$ & 21 \\
\hline
\end{tabular}

*The numbers by gender reflect the proportion of male and female Saudi students studying in Australia as in year 2010-2011, there were 7,747 male students and 1,722 female students (Ministry of Higher Education, 2012).

**The numbers by level of education reflect the proportion of undergraduate and postgraduate Saudi students who are awarded scholarships as 8155 postgraduate students received scholarships in different countries in 2011 whereas the number of undergraduate students was 566 students (Ministry of Higher Education, 2012).

\section{Table 2: The examined factors and strategies}

\begin{tabular}{|c|c|}
\hline Language factors & $\begin{array}{l}\text { 1. Taking notes; 2. Participation in class discussions; } 3 . \text { Reading } \\
\text { texts/articles; } 4 \text {. Written assignments; } 5 \text {. Tests; } 6 \text {. Understanding } \\
\text { lectures; } 7 \text {. Speaking in tutorials and seminars; } 8 \text {. Understanding } \\
\text { questions; and } 9 . \text { Writing reports. }\end{array}$ \\
\hline \multirow[t]{2}{*}{ Cultural factors } & $\begin{array}{l}\text { Academic factors: } \\
\text { 1. Classroom arrangement and activities; 2. Types of assessment } \\
\text { tools; 3. Availability of resources and facilities; } 4 \text {. mix-gender } \\
\text { classes; 5. Relationship with lecturers; 6. Lecturers' role in } \\
\text { classroom; and 7. Student's role. }\end{array}$ \\
\hline & $\begin{array}{l}\text { Social factors: } \\
\text { 1. Loneliness; } 2 \text {. Homesickness; } 3 \text {. Mixing with others from different } \\
\text { cultures; } 4 \text {. Unfamiliar customs; } 5 \text {. Discrimination; 6. Food; } 7 . \\
\text { Climate. }\end{array}$ \\
\hline Coping strategies & $\begin{array}{l}\text { 1. Improving language; } 2 \text {. Making friends with people from other } \\
\text { cultures; } 3 \text {. Time management; } 4 \text {. Participating in different activities; } \\
\text { 5. Increasing knowledge about the new culture; } 6 \text {. Building good } \\
\text { relationships with the academic advisors; } 7 \text {. Asking others for help; } \\
\text { 8. Study in groups; and } 9 \text {. Using the available resources. }\end{array}$ \\
\hline
\end{tabular}




\section{Data Collection and Analysis}

Survey instrument. An online questionnaire was designed using a survey software tool to collect data from participants about their experiences in Australian universities. The questionnaire was constructed around 9 language factors, 7 cultural factors, and 9 coping strategies. The factors and strategies were adopted from the relevant literature (Bifuh-Ambe, 2009; Sawir et al., 2008; Shaw, 2009; Shin, 2011; Trice, 2007; Tseng \& Newton, 2002) based on their relevance and importance to the research questions of the study. The examined factors and strategies are presented in Table 2.

The first section of the survey asked a series of demographic questions about gender, age, level of education, and length of stay. In the next sections of the survey, a five-point Likert scale was used to measure the level of difficulty experienced with each of the examined factors as well as the level of helpfulness of each of the examined coping strategy. Different response scales were used in each section. Frequency scales (5-always, 4usually, 3-sometimes, 2-rarely and 1-never) were used to measure the level of language difficulties, level of problem scales (5-very problematic, 4problematic, 3-not sure, 2-hardly problematic,1-not problematic at all) were used to rate the level of problem experienced with the examined cultural factors, and level of helpfulness scales (5-very helpful, 4-helpful, 3-not sure, 2-hardly helpful, 1-not helpful at all) were used to measure the level of helpfulness of the examined coping strategies. At the end of the questionnaire, respondents were invited to take part in follow-up interviews and asked to provide their details (name and contact details) if they are interested in taking part in the interviews.

After obtaining ethics approval, the researchers sent an email to the Saudi students' Club in Sydney to seek their assistance to distribute the questionnaire link to all Saudi international students who were studying in different Australian universities. After obtaining the agreement, an email invitation to participate in the online survey questionnaire was forwarded to the Club President, who then circulated it to all Saudi students in Australia. The body of the email included a clickable hyperlink to the survey. They were provided with clear details about the study and its purposes. They were assured of their privacy and confidentiality. 100 responses were received.

To analyze the quantitative data, responses to the survey exported into an excel spreadsheet, and then transferred to SPSS software. The data analysis included descriptive statistics (mean and standard deviation) and one-way ANOVA. The mean scores were used to determine the overall level of difficulty experienced with each examined factor as well as the overall level of helpfulness of each of the examined coping strategies (RQ1, 2 and 4). The maximum possible mean score for each factor/strategy was 5 (1-2.33 indicate a low level, 2.34-3.66 indicate a moderate level, and 3.67- 
5.00 indicate a high level). To answer RQ 4, the data analysis procedure involved a comparison of means through one-way ANOVA to explore whether differences between the means of the overall level of difficulties based on the selected demographic factors were significant.

Semi-structured interviews. Qualitative data were collected using semi-structured interviews with 7 students selected from those who indicated their willingness in participating in the interviews. Participants were selected to present a sample of Saudi students with different demographic factors. Interviewees were contacted by email to arrange an appropriate time. English was the language used mainly for the interview with 5 of the participants, and Arabic was used with 2 of the participants. Interviews were conducted by phone with 7 students. Choosing to administer the interviews by phone was for two reasons. Firstly, this method helps reach the participants quickly with the time limit and to collect data most economically. As pointed out by Crano and Brewer (2002), telephone interviews can be accomplished with greater speed, compared to personal interviews. Secondly, the participants indicated their preference in conducting the interviews via phone.

Pre-determined open-ended questions were used as an interview guide to ensure the covering of the important issues. Participants were asked about the main difficulties faced during their study and the main strategies they adopt to overcome these difficulties (see Appendix A). They were given the opportunities to freely talk about their experiences. The length of the interviews ranged from 20-30 minutes and all of them were audio-taped and then transcribed. In order to maintain anonymous, letters (A-G) were assigned to the participants.

The qualitative data were analyzed in different steps (King \& Horrocks, 2010; Mason, 2002). Firstly, the interviews conducted in Arabic were translated to English. Secondly, the interview transcripts were read several times literally and interpretively. Thirdly, the significant statements and sentences were identified, coded and categorized under key themes formulated through the related literature. Fourthly, the themes were connected and interrelated. Finally, the main themes were discussed to give more insight into the statistical analysis.

\section{RESULTS}

\section{Quantitative Data}

Affecting language and cultural factors. The mean sores indicated that the overall level of difficulty experienced with language was in moderate level $(M=2.96)$. The highest level of language difficulties was experienced in 
written assignments and participation in class discussions. On the other hand, understanding questions and understanding lectures were perceived as the least difficult activities. Table 3 illustrates the mean of the experienced level of difficulty with the examined

Table 3: The means of the level of difficulty with the language-associated activities

\begin{tabular}{lcc}
\hline Language-associated activities & Mean & SD \\
\hline Written assignment & 3.21 & 1.09 \\
Participation in class discussions & 3.06 & 1.05 \\
Writing reports & 3.00 & 1.02 \\
Tests & 2.99 & 1.05 \\
Taking notes & 2.97 & 1.07 \\
Reading texts/articles & 2.96 & 1.00 \\
Speaking in tutorials & 2.84 & 1.10 \\
Understanding questions & 2.83 & 0.97 \\
Understanding lectures & 2.74 & 1.03 \\
Overall & 2.96 & 0.71 \\
\hline
\end{tabular}

With respect to the cultural factors, the data revealed that, overall, the level of difficulty experienced with the cultural factors, both academic and social, examined in this study was not high. The level of difficulty experienced with the examined academic and with the examined social factors was in moderate level (M-2.51 and 2.34, respectively). However, the level of difficulty with the social factors was somewhat greater when compared to the academic factors. There were noticeable differences between the levels of difficulty perceived in each factor. The main problematic academic factors were types of assessment tools and classroom arrangement and activities, while the most problematic social factors were loneliness, homesickness and discrimination. Table 4 presents the mean scores of the experienced level of difficulty with the cultural factors.

Table 4: The means of the level of difficulty with the cultural factors

\begin{tabular}{lll|lcc}
\hline \multicolumn{1}{c}{ Academic factors } & Mean & SD & \multicolumn{1}{c}{ Social factors } & Mean & SD \\
\hline Types of assessment tools & 2.97 & 1.13 & Loneliness & 2.90 & 1.34 \\
Classroom arrangement and activities & 2.42 & 1.16 & Homesickness & 2.88 & 1.39 \\
Your relationship with lecturers & 2.33 & 1.16 & Discrimination & 2.80 & 1.36 \\
Availability of resources \& facilities & 2.28 & 1.25 & Unfamiliar customs & 2.43 & 1.17 \\
Lecturer's role in classroom & 2.26 & 1.19 & Food & 2.31 & 1.31 \\
Your role as a student in classrooms & 2.21 & 1.17 & Mixing with others & 2.21 & 1.27 \\
Mixed gender classes. & 1.92 & 1.24 & Climate & 2.04 & 1.16 \\
Overall & 2.34 & 0.80 & Overall & 2.51 & 0.85 \\
\hline
\end{tabular}


Differences in the level of perceived difficulty based on the demographic factors. The analysis indicated significant differences in the level of language difficulties based on age $(\mathrm{F}=3.28, \mathrm{p}<.05)$. No significant differences were found in the level of language difficulties based on the other demographic factors (gender, level of education and length of stay). Table 5 presents differences in the level of difficulty with language based on demographic factors.

Table 5: Differences in the level of difficulty with language based on demographic factors

\begin{tabular}{llllll}
\hline Demographic factors & & $\mathrm{M}$ & $\mathrm{SD}$ & $\mathrm{t} / \mathrm{F}$ & $\mathrm{s}$ sig \\
\hline \multirow{2}{*}{ Gender } & $\mathrm{M}$ & 2.96 & 0.71 & \multirow{2}{*}{0.19} & \multirow{2}{*}{0.66} \\
\cline { 2 - 6 } Age & $\mathrm{F}$ & 2.95 & 0.73 & & \\
\cline { 2 - 6 } & $18-23$ & 3.61 & 0.97 & & \multirow{2}{*}{0.04} \\
\multirow{3}{*}{ Level of Education } & $24-26$ & 3.11 & 0.61 & 3.28 & \multirow{2}{*}{0.22} \\
& $27<$ & 2.88 & 0.70 & & \multirow{2}{*}{0.45} \\
\cline { 2 - 6 } Length of stay (Years) & $\mathrm{UG}$ & 3.15 & 0.73 & \multirow{2}{*}{1.51} & \\
& $\mathrm{PG}$ & 2.90 & 0.69 & & \\
\cline { 2 - 6 } & $<2$ & 3.07 & 0.62 & \multirow{2}{*}{0.80} & \\
\hline
\end{tabular}

Table 6: Differences in the level of difficulty with cultural factors based on demographic factors

\begin{tabular}{|c|c|c|c|c|c|c|c|c|c|}
\hline \multirow{2}{*}{ Demographic factors } & & \multicolumn{4}{|c|}{ Academic factors } & \multicolumn{4}{|c|}{ Social factors } \\
\hline & & $\mathrm{M}$ & SD & $t / f$ & sig & $\mathrm{M}$ & SD & $t / f$ & sig \\
\hline \multirow{2}{*}{ Gender } & $\mathrm{M}$ & 2.35 & 0.84 & \multirow{2}{*}{-0.09} & \multirow{2}{*}{0.92} & 2.44 & 0.83 & \multirow{2}{*}{1.76} & \multirow{2}{*}{$\begin{array}{c}0 . \\
08\end{array}$} \\
\hline & $\mathrm{F}$ & 2.30 & 0.66 & & & 2.77 & 0.89 & & \\
\hline \multirow{3}{*}{ Age } & $18-23$ & 2.89 & 1.57 & \multirow{3}{*}{1.72} & \multirow{3}{*}{0.18} & 2.96 & 1.35 & \multirow{3}{*}{0.59} & \multirow{3}{*}{$\begin{array}{l}0 . \\
56\end{array}$} \\
\hline & $24-26$ & 2.53 & 0.69 & & & 2.56 & 0.97 & & \\
\hline & $27<$ & 2.26 & 0.77 & & & 2.47 & 0.79 & & \\
\hline \multirow{2}{*}{ Level of Education } & UG & 2.45 & 0.77 & \multirow[t]{2}{*}{0.76} & \multirow[t]{2}{*}{0.45} & 2.37 & 0.81 & \multirow{2}{*}{-0.76} & \multirow{2}{*}{$\begin{array}{c}0 . \\
45\end{array}$} \\
\hline & PG & 2.31 & 0.82 & & & 2.55 & 0.86 & & \\
\hline \multirow{3}{*}{ Length of stay (Years) } & $<2$ & 2.19 & 0.75 & \multirow{3}{*}{0.82} & \multirow{3}{*}{0.44} & 2.36 & 0.74 & \multirow{3}{*}{1.99} & \multirow{3}{*}{$\begin{array}{c}1 . \\
14\end{array}$} \\
\hline & $2-4$ & 2.44 & 0.82 & & & 2.66 & 0.84 & & \\
\hline & $4<$ & 2.26 & 0.83 & & & 2.27 & 0.93 & & \\
\hline
\end{tabular}

With respect to the cultural factors, the analysis revealed that no significant differences between the overall experienced level with cultural factors, academic and social, based on the selected demographic factors. Table 6 presents differences in the level of difficulty with cultural factors based on demographic factors. 
Coping strategies. Overall, the mean scores indicated that the perceived helpfulness with the examined strategies was in high level $(M=3.93)$. Improving language, time management, and using the available resources were perceived as the most helpful strategies. Table 7 illustrates the mean scores of the level of helpfulness of each strategy.

Table 7: The means of the level of the helpfulness of coping strategies

\begin{tabular}{lcc}
\hline Coping strategies & Mean & SD \\
\hline Improving language & 4.28 & 0.83 \\
Time management & 4.16 & 0.19 \\
Using the available resources & 4.15 & 0.80 \\
Making friends with people from other cultures & 4.07 & 0.90 \\
Increasing knowledge about the new culture & 3.93 & 0.99 \\
Asking others for help & 3.79 & 0.49 \\
Participating in different activities & 3.76 & 1.03 \\
Building good relationships with academic advisors & 3.61 & 1.06 \\
Study in groups & 3.59 & 1.24 \\
Overall & 3.93 & 0.57 \\
\hline
\end{tabular}

\section{Qualitative Data}

Qualitative data were categorized into three major themes: language challenges, cultural challenges and coping strategies.

Language challenges: Participants indicated that they experienced some difficulties with language, though they did not perceive it as a big barrier. When asking whether the students regarded the language as a barrier, one response was "It is not very much as a barrier because I can understand a lecture and I can still answer the questions...but I still have language difficulties”.

The perceived difficulty with language was reported to be associated mainly with expressive language with both oral and written language. One of the interview responses was "I feel sometimes like I cannot express my ideas enough, particularly, in practical, oral exam and oral presentation". Another participant responded "When I sit and read the questions to start to write the answer... there are some limitations limit me to write in an academic way, in the way that in the Master level”.

Participants reported also some difficulties with receptive language in terms of reading texts and articles. One of the responses was:

I still have some difficulties with some of the scientific words or scientific terminology...I have to, you know, nearly if it is a new subject, I have to check nearly more than $10-15$ words in one page, 
just because I want to understand all the details of this subject...I need an hour to finish three pages in a chapter.

Cultural Challenges. Perceived difficulty with cultural factors indicated in the qualitative data was categorized under academic challenges and social challenges.

Academic challenges. Participants indicated that they experienced some academic difficulties with assessment tools, mainly with tests and oral presentations. One participant stated, "The most difficult thing is the multiple choice questions in the test. For example, you may have 60-70 questions. You need to understand everything in the book”. Another participant said:

The most difficult one is exams or tests especially when Australian style emphasizes on your time management more than on your knowledge. They give you a little bit of time; let's say an hour, to finish 40 or 50 questions.

With regards to oral presentation, one participant mentioned:

... I do not have the full confidence to present my work in front of people, so maybe this one is like a bit challenging...I am not used to present in front of people. It is more than confidence, more than a language for me.

Most participants attributed their perceived difficulty with academic factors to their prior learning experiences. They pointed out to some of the differences between studying in their home country and studying in Australia that caused some academic challenges for them. One participant said, "The main difference is the focus on research. Unlike in Saudi Arabia, you cannot depend on a book or a lecture. You have to work on your own, to read a lot to get a good grade". Another participant stated, "In Saudi Arabia, the teacher is the source of knowledge whereas in Australia, the student needs to search about knowledge. This difference is the main difficulty I faced here in Australia”.

Differences between studying in their home country and studying in Australia were also reported to cause some academic challenges in terms of classroom activities. One student stated, "They focus more here on practical activities more than theoretical, but in Saudi Arabia, they focus on theoretical rather than practical". Another participant said, "Here, they have a strategy called tutorials... but in Saudi Arabia, we do not have such tutorials. We just attend a lecture or a class” 
Social challenges. Participants indicated that they experienced some of cultural challenges especially homesickness and loneliness. Some of the statement made include, "I do miss my family; I do miss my mother and everything. Well, here you have just to keep an eye on the ball. You have to stay focus on your study" and "Sometimes, I feel lonely because here they have their own life style...I cannot be like them because of the religion, because...even their thinking style, the way of thinking is different from us".

Interview responses showed that most participant experienced cultural stress at the beginning, but they could adapt to the new culture later. One of the statements made was: "At the beginning, I felt homesick. But after two or three months, I adapted to the new culture". Another statement was,

Being in a new culture affected my study so much at the beginning especially in the first year because of the cultural differences. But to some extent, I am OK now. Going to Saudi Arabia from one time to another helps me much.

Interview responses indicated that there was no difficulty faced with mixing with others especially when having a good language level. However, some of the responses indicated the preference of having friends from the same cultures. One participant stated, "I prefer to have friends from my culture, not necessary from Saudi Arabia, but at least, they can speak my language. I can have relief. I can express myself easily without any difficulties”. Another participant said:

At the beginning, it was difficult because of difficulty with the language. With a very low level of language proficiency, it is difficult to contact with natives. But with the improvement in language, it became ok. But still I meet with people from my culture in our cultural celebrations.

Coping Strategies. Improving language was indicated as a very helpful strategy to enhance their academic performance and to cop with the new culture. One student stated, "The most important thing is language. Once I have the good language to communicate, I will be good at communicating with people. I will not be isolated...I will not have any barriers”.

Participants identified some other strategies that helped them to adapt to the new culture both academically and socially such as using of the available resources, celebrating specific cultural occasions with people from the same culture and mixing with others. Some of the statement made included "in the academic context, I prefer to work independently, I try to depend on 
myself and use the available recourses", "Mixing with others from different cultures helps to adjust to the new culture", and "Attending special cultural celebrations with people from the same culture helps me reduce stress".

\section{DISCUSSION}

The quantitative and qualitative data indicated that Saudi students experience difficulties mainly with expressive and written language. Respondents reported spending extra time for doing their assignments or studying due to the lack of language competence. This finding is consistent with the findings of other research concerned with international students or Saudi students, in particular. Stoynoff (1997) found that there is a correlation between international students' academic achievement and their language competence. Similarly, Shabeeb's study (1996) that investigates Saudi and Arabian Gulf students' adaptation problems revealed that English language was the main difficult area facing their adjustment process. The current study also indicated that language barriers affect the respondents even in their social life and their contacts with others. This is confirmed by the findings of previous research (Lewthwaite, 1996; Trice, 2007).

With regard to cultural factors, the findings revealed that respondents did not have a high level of difficulty with the cultural factors. However, a greater level of difficulty was experienced with the social factors, compared to the academic factors. The highest level of academic difficulty was experienced in types of assessment tools and classroom activities. Tests and oral presentations were reported as the most difficult types of assessment tools. Beside lack of language competence, difficulties with the academic factors, as the qualitative data indicated, are associated with Saudi students' prior learning experiences and unfamiliarity with the education style in Australia. Saudi students are more accustomed to a teacher-centered teaching style and to memorization strategies in testing as pointed by Vassall-Fall (2011). Additionally, preparing and presenting an oral report is not widely practiced in Saudi Arabia, as the assessment system is more examination based. This may lead to a lack of confidence among Saudi students to present in front of others in class. This finding is consistent with the findings of a study by Kampman (2011) who has pointed out that Saudi students are accustomed to passive learning styles, which make it difficult for them to adapt to the teaching styles that encourage creativity and critical thinking. It also concurs with other studies (Shin, 2011; Sun \& Chen, 1999; Wong, 2004).

As to the social factors, the findings indicated that respondents experienced some aspects of cultural stress especially in their initial semesters. It was found that loneliness, homesickness and discriminations were the main problematic factors. These findings concur with the findings 
of previous research (Poyrazli \& Lopez, 2007; Sawir et al., 2008; Yue, 2012). The findings also indicated that respondents faced some difficulties in making friends from other cultures due to certain barriers, such as lack of language proficiency and cultural differences such as differences in preferred food, social and religious activities. This finding goes in line with the findings of a recent study done by Abdel Razek (2012) that Saudi students' participation in the social life in America is very limited due to different reasons such as religion, mix-gender aspect and dietary restrictions. It is also supported by the findings of another study by Yue (2012) concerned with international students' experience in Australia.

The study revealed significant differences in the perceived level of language difficulty based on age, which concurs with the findings of a study done by Hofmann (2010) which found that younger students experienced language difficulty more frequently than older students. On the other hand, the study showed no significant differences between the experienced language difficulty based on gender, level of education and length of stay. This is inconsistent with the findings of a study conducted by Poyrazli and Lopez (2007) as they found that female international students had higher level of English proficiency than male students and the researchers attributed this to their willingness to establish relationships with others, which create opportunities to practice the language. In the case of Saudi female students, it could be difficult for them to build relationships with others as they come from a segregated culture even in their social lives. No significant differences were found between the experienced level of cultural challenges based on the examined demographic factors (gender, age, level of education and length of stay). This finding concurs with the findings of previous studies (Abdullah, Adebayo, \& Talib, 2015; Yan \& Berliner, 2011).

In relation to coping strategies, improving language was the main strategy that helped the respondents to adapt to the new culture. This result was expectable as lack of language proficiency was reported to be one of the main factors affecting their adjustment. Other strategies such as time management, using of available resources, and celebrating specific cultural occasion were also found to be very helpful strategies. It was also evident that Saudi students try to take the advantages of both mixing with others from different cultures and with people from the same culture. Both of these strategies have their advantages. Having friends from different cultures can help in understanding other cultures, which facilitates the adaptation process. On the other hand, having friends from the same culture helps in gaining the social support, which helps decrease the effect of the cultural stress such as homesickness and loneliness. These coping strategies are also highlighted in previous research (Shaw, 2009; Tseng \& Newton, 2002). 


\section{CONCLUSIONS AND IMPLICATIONS}

Students' language competence, especially in expressive and written language, plays a significant role in their academic and social adjustment process. Saudi students' academic performance was affected mainly by classroom activities and assessment methods that require practical use of language such as tutorial discussion and oral presentation. Socially, Saudi students were most affected by such cultural factors as homesickness, loneliness and discrimination. The students coped with difficulties by improving their language skills, by exerting study skills (e.g. time management) and/or by attempting socio-cultural skills (e.g. mixing with others). While there were significant differences in the perceived level of language difficulties based on age, there were no significant differences found based on the other factors. Similarly, there were no significant differences between the perceived levels of cultural difficulties based on the demographic factors.

The study has a number of implications. For Saudi and other Arabian Gulf international students, the study reinforces the importance of having a high level of English proficiency as well as cultural competence, awareness of different educational approaches and provisions for challenges and socio-cultural difficulties. For sponsors and education providers, the findings highlight the importance of orientation programs for future students before coming to Australia about life and study in Australia with a particular focus on the main differences in the education systems and learning/teaching approaches. A further implication may be a question of what social activities will be effective for students' cultural adjustments and how effectively students can be encouraged to participate in those activities. A further research is required to find out specific areas of difficulties in language, academic and so-cultural domains, as well as ways of helping Saudi international students adjust to a new environment.

\section{REFERENCES}

Abdel Razek, A. (2012). An exploration of the case of Saudi students' engagement, success and self-efficacy at a Mid-Western American university. (Doctor of Education dissertation), University of Akron. Retrieved from https://etd.ohiolink.edu/

Abdullah, M., Adebayo, A., \& Talib, A. (2015). Relationship between demographic factors, social support and sociocultural adjustment among international post graduate students in a Malaysian public University. Journal of Educational and Social Research, 5(2), 8792. 
Adler, P. (1975). The transitional experience: An alternative view of culture shock. Journal of Humanistic Psychology, 15(4), 13-23. doi:10.1177/002216787501500403

Berry, J. (1997). Immigration, acculturation and adaptation. Applied Psychology: An International Review, 46(1), 5-34. doi:10.1111/j.1464-0597.1997.tb01087.x

Bifuh-Ambe, E. (2009). Literacy skills acquisition and use: A study of an English language learner in a U.S. university context. Adult Basic Education and Literacy Journal, 3(1), 24-33.

Borland, H., \& Pearce, A. (2002). Identifying key dimensions of language and cultural disadvantage at university. Australian Review of Applied Linguistics, 25(2), 101-127.

Crano, W., \& Brewer, M. (2002). Principles and Methods of Social Research (2nd ed.). Mahwah, NJ, US: Lawrence Erlbaum Associates.

Creswell, J., \& Clark, V. (2011). Designing and conducting mixed methods research. Thousand Oaks, CA: Sage Publications.

Hechanova-Alampay, R., Beehr, T., Christiansen, N., \& Horn, R. V. (2002). Adjustment and strain among domestic and international student sojourners: A longitudinal study. School Psychology International, 23(4), 458-474. doi:10.1177/0143034302234007

Hofmann, P. N. (2010). Examining factors of acculturative stress on international students as they affect utilization of campus-based health and counseling services at four-year public universities in ohio. (Doctoral dissertation), Bowling Green State University. Retrieved from http://search.proquest.com/docview/1651842866?accountid=12763 Eric database. (1651842866)

Kampman, D. (2011). From Riyadh to Portland: The study abroad experiences of five Saudi Arabian female students. (MA dissertation), SIT Graduate Institute, SIT Digitial Collection. Retrieved from http://digitalcollections.sit.edu/ipp_collection/512

Kegel, K. (2009). Homesickness in International College Students. In G. R. Walz, J. C. Bleuer, \& K. Y. R (Eds.), Compelling counseling interventions: VISTAS 2009 (pp. 67-76). Alexandra, VA: American Counseling Association.

King, N., \& Horrocks, C. (2010). Interviews in qualitative research. London: SAGE.

Kwon, Y. (2009). Factors affecting international students' transition to higher education institutions in the United States-from the perspective of office of international students. College Student Journal, 43(4), 1020-1036. 
Lewthwaite, M. (1996). A Study of international students' perspectives on cross-cultural adaptation International Journal for the Advancement of Counseling, 19(2), 167-185. doi:10.1007/BF00114787

Mason, J. (2002). Qualitative researching. London: SAGE.

Ministry of Higher Education. (2010). Students Abroad: Statistics Indicators and Analysis.Retrieved from < ohe.mohe.gov.sa/ar/Documents/Students\%20Abroad.pdf >.

Ministry of Higher Education. (2012). Higher education statistics. Retrieved from <http://www.mohe.gov.sa/ar/Ministry/DeputyMinistry-for-Planning-and-Information-

affairs/HESC/Pages/default.aspx>

Mittal, M., \& Wieling, E. (2006). Training experiences of international doctoral students in marriage and family therapy. Journal of Marital and Family Therapy, 32(3), 369-383.

Poyrazli, S., Arbona, C., Bullington, R., \& Pisecco, S. (2001). Adjustment issues of Turkish college students studying in the United States. College Student Journal, 35(1), 52-62.

Poyrazli, S., \& Grahame, K. (2007). Barriers to adjustment: Needs of international students within a semi-urban campus community. Journal of instructional Psychology, 34(1), 28-45.

Poyrazli, S., \& Kavanaugh, P. R. (2006). Marital status, ethnicity, academic achievement, and adjustment strains: The case of graduate international students. College Student Journal, 40(4), 767-781.

Poyrazli, S., \& Lopez, M. (2007). An exploratory study on perceived discrimination and homesickness: A comparison of international students to the U.S. Students. The Journal of Psychology, 141(3), 263-280. doi:10.3200/JRLP.141.3.263-280

Robertson, M., Line, M., Jones, S., \& Thomas, S. (2000). International students, learning environments and perceptions: A case study using the Delphi technique. Higher Education Research and Development, 19(1), 89-102. doi:10.1080/07294360050020499

Sawir, E., Marginson, S., Deumert, A., Nyland, C., \& Ramia, G. (2008). Loneliness and international students: an Australian study. Journal of Studies in International Education, 12(2), 148-180. doi:10.1177/1028315307299699

Shabeeb, S. (1996). Saudi and Arabian gulf students' adjustment problems in Eastern Washington. (PhD diss), Gonzaga University, Pro Quest Dissertations and Theses.

Shaw, D. (2009). Bridging differences: Saudi arabian students reflect on their educational experiences and share success strategies. (PhD diss), Oregon State University.

Shin, S.-C. (2011). Cross-Cultural Factors Affecting Korean Students' Study at Australian Universities. Paper presented at the Korean Studies in 
Shift-Proceedings of the 2010 Pacific-Asia Conference on Korean Studies, University of Auckland.

Stoynoff, S. (1997). Factors associated with international students' academic achievement. Journal of instructional Psychology, 24(1), 56-68.

Sumer, S., Poyrazli, S., \& Grahame, K. (2008). Predictors of depression and anxiety among international students. Journal of Counseling and Development, 86(4), 429-437. doi:10.1002/j.15566678.2008.tb00531.x

Sun, W., \& Chen, G. M. (1999). Dimensions of difficulties mainland Chinese students encounter in the United States. Intercultural Communication Studies, 9, 19-30.

Tashakkori, A., \& Creswell, J. (2007). The New Era of Mixed Methods. Journal of Mixed Methods Research, 1(1), 3-8.

Thomson, G., Rosenthal, D., \& Russell, J. (2006). Cultural stress among international students at an Australian university. Paper presented at the the Australian International Education Conference, Australia.

Trice, A. (2007). Faculty perspectives regarding graduate international students' isolation from host national students. International Education Journal, 8(1), 108-117. Retrieved from http://iej.com.au

Tseng, W., \& Newton, F. (2002). International students' strategies for wellbeing. College Student Journal, 36(4), 591-598.

Valadez, J., \& Bamberger, M. (1994). Monitoring and evaluating social programs in developing countries: A handbook for policymakers, managers and researchers. Washington, DC: The World Bank.

Vassall-Fall, D. (2011). Arab Students' Perceptions of Strategies to Reduce Memorization. AWEJ, 2(3), 48-69

Vole, S., \& Renshaw, P. (1996). Chinese students at an Australian university: Adaptability and continuity. In D. A. Watkins \& J. B. Biggs (Eds.), The Chinese Learner: Cultural, Psychological, and Contextual Influences (pp. 205-220). Hong Kong: Comparative Education Research Centre.

Wong, J. K. (2004). Are the learning styles of Asian internationals culturally or contextually based? International Education Journal, 4(4), 154166. Retrieved from http://iej.cjb.net

$\mathrm{Wu}$, I. J. (2011). Learning strategies use by international students from Taiwan in a university context: A case study. (MA diss), California State University, Chico.

Yan, K., \& Berliner, D. (2011). An examination of individual level factors in stress and coping processes: Perspectives of Chinese international students in the United States. Journal of College Student Development, 52(5), 523-542. doi:10.1353/csd.2011.0060 
Yue, Y. (2012). Health and wellbeing of international students in an Australian tertiary context. (Doctoral dissertation), University of Tasmania. Retrieved from http://eprints.utas.edu.au/id/eprint/15009

NISREEN ALSAHAFI, is currently completing a PhD in Linguistics in the Faculty of Arts and Social Sciences at the University of New South Wales. Email: n.alsahafi@student.unsw.edu.au

SEONG-CHUL SHIN, PhD, is a Senior Lecturer in the School of Humanities and Languages. His research interests include error analysis, socio-linguistic issues in L2 contexts and other topics such as L2 pedagogy and curriculum planning. Email: s.shin@unsw.edu.au

Manuscript submitted: April 15, 2015

Manuscript revised: November 2, 2015 Accepted for publication: February 21, 2016 
Peer-Reviewed Article

ISSN: 2162-3104 Print/ ISSN: 2166-3750 Online

Volume 7 Number 1 (2017), pp. 73-93

(C) Journal of International Students

http://jistudents.org/

\title{
Challenges of International Students in a Japanese University: Ethnographic Perspectives
}

\author{
Ju Seong Lee \\ University of Illinois at Urbana-Champaign, USA
}

\begin{abstract}
The author investigates what challenges four international students (Vietnamese, Filipino, Brazilian, and Chinese) faced and how they coped with these dilemmas in a Japanese language program during the first semester in 2014. Multiple apparatuses (e.g., field notes, face-to-face oral interviews, focal group conversations, and semi-structured written interviews) were employed to triangulate the data. The findings show four major challenges: Personal psychological issues, general living issues, sociocultural issues, and Japanese language issues. Additionally, supporting group, positive attitude, interaction with Japanese friends, financial assistance, and useful learning strategies are identified as coping strategies. The results will provide implications for international students as well as language instructors and program coordinators in a higher education institution to better assist the international students.
\end{abstract}

Keywords: Ethnographic research, International students in a Japanese university, challenges during the first semester

In recent years, the population of international students who study abroad has dramatically increased. According to World Education Services (2012), the number of the international students reached more than 3.5 million around the world in 2010, an increase of almost 50 percent from the figure (of 2.1 million) in 2002. More recently, World Education News and Review (2013) released a report that the percentage of international undergraduate enrollment in the four leading countries in 2009 has significantly increased in comparison to the figures of 2002 (e.g., 67\% in Canada, 62\% in the United Kingdom, 43\% in Australia, and 13\% in the United States). As the higher education system is increasingly becoming more internationalized 
and a degree from prestigious foreign countries hold comparative advantages (e.g., higher social status, better professional career, networking opportunities), the number of international students is expected to continuously increase for years to come (Ghazarian, 2014; Lee \& Brinton, 1996; Varghese, 2008; Wenhua \& Zhe, 2013).

As the number of international students is on the rise, a variety of problems and challenges involved in overseas study also occurs (Andrade, 2006; Gebhard, 2012; Huang, 2004; Huang \& Brown, 2009; Li et al., 2014; Lin \& Scherz, 2014; Marui \& Lee, 1995; Murphy-Shigematsu \& Lee, 1999; Murphy-Shigematsu \& Shiratsuchi, 2001; Murphy-Shigematsu, 2002; Roy, 2013; Wenhua \& Zhe, 2013). Based on the documentary analysis, for instance, Wenhua and Zhe (2013) identify five major adjustment problems international students face in foreign countries: personal psychological issues, academic issues, sociocultural issues, general living issues, and language proficiency.

According to University World News (2012), the most popular destination with the number of international students was the United States (19\%), followed by the United Kingdom (11\%), Australia (8\%), France (7\%), Germany (6\%) and Japan (4\%). Therefore, it may seem plausible that a majority of the research on the challenges facing international students is concentrated on the top three destinations, namely the United States, the United Kingdom, and Australia (Andrade, 2006; Gebhard, 2012; Huang, 2004; Huang \& Brown, 2009; Li et al., 2014; Lin \& Scherz, 2014; Marui \& Lee, 1995; Roy, 2013; Wenhua \& Zhe, 2013). However, several scholars have also maintained that the research on the challenges of international students in non-English speaking countries is still in its infancy and should receive more attention (Ikeguchi, 2012; Jou \& Fukada, 1996; MurphyShigematsu \& Lee, 1999; Murphy-Shigematsu \& Shiratsuchi, 2001; Murphy-Shigematsu, 2002; Tamaoka et al., 2003).

Recently, the Japan Student Services Organization (JASSO) (2014) released a report on trends for a number of international students. In 1993, there were 48,560 international students in Japan. In 2003, this figure increased to 109,508. By May of 2013, the total number of international students in Japan was 135,519. If international students enrolling in Japanese language institutes are included, this figure rises to 168,145. Although Japan's share of international students seems disproportionately lower than in western countries (e.g., the United States, the United Kingdom), Japan is the top destination in Asia. However, little research has been conducted on adjustment issues among international students in Japan. In particular, almost no attention has been paid to international students in a Japanese context in the Journal of International Students. To fill these gaps, this ethnographic study aims to examine the adjustment problems and coping strategies identified and experienced by international students in a 
Japanese university during the first semester in 2014. The findings of this study will provide insights and implications for international students as well as language instructors and program coordinators in a Japanese university, to better understand the international students.

\section{LITERATURE REVIEW}

\section{Challenges of International Students in English-speaking Countries}

In the published literature, there are a variety of definitions of international students. In this study, the definition of international students is adopted from Andrade's (2006) study as defined as "individuals enrolled in institutions of higher education who are on temporary student visas and are non-native speakers” (p. 134). In particular, the author distinguishes international students by their nationality (e.g., Chinese, Brazilian) and provides more details when necessary.

As the higher education system is increasingly becoming more internationalized, and a degree from prestigious foreign countries holds comparative advantages (e.g., higher social status, better professional career, networking opportunities), the number of international students has been dramatically on the rise for the past decade (Ghazarian, 2014; Lee \& Brinton, 1996; Varghese, 2008; Wenhua \& Zhe, 2013). For instance, the World Education News and Review (2013) reports that the percentage of international undergraduate enrollment in the four leading countries in 2009 has significantly increased in comparison to the figures in 2002 (e.g. 67\% in Canada, 62\% in the United Kingdom, 43\% in Australia, and 13\% in the United States).

As the population of international students has increased, several problems and challenges in relation to studying abroad have been also identified (Andrade, 2006; Gebhard, 2012; Huang, 2004; Huang \& Brown, 2009; Li et al., 2014; Lin \& Scherz, 2014; Marui \& Lee, 1995; MurphyShigematsu \& Lee, 1999; Murphy-Shigematsu \& Shiratsuchi, 2001; Murphy-Shigematsu, 2002; Roy, 2013; Wenhua \& Zhe, 2013). For example, several studies have researched the challenges that international students face in English-speaking countries. Andrade (2006) explored what influences the adaptation and academic achievement of international students had been, based on a documentary analysis of published literature. The findings suggest that international students had more difficulty adjusting to new academic and social environments, in contrast to domestic students. In particular, the academic challenges for international students are associated with language issues, which can negatively affect their emotions (e.g., embarrassment, disappointment and boredom). As a coping strategy, international students need to seek help from English language support programs. In terms of social adjustment, international students have more 
difficulty than domestic students because of the absence of a close inner circle group (e.g., family and close friends), which could lead to loneliness and homesickness. Social support and having friendships with domestic students can help international students cope with social adjustment issues.

Gebhard (2012) investigated the types of adjustment issues among 85 international students at an American university, through interviews, observation field notes and students' self-reports. The findings indicate that students were challenged by academic, social, and emotional difficulties in the new environment. He indicated that international students were not familiar with social and cultural norms, which could negatively affect social interaction in America. As a coping strategy, the study suggests that international students establish supporting groups with co-nationals or friends who share similar cultural backgrounds. Additionally, interaction with domestic students is encouraged as a means of coping with adjustment challenges, which positively influences students' satisfaction with life and learning.

Lin and Scherz (2014) conducted a study on linguistic and cultural challenges that five Asian international graduate students encountered in an American university. Drawing on interviews and focal group conversations, the findings suggest that understanding lectures, as well as participation on discussions posed linguistic challenges to the international students. Regarding cultural challenges, most participants struggled due to a lack of opportunities to interact with domestic students. To overcome linguistic difficulties, participants employed a variety of strategies (e.g., recording lectures, self-talk in English, talking with native speakers in the cafeteria). They also coped with cultural challenges by traveling to other places, attending church services and learning about American sports from American friends. The researchers called for pedagogical change among instructors by adopting more linguistically and culturally sensitive methods of instruction for the international students.

Roy (2013) discussed learning difficulties experienced by Asian international students (e.g., Chinese, Japanese, and Korean) in the United States due to the language barrier. As a solution, he suggested that American professors should be more responsible for employing culturally responsive pedagogical strategies in the classroom. For example, it would create more optimal classroom atmosphere for international students if instructors incorporated emotional intelligence (Goleman, 1998) into their teaching by being more self-aware, motivated, and empathic. He also stressed the importance of 'the respectful mind' (Gardner, 2007), which "welcomes differences between human individuals and between human groups, tries to understand these 'others,' and seek to work effectively with them” (p. 3).

There has been research that focuses on adjustment issues facing Chinese students at North American universities (Huang, 2004; Huang \& 
Brown, 2009). Due to a different cultural background (e.g., Confucian philosophy) and educational system (e.g., a test-driven system), Chinese students struggle greatly in learning and participating in the classroom, which creates stress and anxiety. For instance, Chinese teachers are so influential in the classroom due to the Confucian belief that Chinese students simply follow teachers' pedagogy (e.g., lecture-based instruction) as a model of knowledge and view their teacher as a lifetime master. Unlike China's instructional style, American professors tend to emphasize classroom discussions, which play a negative role in Chinese students' learning. As implications for education, the researchers emphasize the importance of creating a culturally sensitive classroom environment (e.g., lecture style, with accompanying teaching materials).

$\mathrm{Li}$ et al. (2014) conducted a systematic review of 18 studies on psychological wellbeing among East Asian international students. A majority of the studies $(n=13)$ look at Chinese international students and identify several variables such as multicultural competence (e.g., English proficiency, intercultural competence), sociocultural factors (e.g., acculturation, discrimination), and psychological factors (e.g., anxiety, homesickness) that affect the psychological status of Asian international students

Wenhua and Zhe (2013) also conducted a systematic literature review to identify international students' adjustment issues in Englishspeaking countries (e.g., the United States, the United Kingdom, New Zealand, and Australia). They provided a summary of problems experienced by international students, with five categories (e.g., personal psychological issues, academic issues, sociocultural issues, general living issues, and English language proficiency) and specific problems (e.g. financial problems, homesickness, cultural shock).

\section{Challenges facing International Students in Japan}

Unlike English-speaking countries such as United States (19\%), the United Kingdom (11\%), and Australia (8\%), Japan ranked as the sixth-mostpopular location (4\%) for international students (University World News, 2012). Although Japan's share of international students seems disproportionately lower compared to the western countries, Japan is the top-notch destination in Asia. Recently, therefore, a growing number of studies have paid attention to the challenges of international students in nonEnglish speaking countries, specifically in a Japanese university context, although such studies are still in their infancy (Ikeguchi, 2012; Jou \& Fukada, 1996; Murphy-Shigematsu \& Lee, 1999; Murphy-Shigematsu \& Shiratsuchi, 2001; Murphy-Shigematsu, 2002; Tamaoka et al., 2003).

Murphy-Shigematsu and Lee (1999) and Murphy-Shigematsu (2002) carried out a survey on challenges facing Korean students ( $\mathrm{n}=96)$ in 
Japan, at Japan's national university. The findings show that Korean students have difficulties due to financial hardship, the perceived value of a degree from Japan (in comparison to a similar degree from the United States), and attitudes toward Japanese society and inter-cultural relationships with Japanese people. This study further analyzed and highlighted the characteristics of the psychological struggles of Korean international students in Japan. The data suggests that Korean students feel prejudiced against and discriminated toward by Japanese people, most likely due to the nature of Japan's 'strong sense of group-consciousness (shudan-shugi)' (Murphy-Shigematsu, 2002, p. 78), which tends to make groups or communities exclusively for Japanese people. Korean students perceive this closed (heisateki) and discriminatory Japanese way of thinking and behavior as hindrances to their general quality of living and study in Japan. Additionally, some Korean students find it difficult to interact with Japanese due to a discrepancy between true feelings (honne) and formal behavior (tatemae), even though they share the similar cultures. To Koreans, this gap between how they feel and how they behave is seen as insincere and even offensive.

There was one study done on international students with family dependents in Japan (Murphy-Shigematsu \& Shiratsuchi, 2001). The results showed that they are mostly challenged by factors related to accommodation, language barrier, and children's education. The researchers argued for more proper support and assistance for international students studying and living in Japan.

Ikeguchi (2012) conducted a survey with 100 Chinese students in several Japanese universities regarding their adjustment problems. The results show that a majority of international students believed that Japanese language is difficult to understand and use (81\%). In addition, $77 \%$ of the respondents said classes were not interesting and enjoyable. Sixty-seven percent of them answered that it was difficult to get a part-time job in Japan (67\%). Surprisingly, more than half of the respondents (55\%) believed that Japanese people do not like foreigners. The researcher argued that Japanese institutions do not properly address these issues raised by international students studying in Japan. Additionally, the authors concluded that more financial assistance, psychological and social assistance, and intensive culture training are needed to better accommodate international students in Japan.

Considering the trends in the number of international students in Japan (from 48,560 in 1993, up to 168,145 in 2013), more research on this critical issue is required (Japan Student Services Organization, 2014). In particular, it is unfortunate that in the Journal of International Students almost no attention has been paid to international students in the Japanese context. To fill these gaps, this ethnographic study aims to examine the 
adjustment problems and coping strategies identified and experienced by international students in a Japanese university during the first semester in 2014. The findings of this study will provide insights and implications for international students as well as language instructors and program coordinators in a Japanese university setting, to better understand international students.

\section{RESEARCH METHOD}

\section{Research Questions}

1. What challenges do international students in a Japanese university experience during the first semester of their course of study?

2. What strategies do they employ to cope with these challenges?

\section{Setting and Participants}

Ethnographic research was conducted from March to August 2014 in and outside of class in a Japanese language program operated by a major private university in Tokyo. This language program was aimed primarily at non-native speakers of Japanese, providing a core Japanese language course, with subjects with a specific focus (i.e., speaking, listening, reading and writing). It also offered a range of subjects in Japanese studies such as Japanese studies on society and culture, as well as optional subjects presented in lecture format, in English.

The author (hereafter referred to the 'first-participant') was assigned to Level 1 or beginner level. The class took place on Monday, Wednesday, and Friday for three hours, respectively. The curriculum was very systematic and well organized. For example, every class began with dictation, vocabulary, grammar, and Kanji (a Chinese character) test. Monday and Wednesday classes focused on conversation practice, while Friday classes concentrated on grammar explanation. Students were given homework for each class.

In the initial stage of this research, I intended to focus on nine international students who studied in the same classroom but who had diverse personal and professional backgrounds. After a month, however, I decided to narrow down the participants to four (Vietnamese, Filipino, Brazilian, and Chinese) because these participants seemed to be struggling greatly in a distinctive but somehow similar pattern. For instance, all of them had a successful professional career at their respective home country, but felt disparaged in Japan during the first semester of their study period due to a variety of adjustment issues. Table 1 displays the basic profile of the participants in this study. To protect the subject's privacy, I used pseudonyms for them after consulting with each participant. 
TABLE 1. Basic profile of the participants

\begin{tabular}{|c|c|c|c|c|}
\hline Name & Nationality & Age & Purpose of Studying Japanese & Profession \\
\hline Smith & Philippines & 26 & $\begin{array}{l}\text {-Enter graduate work in Japan } \\
\text {-Teach English in Japan }\end{array}$ & $\begin{array}{l}\text { University } \\
\text { Instructor }\end{array}$ \\
\hline Liu & China & 27 & $\begin{array}{l}\text {-Improve professionally } \\
\text {-Enter MBA program }\end{array}$ & Accountant \\
\hline Mickey & Brazil & 31 & $\begin{array}{l}\text {-Get government grants } \\
\text {-Take graduate work }\end{array}$ & Finance Manager \\
\hline Chu & Vietnam & 32 & $\begin{array}{l}\text {-Get Government grants } \\
\text {-Take graduate work }\end{array}$ & Ophthalmologist \\
\hline
\end{tabular}

\section{Data Collection and Analysis}

To accomplish these objectives, I employed four instruments (i.e., field notes, face-to-face oral interviews, semi-structured online interviews, and focal group conversations) to triangulate the data and thereby attain a higher level of reliability of the data. The study was carried out from March to August 2014. I used an ethnographic approach, the characteristics of which are summarized in Table 2. Based on Nunan's (1992) summary of the main features of ethnographic research, I closely observed and interacted with the participants in various "informal" natural settings to understand their "genuine" challenges.

TABLE 2. Characteristics of ethnographic research (from Nunan, 1992, p. 56)

\begin{tabular}{ll}
\hline \hline Characteristic & \multicolumn{1}{c}{ Gloss } \\
\hline Contextual & $\begin{array}{l}\text { The research is carried out in the context in which the } \\
\text { subjects normally live and work. }\end{array}$ \\
Unobtrusive & $\begin{array}{l}\text { The researcher avoids manipulating the phenomena under } \\
\text { investigation. } \\
\text { Longitudinal }\end{array}$ \\
The research is relatively long-term. \\
Interpretive & $\begin{array}{l}\text { The research involves the participation of stakeholders } \\
\text { other than the researcher. }\end{array}$ \\
Organic & $\begin{array}{l}\text { There is interaction between questions/ hypotheses and } \\
\text { data collection/ interpretation. }\end{array}$ \\
\hline
\end{tabular}

The ethnographic approach was beneficial because I could get to know the participants closely and understand their struggles at a deeper level, which allowed me to interpret the data more accurately. At the same time, I conducted 'informal' oral interviews with the participants in various real-life contexts (i.e., classrooms, restaurants, cafés, tourist attractions, and a hot spring), which caused me to re-check my understanding of the data and 
helped me obtain additional authentic information. All data obtained through observation and informal oral interviews were recorded in blogs as field notes. In July 2014, I conducted and moderated a focus group conversation session for two hours in order to clarify the data for an accurate and deeper level of analysis. Unlike the informal interview, the participants gathered together at one place to discuss given topics. From July to August 2014, I interpreted the data by juxtaposing it with other research and conducted semi-structured online interviews with the participants by email and by social media (e.g., Facebook).

TABLE 3. Summary of adjustment issues faced by international students (modified and adopted by Wenhua \& Zhe, 2013)

\begin{tabular}{ll}
\hline Category & Specific problems \\
\hline Personal psychological & Homesickness, loneliness, stress, depression, \\
& frustration, loss of status or identity, anxiety, \\
& confusion, etc. \\
\hline Sociocultural issues & Cultural shock, cultural fatigue, stereotyping, \\
& prejudice, racial discrimination, difficulties in \\
& adjusting to new social/cultural customs, \\
& norms and regulations and participating in \\
& intercultural/social activities, relationship \\
& problems, etc. \\
\hline General living issues & $\begin{array}{l}\text { Accommodation difficulties, difficulties in } \\
\text { using student support services, financial }\end{array}$ \\
& stress, dietary restrictions, safety threats, etc. \\
\hline Japanese language issues & $\begin{array}{l}\text { Difficulties in communicating with native } \\
\text { speakers, understanding lectures, writing up } \\
\text { essays, etc. }\end{array}$ \\
\hline
\end{tabular}

\section{FINDINGS AND DISCUSSION}

\section{Challenges faced by International Students}

\section{Smith}

Smith is 26-year-old Filipino. Before coming to Japan, he taught philosophy and English literature in a Filipino national university. He was studying Japanese for two reasons: to enter a graduate school and teach English in Japan.

During the first semester, Smith suffered from factors related to general living issues and sociocultural issues. Regarding general living issues, one of his greatest challenges was financial stress due to unstable financial support. In this aspect, he was fortunate because in March of 2014 he found a fine Filipino host family, which charged decently low rental fees. 
According to my field note (March, 2014), he only paid \$350 per month for accommodation, including electricity, water, and a Wi-Fi Internet connection, which was almost twice as cheap as the average such rental fee in Tokyo. However, there also were some disadvantages concerning this budget accommodation, as described in Excerpt 1.

Excerpt 1. Semi-structured interview regarding 'Financial stress' (August, 2014)

The only complaint I had was its unfavorable location. At the beginning of the semester, I was often late for the class. That is because I had to take a bicycle from home to the nearest station, take a subway, and transfer to another subway line, get off a train, and walk all the way to the school. In total, it took me around 90 to 120 minutes just to go to school.

During the focal group conversation conducted in July 2014, he also shared some painful anecdotes about how the unfavorable location of his accommodation negatively affected his level of academic achievement. For instance, he did not have enough time to study the Japanese language, as he spent almost three hours merely commuting between home and school, in addition to working more than 25 hours a week. Also, he would have no time to practice Japanese conversation simply because he had no time to meet or interact with native Japanese speakers. Finally, his struggle became more severe over time. This is consistent with my field note that shows how Smith was struggling due to his unstable financial situation, as illustrated in Excerpt 2.

Excerpt 2. Field note regarding 'Financial stress' (May, 2014) Fortunately, he found a job nearby his home and worked in a noodle-manufacturing factory every Tuesday, Thursday, and Saturday. But he also applied for a few other job interviews to secure the financial source. He was extremely concerned about his tuition in the next semester already, so he applied for a scholarship last April. This month [in May], it seems that he still struggled between studying Japanese and working for securing his stable finance.

This finding is supported by previous studies (Li et al., 2014; Murphy-Shigematsu \& Lee, 1999; Murphy-Shigematsu, 2002; Wenhua \& Zhe, 2013). Unlike other participants in this study, he was a privately funded student and had to strike a balance between doing a part-time job and studying Japanese. In fact, he would not have enough time to study Japanese on the days he worked because he became physically exhausted at the end of 
each work day. Regarding sociocultural issues, he experienced stereotyping and racial discrimination while living in Japan, as described in Excerpt 3.

Excerpt 3. Semi-structured interview regarding 'stereotyping and racial discrimination' (August, 2014)

I find the logic like this in terms of discrimination in job employment. Japanese firms with Western interviews kind of discriminated and preferred to choose Westerns for one sole reason: They think the Japanese would prefer that.

The previous studies have also supported this finding (MurphyShigematsu \& Lee, 1999; Murphy-Shigematsu, 2002; Wenhua \& Zhe, 2013) as some international students report they feel Japanese are biased and discriminatory toward different nationalities. According to field notes (May, 2014), he also mentioned that there was discrimination by some companies in Japan that were handled by Caucasians. He said he felt that these companies seemed to find non-Caucasian less appealing than Japanese. On the other hand, he obtained an English teaching job in a Japanese firm. For Japanese job interviewers, he believed that as long as he "could speak good English they were okay with it.” Caucasian employers in Japan might have had a perception of Standard English because he exhibited some accent, which is often "an implicit code for race or ethnicity" (Tollefson, 2002, p. 150). Discrimination based on accent, however, can be problematic and may stir up racism. The employers devalued other varieties of English (e.g., Filipino English) in that it differs from so-called Standard English in pronunciation and some linguistic features.

\section{Liu}

Liu is a 27-year-old Chinese woman. She was born and educated in a small country town in China. After obtaining her B.A. in business administration in 2009, she worked as an accountant in a large multinational corporation, until February 2014. She decided to leave her profession and come to Japan to study Japanese for two reasons: first, she wanted to improve herself professionally. Second, she wanted to pursue an MBA degree in a Japanese graduate school—after achieving a certain level of Japanese proficiency.

During the first semester, Liu was challenged due to Japanese language issues and personal psychological issues. Regarding Japanese language issues, she struggled linguistically for the first month of her study in Japan because she had difficulties in communicating with others both in English and Japanese, as described in Excerpt 4.

Excerpt 4. Semi-structured interview regarding 'Japanese language issues' (August, 2014) 
I feel the first month (April) in Japan was hard and confusing. The hardest part was language. In April, I knew nothing about Japanese. I did not know Hiragana. In the beginning of the semester, teachers explained everything in English. Since my English was poor, I could not understand them well. I felt anxious and frustrated. Even when I had to talk with my classmates, I also had to speak in English. Because of language, I had lots of difficulties in adjusting to this new school life.

During the focal group conversation, I asked her why she did not study foreign languages (e.g., English and Japanese) until she came to Japan. She responded with two answers: first, she was not talented in learning foreign languages. Second, she had no need to learn a foreign language in the company because of her job (e.g., accountant). Considering the fact that Liu had been living in a small country town in China for her entire life up to the point that she left it to enroll in school elsewhere, and Japan was the first foreign country she ever visited, it seemed evitable she would initially struggle greatly in area of language.

Although Liu struggled linguistically in April, over time she began to speak Japanese and English fluently with a high degree of accuracy. Especially in the classroom setting, she was confident in her command of Japanese. According to field notes (June 2014), she was one of the best students in the classroom and seemed confident, with a good command of Japanese. However, she still had difficulties in communicating with native Japanese speakers outside the classroom, as depicted in Excerpt 5.

Excerpt 5. Semi-structured interview regarding 'Japanese language issues' (August, 2014)

At the third month of school, I already adapted to the new school life. The greatest improvement was I could speak some basic Japanese, which made my daily life more convenient. But when I went to visit Japanese language program office to ask something about scholarship, I was frustrated because I could not communicate with the Japanese staff in Japanese. I was shocked and very stressed out. Because of the limited language proficiency, I could not express myself properly and couldn't get the information I wanted.

Excerpt 5 was intriguing because Liu still struggled in everyday conversation outside of the classroom, although she improved her Japanese language proficiency and thus was regarded as the best Japanese speaker by her classmates. The field note (June 2014) recorded that toward the end of the semester, Liu became more vocal, with diverse Japanese structures and vocabularies. However, according to Excerpt 5, a foreign language learned 
in the classroom cannot be always translated into communicative competence outside the classroom, which can make language learners feel frustrated and challenged. This finding is congruent with a finding from the study done by Andrade (2006), in which international students had difficulties adjusting to new academic and social environments, most likely due to language issues, which can negatively affect their emotions (e.g., embarrassment, disappointment and boredom), as well as their level of academic achievement.

Regarding personal psychological issues, their appearance could have been inevitable because it was her first overseas trip and longest period ever away from her family. In light of Andrade's study (2006), her challenge involving Japanese language issues could make her feel lonely and disappointed, which could exacerbate her psychological issues. In Excerpt 6, Liu did point out that she felt lonely and homesick, but that her Chinese friends living in the same area helped her tremendously.

\section{Excerpt 6. Semi-structured interview regarding 'Personal psychological issues' (August, 2014) \\ If I did not need to go to school, most of time I stayed with new Chinese friends who gave me lots of help to adjust to the new life in Tokyo. Because of them, I did not feel lonely and did not miss my hometown as much as before.}

During the focal group conversation, Liu confessed that she missed her parents very much when the result of her attempt to speak Japanese did not go well. In June, she even began to doubt whether her decision to study Japanese was correct. Her Japanese was not as fluent as she had hoped based on her previous efforts, and over time, she knew that studying in a foreign country would not be easy. In this aspect, Li et al.'s study (2014) indicates that East Asian students are more likely to improve in the target language if they remain in the host country for a longer period of time, which can lead to mitigating the level of personal psychological stresses and anxieties.

\section{Mickey}

Mickey is 31 years old. Mickey was one of the most elite students in the classroom. Ostentatiously, he earned three bachelor's degreesin advertisement, social science, and economics-at one of the best national universities in Brazil. He had worked as a manager in a major bank in Brazil for ten years. He came to Japan through a Japanese government scholarship program. His goals for studying in Japan were three-fold: First, he wanted to improve his Japanese and English abilities; second, he wanted to earn a M.A. in economics at this university; third, he wanted to thoroughly 
experience Japan and Asia and thereby obtain a more thorough perspective about Asia. His younger brother studied for six years and earned M.A. and Ph.D. degrees from a major Japanese university. He encouraged Mickey to study abroad in Japan and introduced him to some of his personal and working networks.

Considering his academic achievement, clear goals for study, and extensive networking in Japan (thanks to his younger brother), it seems apparent that Mickey would successfully assimilate into Japan. During the first semester, however, Mickey was challenged due to Japanese language and sociocultural issues. Regarding Japanese language issues, he struggled greatly in the classroom at the beginning of the semester. According to field notes (March, 2014), he arrived and attended a Japanese language class one week after the program started, so that he skipped three classes and was already behind in comparison to the rest of his classmates. He confessed that the most difficult period of his life in Japan was the beginning stage, as described in Excerpt 7.

Excerpt 7. Semi-structured interview regarding 'Japanese language issues' (August, 2014)

The most difficult period of my life in Japan was at the beginning stage. I did not know any Japanese character (e.g. Hiragana, Katakana, Kanji) at all. I studied eight hours a day to catch up and it was in vain.

According to the field note (March, 2014), on the first day when I met him, he told me that he was still struggling with 'jet lag.' Also, his Brazilian friends and his brother repeatedly told him that this Japanese language program would be easy, with many fun and intercultural activities - all of which made him frustrated and embarrassed because it was anything but fun. During the focal group conversation, he said, "My first month in Japan was very busy and confused, mainly because in the end nobody could explain to us what was happening." A field note record in April 2014 indicated that his linguistic struggle became more serious and noticeable. For instance, nearly one month after the semester started, Mickey did not even know how to properly pronounce a word, whereas his classmates could already command an effective everyday conversation. So, the program provided him with extra Japanese classes, but did not help him catch up on weeks of missing classes. After all, the enormous workload and intensity of this Japanese language program overwhelmed him. Finally, he decided to study in a lower-level class (0.5 Level), which was created expressly for him. Technically, he dropped the course. But he could come to our class every Friday for grammar class. His difficulty in learning Japanese language lasted until the end of the semester, as described in Excerpt 8. 
Excerpt 8. Field note regarding 'Japanese language issues' (July, 2014)

On July 4, 2014 ('Grammar class' on Friday), he went out in the first period (9:00-10:30 am) and did not come back until the recess. His eyes were red. I assumed he cried. Later, he said, "I do not want to take class in the second period. I have many other things to do. I can't concentrate!” After all, he did not come back on the second period nor attend the last class.

Another challenge he encountered was related to the difficulty in understanding Japanese culture. According to the semi-structured interview, he candidly shared his struggle about understanding the totally different culture of Japan, as indicated in Excerpt 9.

Excerpt 9. Semi-structured interview regarding 'Sociocultural issues' (July, 2014)

I admit that this Japanese program curriculum is very well organized and structured. Teachers did their best to make us successfully acquire Japanese language. But I was not happy about Japanese culture. It is very inflexible but often works according to the manual. I am very flexible and spontaneous so I find it difficult to understand and study under this cultural environment.

Excerpt 9 is pedagogically significant in that none of the Asian participants in this study made mention of this cultural difficulty. For instance, Mickey is extremely extroverted and outgoing, so he had already made a lot of Japanese friends during the first semester. According to one field note (July, 2014), Mickey was also a culturally competent individual, as he had traveled, by his count, to more than 51 different countries at the time of this research. However, the difficulty he had may have been due to Japan's classroom culture, which Mickey had not previously experienced. From my observations and interviews, Mickey possessed a great sense of social intelligence, intercultural competence and linguistic ability. Nonetheless, in the classroom he looked utterly helpless and frustrated. According to semi-structured interview, he confessed he only put 20 percent of his effort into the class. As could be inferred from Excerpt 9, the instructor's "inflexible" teaching style and curriculum might have played a negative role in Mickey's classroom performance. In order words, Mickey is a typical field-dependent person and a frequent risk-taker in terms of learning, but his "linguistic guess" was not fully accepted in the Japanese classroom. He felt unsafe and uncomfortable in this environment, which also might not only have affected his Japanese language learning but also 
caused severe cultural fatigue. He would have adjusted to this new set of customs much easier if he had known that teachers were accustomed to holding absolute authority and are not challenged by students in Japanese culture, which markedly differed from higher education in Brazil (Ariza, 2010). Pedagogically, it is important for language instructors in Japan to establish a classroom atmosphere of acceptance (although it is against the cultural norm), where second language learners can freely make linguistic mistakes, a point Dufeu (1994) made-namely, that language learners should be encouraged to take risks without feeling embarrassed.

\section{Chu}

Chu is a 32-year-old Vietnamese woman. She was an ophthalmologist in Vietnam and was sent to Japan by the Vietnamese government to further her studies. Her primary goal for studying Japanese was to take coursework (lectured in Japanese) in graduate school. She took a Japanese language class every Monday, Wednesday, and Friday while working in the university-affiliated hospital on Tuesday and Thursday. Although she was a proficient English speaker, in the hospital she would need to use Japanese predominantly because a majority of the faculty and students were Japanese.

For the first semester, Chu had difficulties in terms of general living and sociocultural issues. Concerning general living issues, Chu struggled greatly in the early period of her new school life. According to one field note (April 2014), she had several factors to deal simultaneously, such as new accommodations, a new language, a new culture, new food, a new school, new people, and necessary administrative work (e.g., being issued an insurance card, registering her residency, buying a phone). Additionally, she had to work in the hospital twice a week, which was located at a different campus. She wanted to complete all these tasks at once, which caused physical fatigue and sleep deprivation, as indicated in Excerpt 10.

Excerpt 10. Semi-structured interview regarding 'General living issues' (August, 2014)

I arrived [in] Japan on April $2^{\text {nd }}$ and the day after that started Japanese class. I had very little time for rest but had to hastily settle down for new life. My first two weeks in Japan was exhausted and sleep-deprived.

In addition, Chu had to suffer from sociocultural issues for the entire semester. When asked to describe her struggle in Japan during the focal group conversation session, she used the words "frustration and anxiety"-especially in relation to her experience in a Japanese hospital. In Excerpt 11, Chu depicted her struggle while doing research at the hospital. 
Excerpt 11. Semi-structured interview regarding 'Sociocultural issues' (August, 2014)

When I started going my lab twice a week, the time of frustration and anxiety began. Language barrier and new working environment made me feel like I was lost. Not to mention the amount of new knowledge that I need to consume, I was also vague about my future research plan, which made me frustrated. I really didn't know what to do, how to deal with a whole new group of people with different work etiquette that I've never encountered before. I couldn't talk to anyone and I felt like I didn't belong here. That feeling lasted until recently.

Excerpt 11 implies that her struggle was intertwined with several variables, such as the language barrier, a new working environment/culture, pressure about her future research, and isolation. For the entire semester she had to constantly juggle three goals at the same time: learn a new language (in the Japanese language course), learn new content area(s) through the target language (in Japanese hospital), and figure out her future research topic (for her career). Similar to the findings of Murphy-Shigematsu and Lee (1999) and Murphy-Shigematsu (2002), Chu had a hard time in a Japanese hospital due to the cultural complexity of interacting with Japanese people. Considering the nature of Japan's 'strong sense of groupconsciousness (shudan-shugi)’ (Murphy-Shigematsu, 2002, p. 78), which make groups or communities exclusively for Japanese people (as indicated in Excerpt 11), she found it difficult to assimilate and integrate into this small Japanese community (a Japanese hospital) and felt isolated from her Japanese colleagues or other lab members.

\section{Coping Strategies}

The participants in the study employed a variety of coping strategies to overcome the challenges they faced while living in Japan. For coping strategies to overcome personal psychological issues, Chu shared her feelings with others and tried to stay optimistic. Her closest friend was a classmate from Thailand. Outside of class, they spent much time eating, shopping, and conversing. She also spent at least once a week eating out with other classmates and joined in when they went on an outing. In terms of positive mindset, she kept reminding herself of the long-term benefits of what she was undergoing. She mentioned in the focal group conversation that she disciplined herself to stay positive about the task until it is complete. Although she felt discouraged and unsure about encountering several problems and challenges she faced in Japan, she persisted and remained optimistic about her situation. In the case of Liu, her Chinese friends were very helpful in aiding her in adapting to a new environment and 
cope with psychological issues. When there was no class, she stayed with Chinese friends, mostly who were of great help for her in Tokyo. According to the focal group conversation session, she admitted that it was a safe space where she could freely vent her emotional difficulties and travails in her personal life.

When it comes to coping strategies to overcome sociocultural issues, Mickey remained positive about his life in Japan. Although he hit the rock bottom in terms of his Japanese language proficiency in the classroom, he wanted to continue to study until the end. During a focal group conversation, he said, "[I was] very excited about be in Japan and felt prestigious to have this opportunity. Although I was challenged, I believe it will be paid off in the long run.” In addition, Mickey engaged in a variety of activities and spent time socially with Japanese friends. For instance, he joined a language exchange program through which he taught Japanese students Portuguese and they taught him Japanese. In the case of Smith, he could minimize the negative emotions of being discriminated against, as he was living with a Filipino family. During a semi-structured interview (July, 2014), he said he spent a large portion of time watching dramas and movies together with the Filipino family, which helped him stay optimistic about his life in Japan, although there were some sociocultural difficulties. He emphasized the importance of his support group while living in Japan.

With regard to coping strategies to overcome general living issues, Chu mentioned during the focal group conversation session that everything in Japan was almost five times as expensive as in her home country. She often cooked her own dish, which was more delicious and much cheaper. Unlike privately funded students (e.g., Smith), she was a recipient of a government scholarship, which covered her tuition with adequate monthly stipends. In that aspect, she did not have to worry too much about financial constraints.

In terms of coping strategies to overcome Japanese language issues, Smith employed several learning strategies that would meet his situation. Since he did not have enough time to study and practice Japanese, he joined a basic Japanese conversation group in the city hall near his home. He also signed up for a 'conversation partner' program that allowed him to meet and interact with Japanese students on campus on a weekly basis. During the focal group conversation session, he mentioned that he also downloaded several useful Japanese learning apps on his smartphone and studied them in his spare time.

\section{CONCLUSIONS AND IMPLICATIONS}

This ethnographic study attempts to explore what challenges four international students (Vietnamese, Filipino, Brazilian, and Chinese) faced 
and how they coped with these difficulties in a Japanese language program during the first semester of 2014. A variety of instruments (e.g., field notes, face-to-face oral interviews, focal group conversations, and semi-structured written interviews) were employed to triangulate the data. The findings suggest four major challenges: personal psychological issues (e.g., stress, anxiety, loneliness, and depression), general living issues (e.g., financial stress), sociocultural issues (e.g., stereotyping, cultural fatigue), and Japanese language issues (e.g., difficulty in talking with native Japanese speakers). Coping strategies such as support groups, positive attitude, interacting with Japanese friends, financial assistance, and useful learning strategies are identified in the study.

However, some caveats need to be applied to the present study. Above all, the results of this study cannot be generalized since it only examined four international students in one Japanese university. With such a small sample size, the findings may not be transferable to other international students in other contexts. For further research, therefore, more international students in the same or other contexts need to be examined. In addition, the study should probably require longitudinal data to support the findings of this study, in order to increase the credibility and reliability of the data.

To conclude, I would like to provide insights and implications for international students, as well as language instructors and language program coordinators, in an institution of higher education. First of all, international students should be aware of these potential challenges and prepare in advance to effectively handle these issues. It is highly recommended that they secure financial assistance and know about the linguistic and cultural issues beforehand. Second, language instructors should create and adopt teaching methodologies that are more linguistically and culturally sensitive for their international students (Lin \& Scherz, 2014). Also, instructors should try to know students' situations at a personal level and connect with their students through informal (e.g., social media) as well as formal dialogues (e.g., student-teacher conference). Finally, language program coordinators should become more aware of these issues, which present many and varied challenges for international students, and strive to authentically help them, by means of psychological assistance, cultural training, or counseling (Ikeguchi, 2012).

\section{REFERENCES}

Andrade, M. S. (2006). International students in English-speaking universities:

Adjustment factors. Journal of Research in International Education, 5(2), 131-154.

Ariza, E. N. (2010). Not for ESOL teachers: What every classroom needs to know about the linguistically, culturally, and ethnically diverse students ( $\left({ }^{\text {nd }}\right.$ ed.). Boston, MA: Allyn \& Bacon.

Dufeu, B. (1994). Teaching myself. Oxford: Oxford University Press. 
Gardner, H. (2007). Five minds for the future. Boston, MA: Harvard Business School Press.

Gebhard, J. G. (2012). International students' adjustment problems and behaviors. Journal of International Students, 2(2), 184-193.

Ghazarian, P. G. (2014). Actual vs. ideal attraction: Trends in the mobility of Korean international students. Journal of International Students, 4(1), 89103.

Goleman, D. (1998). What makes a leader? Harvard Business Review, 82(1), 82-91.

Huang, J. (2004). Voices from Chinese students: Professors' use of English affects academic listening. College Student Journal, 38(2), 212-223.

Huang, J., \& Brown, K. (2009). Cultural factors affecting Chinese ESL students' academic learning. Education, 129(4), 643-653.

Ikeguchi, T. (2012). Internationalization of education and culture adjustment: The case of Chinese students in Japan. Intercultural Communication Studies, 21(2), 170-184.

Japan Student Services Organization (JASSO). (2014, March 25). International students in Japan in 2013. Retrieved from http://www.jasso.go.jp/statistics/intl_student/data13_e.html

Jou, Y, H., \& Fukada, H. (1996). Comparison of differences in the association of social support and adjustment between Chinese and Japanese students in Japan: A research note. Psychological Reports, 79, 107-112.

Lee, J. T., \& Brinton, M. C. (1996). Elite education and social capital: The case of South Korea. Sociology of Education, 69, 177-192.

Li, J., Wang, Y., \& Xiao, F. (2014). East Asian international students and psychological well-being: A systematic review. Journal of International Students, 4(4), 301-313.

Lin, S.-Y., \& Scherz, S. D. (2014). Challenges facing Asian international graduate students in the US: Pedagogical considerations in higher education. Journal of International Students, 4(1), 16-33.

Marui, E. \& Lee, J. (1995). International students life conditions and stress, University of Tokyo International Center Bulletin, 6, 217-240.

Murphy-Shigematsu, S. \& Lee, J. (1999). Human relations of Korean international students in Japan. University of Tokyo International Center Bulletin, 9, 153-177.

Murphy-Shigematsu, S. \& Shiratsuchi, S. (2001). Supporting international students with families. University of Tokyo International Center Bulletin, 11, 1-24.

Murphy-Shigematsu, S. (2002). Psychological barriers for international students in Japan. International Journal for the Advancement of Counseling, 24, 1930.

Nunan, D. (1992). Research methods in language learning. Cambridge: Cambridge University Press.

Roy, S. R. (2013). Educating Chinese, Japanese, and Korean international students:

Recommendations to American Professors. Journal of International Students, 3(1), 10-16.

Tamaoka, K., Ninomiya, A., \& Nakaya, A. (2003). What makes international students satisfied with a Japanese university? Asia Pacific Education Review, 4(2), 119-128.

Tollefson, J. W. (2002). Language policies in education: Critical issues ( $1^{\text {st }}$ ed.). 
New York, NY: Routledge.

University World News (2012, November 4). New UNESCO interactive map on global student mobility. Retrieved from

http://www.universityworldnews.com/article.php?story=201211021435243

Varghese, N. V. (2008). Globalization of higher education and cross-border student mobility. Paris: UNESCO.

Wenhua, H., \& Zhe, Z. (2013). International students' adjustment problems at university: A critical literature review. Academic Research International, 4(2), 400-406.

World Education Services (2012, February). Trends in international student mobility.Retrieved from http://www.uis.unesco.org/Library/Documents/ research-trends-international-student-mobility-education-2012-en.pdf

World Education News and Review. (2013, March 1). International student mobility trends 2013: Towards responsive recruitment strategies. Retrieved from http://wenr.wes.org/2013/03/wenr-march-2013international-student-mobility-trends-2013-towards-responsiverecruitment-strategies

JU SEONG (JOHN) LEE is a doctoral student at the University of Illinois at Urbana-Champaign (UIUC). His research interests include international student issues, World Englishes, technology-integrated learning in the second/foreign language classroom (via video conferencing, telecollaboration, wearable devices), and self-directed teacher professional development (TPD). Email: jlee682@illinois.edu

Manuscript submitted: April 23, 2015 Manuscript revision submitted: July 13, 2015 Manuscript revised and accepted. August 2, 2015 
ISSN: 2162-3104 Print/ ISSN: 2166-3750 Online Volume 7 Number 1 (2017), pp. 94-112 (C) Journal of International Students http://jistudents.org/

\title{
Collectivists’ Decision-Making: Saudi Arabian Graduate Students' Study Abroad Choices
}

\author{
Tamara Yakaboski \\ University of Northern Colorado, USA \\ Karla Perez-Velez \\ University of Northern Colorado, USA \\ Yousef Almutairi \\ University of Northern Colorado, USA
}

\begin{abstract}
The authors in this qualitative study explored how Saudi Arabian students selected a teaching focused research institution by examining Kingdom of Saudi Arabia and U.S. national influences, institutional factors, and personal influencers. Despite the continued rise in Saudi Arabian students studying at U.S. universities, limited published research exists on this unique student population. This study on Saudi graduate students reconceptualizes the homogenous perspectives on international student mobility. It demonstrates that study abroad decisions are not made from just push-pull or economic factors but through culturally specific social processes involving various actors both in and beyond their home country as well as intermediaries that is indicative of a more collectivist society.
\end{abstract}

Keywords: Saudi Arabia, student mobility, college choice , international students

International student decisions to migrate for graduate degrees are not only made at the individual or family level but can be highly influenced and even driven, by employers and governmental entities. Adding to the complexity of college choice is how international graduate students select institutions that lack a global ranking or reputation. The perspectives of two commonly applied theories in international student mobility studies, push-pull (Mazzarol \& Soutar, 2002) and human capital (Becker, 1993), focus mostly 
on private benefits to the individual and public benefits for the home nation state. However they fail to illuminate more nuanced or culturally specific reasons why individuals participate in study abroad and where they end up studying. Recent research within the international student mobility literature has looked at the influence of international study abroad scholarships funded by governmental programs (Perna, Orosz, Gopaul, Jumakulov, Ashirbekov, \& Kishkentayeva, 2014; Perna, Orosz, Jumakulov, Kishkentayeva, \& Ashirbekov, 2015). These programs are seen as governmental "intervention" that increases student participation in transnational higher education and play a role in student study abroad decisions (Paulsen, 2001; Perna, et al, 2015).

The Kingdom of Saudi Arabia (KSA) has developed a successful government scholarship program through its commitment to the Saudi Arabian education systems by educating citizens overseas in needed fields of study. The KSA invests over $\$ 2$ billion dollars annually to fund the main international scholarship program, The King Abdullah Scholarship Program (KASP). The King Abdullah Scholarship Program (active from 2005 2020) is an international scholarship program funded and run by the Saudi government to provide quality higher education for qualified Saudis, to bring about high levels of academic and professional standards, exchange culture with other countries and build up a qualified and professional Saudi staff and faculty (Hall, 2013). Additionally, many Saudi higher education institutions also fund their employees to study abroad for advanced degrees through institutional or employer sponsored scholarship programs (Higher Education Council of Saudi Arabia, 1997).

The Saudi Arabian Cultural Mission (SACM) administers all KSA scholarship programs and functions as the intermediary between U.S. institutions and their counterparts in the KSA (SACM, n.d.). As with all Saudi funded scholarships, students face a limit of which academic fields and degree types the government will cover and they have a return obligation, where recipients much return back to KSA after degree completion (Perna, et al., 2014). While these governmental funding programs are quite influential as in the case for Saudi students, they are not absolute influencers on institutional choice.

The KSA is the fourth largest sender of students to the U.S. for higher education for five years in a row, just behind China, India, and South Korea, and over $20 \%$ of these Saudi Arabian students are at the graduate level (Institute of International Education, 2015). Saudi students will continue to study in the U.S. in steady numbers at least until 2020 when the scholarship program is set to expire. Yet, even with the continuous rise in Saudi Arabian students studying at doctoral/research universities (DRU) in the U.S. since the scholarship programs began, limited published research exists on what influences these student's study abroad decisions as well as 
their national and institutional selections. While the Saudi Ministry of Higher Education maintains a recommended list of approved universities, this alone does not explain how Saudi students find their way to a DRU that lacks a worldwide reputation and is more teaching focused. Therefore, the purpose of this study was to explore Saudi student mobility at national, institutional, and personal levels related to their decision making about institutional choice.

\section{LITERATURE REVIEW}

The majority of international student mobility research focuses on national level economic or education determinants rather than the individual level (Becker \& Kolster, 2012; Shanka, Quintal \& MEdMan, 2006; Wei, 2013) and some studies look at institutional choice as a by-product of national choice (Chen, 2007; Lee, 2008). The decision to study in the U.S. over other countries includes reasons, such as improving English language abilities (Eder, Smith, \& Pitts, 2010), economic factors (Wei, 2013), feelings of safety (Lee, 2008; Shanka et al., 2006; Urias \& Yeakey, 2009), and the desire to experience the American culture (Eder, et al., 2010). For graduate students specifically a U.S. doctoral degree implies an increase in opportunities as well as research training (Zhou, 2015).

International students choose their institutional host site based on a variety of factors and which factors have the most influence on a student depends on their background and reasons for studying overseas (Bista \& Dagley, 2015; Lee, 2008). Two common reasons are prestige and national ranking of institutions (Lee, 2008). Other researchers have found that the use of recruiters (Becker \& Kolster, 2012; Hagedorn \& Zhang, 2011), family and friend recommendations and networks (Eder, et al., 2010; Pimpa, 2003), and marketing (Lee, 2008; Shanka et al., 2006) all play roles in informing the decision making process for international students studying in the U.S. Location of the institutions in terms of cost of living or proximity to urban environments or their home countries have also been found as a minor influence (Lee, 2008; Shanka et al., 2006; Wilkins \& Huisman, 2011).

\section{Saudi Students as International Students}

The literature on Saudi higher education students studying abroad focuses on benefits of studying overseas (Heyn, 2013; Hofer, 2009) and challenges with adjustment, academics, and values (Al-Nusair, 2000; Rasheed, 1972; Shaw, 2010). Heyn's (2013) dissertation confirmed limited research on Saudi students studying in the U.S. Heyn indicated that 17 studies have been quantitative studies and five have been qualitative studies all dedicated to Saudi students' experiences and learning in the classroom 
and many of these are dissertations. Also, these 22 studies were published over more than a 30-year time period, thus leaving researchers with an incomplete understanding of current Saudi students' institutional choice and study abroad decision-making.

The few studies that have examined choice and reasons for studying in the U.S. found that KSA government policies and current Saudi faculty in KSA both play an important role (Denman \& Hilal, 2011; Hall, 2013; Onsman, 2012). Considering some version of a scholarship program has been available over the last few decades and many current faculty at Saudi Arabian universities were educated in the West, primarily in the U.S. (Onsman, 2012), these same faculty may encourage their students to attend their alma maters. One study limited to Saudi men found three dominant reasons for studying in the U.S.: family ties, prestige of American universities, and policies of the KASP (Hall, 2013). Another study identified policies that might influence which country Saudi students choose for higher education and explain mobility patterns (Denman \& Hilal, 2011). Given the increase of Saudi students studying overseas, this study attempts to bridge the gap by offering a qualitative exploration into choice and decisionmaking beyond just using governmental policies as the main or sole influencer.

\section{RESEARCH METHOD}

\section{Theoretical Framework}

Much of the research on international students' choice to study in the U.S. has developed from push-pull migration theory (Lee, 1966). The tendency is to view study abroad decisions as one directional; some factors push students out of their home countries while others pull or entice students to specific host countries (Altbach, 2004; Chen, 2007; Eder et al., 2010; Mazzarol \& Soutar, 2002; Wilkins \& Huisman, 2011). Some studies suggest that this framework fails to understand the complexity and nuances with student mobility decisions (Lee, 2008; Yakaboski, 2013) and views international students as a homogenous group (Gargano, 2009). Human capital theory often is used in conjunction with push-pull theory and assumes that students study abroad because it benefits them directly either monetarily or in other ways, such as enjoyment or adventure (Becker, 1993). This presents a narrow understanding of influences and students.

On the other hand, transnationalism theory explains structural factors in international student mobility and work that is more recent has argued for using it to examine students working with and within structures across borders (Schneider, 2013). Transnationalism considers that international students exist in transnational social fields with interlocking networks of ideas, practices, and social networks (Gargano, 2009). Student 
mobility and migration through a lens of transnationalism is about not only material or financial transactions and gains but symbolic or cultural meaning (Brooks \& Waters, 2011). Transnationalism focuses on processes that are not linear but highlights how multiple actors and structures may influence students' choices or how they may not view decisions as their choices but decisions of other people or entities. Transnationalism helps to explain the interplay between the international scholarship programs of KASP, SACM, and Saudi institutions, U.S. institutions and students and their families as well as cultural, religious, and gendered influences.

Given the unique interplay of national and cultural influences with Saudi graduate student choice, this research sought to answer the following research questions:

1. How do Saudi Arabian graduate students make study abroad decisions at national, institutional, and personal levels when sponsored by Saudi-based programs funded by either the government or employers?

2. How are Saudi Arabian graduate students' study abroad decisions influenced by culture, religion, and gender?

\section{RESEARCH METHOD}

We used an interpretivist exploratory qualitative design due to a limited foundation of literature on Saudi graduate student decisions and institutional selection or choice (Creswell, 2014; Lincoln, Lynham, \& Guba, 2011). Interpretivism seeks to understand and interpret the lived experiences of participants and uses these experiences to inform praxis (Lincoln, et al., 2011). Interpretivism also identifies meaning as socially constructed and interpreted by participants through interactions with their world, which was important in order to not analyze the stories through a Western perspective (Broido \& Manning, 2002; Merriam, 2009).

\section{Participants}

We gathered data for this study from one mid-sized research university (MRU) in the Western region of the United States. MRU is located in a state among the ten highest for enrollment of Saudi students (SACM, n.d.). Yet, the institution is a mid-sized, more teaching focused research institution that enrolls a small but growing number of international students with Saudi Arabia as the largest sender. Of the university enrollment, international students (undergraduate and graduate) make up only three percent of the student body representing 21 different countries at the graduate level and 34 countries at the undergraduate level (MRU Impact Profile, 2014). Saudi students consist of the largest population with a total of 164 Saudi students of the 367 international students at both undergraduate 
and graduate levels. Half of the Saudi students are at the graduate level hence the decision to focus on the masters and doctoral degree seeking students as opposed to those enrolled in undergraduate programs or the institution's English as a second language program. Of the 84 total Saudi graduate student population exactly half are women.

\begin{tabular}{|c|c|c|c|c|c|}
\hline Pseudonym & Sex & Degree level & Program of study & Age & $\begin{array}{l}\text { Marriage } \\
\text { status }\end{array}$ \\
\hline$\overline{\text { Ali }}$ & Male & Master & Special Education & 25 & Married \\
\hline Fahd & Male & Professional & Nursing & 34 & Married \\
\hline Omar & Male & $\mathrm{PhD}$ & Education Technology & $\mathrm{n} / \mathrm{a}$ & Married \\
\hline Majed & Male & $\mathrm{PhD}$ & Education Technology & 28 & Married \\
\hline Ahmed & Male & Master & Special Education & 25 & Single \\
\hline Marwan & Male & Master & Psychology & 24 & Single \\
\hline Essa & Male & Master & Special Education & 30 & Single \\
\hline Saad & Male & $\mathrm{PhD}$ & Applied Statistics & 34 & Married \\
\hline Bandar & Male & Master & Psychology & 26 & Married \\
\hline Reem & Female & $\mathrm{PhD}$ & Special Education & $\mathrm{n} / \mathrm{a}$ & Did not share \\
\hline Lamia & Female & $\mathrm{PhD}$ & Psychology & $\mathrm{n} / \mathrm{a}$ & Single \\
\hline Rana & Female & $\mathrm{PhD}$ & Education Technology & $\mathrm{n} / \mathrm{a}$ & Married \\
\hline Nasser & Male & $\mathrm{PhD}$ & Special Education & 32 & Married \\
\hline Yaser & Male & $\mathrm{PhD}$ & Education Technology & 40 & Married \\
\hline Atif & Male & Master & Special Education & 25 & Married \\
\hline Mohanad & Male & Master & Education Leadership & 42 & Married \\
\hline Saif & Male & Master & Education Technology & 25 & Single \\
\hline Ghada & Female & Master & Education Technology & $\mathrm{n} / \mathrm{a}$ & Single \\
\hline
\end{tabular}

After receiving institutional IRB approval, we invited Saudi students via emails sent by MRU's international student office requesting their participation as well as personal invitations from one of the researchers. 
Eighteen Saudi graduate students were interviewed, eight doctoral, nine masters, and one graduate level professional degree. All Saudi students received pseudonyms to protect their confidentiality. See Table 1 for names used and demographics. Even though the research team was mixed-gender, it was much easier to recruit male students to participate. As a result, the final sample included 14 male and four female participants. All were on full scholarship from the government, KASP (8), or their employer institution (10). The participants who were on institutional scholarship were teaching faculty at Saudi higher education institutions and were working on terminal degrees in the U.S.

\section{Data Collection and Analysis}

We followed the principles of qualitative research and case study methods to conduct semi-structured interviews, which allowed the participants and researchers to move freely from the initial questions to other emergent topics and allowed the participant or researcher to probe deeper into responses or further explain interview questions (Merriam, 2009). By conducting one hour face-to-face interviews, we were able to develop themes about decisions and choices made by Saudi graduate students that may guide future quantitative research. The participants were interviewed in English instead of their native language but one of the researchers served as an insider member and key informant that assisted in not only identifying participants but advising the team in cultural considerations and assisting with language challenges (Jones, Torres, \& Armino, 2006). Due to cultural and religious factors, the Saudi researcher, as a male, interviewed the male students and the other two researchers as females interviewed the Saudi women students.

To support the rigor and trustworthiness of the study given a member of the team was an insider, the research team engaged in researcher reflexivity (Jones, et al., 2006) assessing our integrity as a research team via an audit trail and being explicit with our research design (Gibbs, 2007). Transnationalism theory provided an analysis framework that pushed the research team to think beyond a Western perspective and to incorporate a variety of considerations from cultural, religious, gender, societal, and governmental influences. All members of the research team developed codes and themes and then shared responses for inter-rater reliability (Maxwell, 2004; Patton, 2001). We resolved any coding and analysis differences by discussing Western versus Middle Eastern cultural understandings and interpretations until we reached consensus. For this study's participants, the most significant influencers functioned at the national, institutional, and societal levels and were influenced by culture, gender, and religion. 


\section{RESULTS}

\section{U.S. and KSA National Level Influences}

A narrative of U.S. prestige and quality education. Institutional rankings and ratings seemed to matter less to these participants as they relied more heavily on the known narrative that U.S. degrees were more prestigious and of good quality compared to other countries, including their own. Reem shared that,

It was my dream to come here and study in the USA. I found the USA [degree] is, like, more valuable in Saudi Arabia. That study in the USA is more valuable because it [is from a] very good university, very high-ranking university and a good community, a good educational system here in USA so that's why they [SACM] encourage us to come to the USA.

Yet, for Bandar, studying in the U.S. was not his dream but rather something he felt pressured to do by his university employer:

I didn't have a choice to study in another country, even my country, which is home because my university wanted me to get a strong academic experience, which they believe the United States has more powerful academics than my country, especially in [specific social science field].

Some participants reinforced the value of learning English as a global language (Elyas, 2008) and experiencing cultures. Saad shared, "since the English language is a world language it will open resources for me, I can find more resources." As Marwan said, "unless you have experience, you have to go outside of your country, especially to the United States and engage with the different cultures and gain new experiences.”

While it is not new that the participants considered it prestigious to study in the U.S., one of the women expressed a gendered perspective to the prestige. Lamia explained,

It [Saudi students studying overseas] used to be very rare but now I think people are now used to the idea that, "yes, my son and my daughter are studying abroad, and that's okay.” But for conservative families this is not okay, I mean, even if the government is sending us. But I think it's viewed positively for males that, yes, you will continue your education. For girls, it's not same, some of my uncles, they still question my father, like, "what is she doing there?” but my 
mom and all the females in my family like my aunts, they're excited because this has a real benefit.

Prestige and family pride may not be universal when viewing study abroad through a gendered, cultural perspective.

Absence of graduate programs and quality ones in Saudi Arabia. The limited number of graduate level programs in Saudi Arabia required that students leave their homes to gain terminal degrees in order to return and grow Saudi Arabian programs and institutions. Participants often expressed these decisions as feeling that they did not have a choice in going overseas but rather that their institutions required them to temporarily migrate for graduate education and then return to their job, which was especially the case for the ten participants on institutional scholarship. Even the other eight with KASP funding discussed the common goal of returning after graduation and obtaining faculty positions in KSA higher education institutions. A few of the participants discussed opportunity in the recent growth of master's level educational programs in fields that might not have existed when they were undergraduate students in Saudi Arabia, such as educational technology or special education.

It is a common strategy for a country to send students overseas for advanced education when growing its own higher education system. As Saudi departments and institutions expand, fewer students will study overseas once they have the capacity and ability to train their own graduate students. This is already shifting as Lamia expressed:

Because our universities don't have graduate degrees. If you have a doctorate, you must get it from outside so that's why they send people, mostly graduate students, because we didn't have the programs. We didn't have schools teaching but now since I mean, new graduates came home so now we have [graduate programs]. So in my school that I graduated from, they still don't have educational psychology doctorate programs but I think they do you have a masters program.

Educating graduate students overseas is a useful strategy when a government requires that students return home after completing their studies, such as what all Saudi Arabian scholarships require, which also helps to prevent brain drain.

Another program concern is a perceived lower quality of educational programs in Saudi Arabia due partially to a lack of focus on research, which was seen as a strength to studying in the U.S. Lamia offered a view on the absence of research in Saudi Arabia: 
One of the things that I noticed about Saudi Arabia is that they don't focus on research. So when I arrived [in the U.S.], for example, I Googled motivation and international students. Most of the research, if it was done in the Middle East, it would be done either in Israel, Egypt, United Arab Emirates, so Saudi Arabia is not really focused on research. Which is sad because we need some research institutions ... and I think that we have to consider that back home and start the research movement.

Saif expressed the need for Saudi institutions to incorporate other practices and knowledge that can be gained abroad:

I'm an administrator at a university in Saudi Arabia, that is my country, and actually we need to improve our education in Saudi Arabia and I would like to merge some of the education from another countries, like the United States, to our Arabic education.

Participants viewed U.S. graduate education as an opportunity to develop KSA educational systems and knowledge. The participants were aware that they were helping to grow and improve Saudi higher education programs through their transnational temporary migration.

Saudi government or institutional sponsors. While the Saudi Ministry of Higher Education maintains lists of approved U.S. educational programs and institutions, it is the financial sponsors, through either KASP or individual institutions, who influence both institutional and program of study choice. All Saudi scholarship programs stipulate that students cannot change their majors without prior sponsor approval and justification (SACM, n.d.). Three participants discussed how they had wanted to study one field but were told to study in a different, related field by their sponsor or government. As Reem expressed, "I get accepted in psychology and educational technology but my sponsor wants me to study gifted education, specifically, they didn't accept my change of major." Saad explained this as the need for certain majors and not for others in Saudi Arabia. Given that ten of the participants were on institutional/employer scholarships and that they will return to their university jobs, these students need to have graduate degrees that their home departments can support and use.

Regardless of the prestige associated with studying in the U.S., some students preferred to have stayed in their home country for graduate education. Atif said, "if I have a chance to study inside my country, I would go there and I still want to go there. I didn't have an option.” Also, Ahmed said, "they [Saudi institutional employer] did not let me. I want to study there because I wanted to stay with my family but they won't let me. My 
advisor didn't let me study in Saudi Arabia so I had to study in the United States, so I came here.”

For some participants, their institutional choice was limited to MRU. Lamia expressed that, "I did not pick MRU... for me I told them [SACM] I just want to study in the U.S. because this scholarship program they give you the choice in the country but not the institution." Similarly, Nasser shared that "the minister of higher education brought [him] to MRU. [He didn't] have any knowledge of MRU before.” For many students with KASP funding, they did not feel they had an option as to which institution to apply to and could only suggest specifics for extenuating circumstances.

\section{Institution Level Influences}

Reputation for education over institutional ranking. The participants were not aware of various Carnegie classifications of institutions and assumed that all graduate programs were research-based but they had an awareness of institutional rankings. The male participants considered institutional ranking slightly more than the women, but it was the men who in the end said that the ranking did not matter. One student expressed skepticism about how rankings work and what matters for a graduate student. Marwan said,

For my personal point of view about rankings, I don't care what's the rank of the university, or whatever, I do care about who's my teacher and who is my advisor. So I was told that some of the [ranking] checklist or rubric that they use that gives the university [its] ranking, is the football team. ...I don't care about the football team. I do care about who's the person that gives me the knowledge. That's my biggest concern.

As Marwan later said, “It [the institution] doesn't have that prestige as a top ten university but it does have the quality to study and to gain the knowledge and do research."

While many of the graduate students considered institutional ranking, the fact that they did not gain acceptance into higher-ranking institutions meant that they focused on program quality rather than rankings. As Reem shared, "They [financial sponsor] asked me to look to the ranks but because I didn't get acceptance from them, there is no other university that offered [specific program].”

What worked in the favor of MRU was that because it was a teaching focused institution and a former normal school, it had a wellknown reputation for education. For example, Nasser, discussed his appreciation for the blended praxis and theory he received, 
In Saudi Arabia, I wasn't satisfied with the education they provided us because they only give us a theoretical stuff without implementation. So when I was in the field teaching special ed students, I was struggling. I didn't know how to deal with them. There is nothing from the book [to help me]. It's totally different than the realities so I decided to seek another place to get the information to help me to be successful in my field. So, yeah, that's why I chose this [institution].

Given MRU's educational reputation and history, it stands to reason that $89 \%$ of all Saudi graduate students were in education departments at this institution

Institution Alums. Saudi MRU alums influenced twelve of the participants to select this institution for graduate education. Influential alums were friends, family members, or faculty and administrators in various Saudi institutions. Majed expressed an influence from two of these categories,

While I'm searching [for institutions], I met one of my friends who was a student at MRU and I asked him about the university in general and he recommended me to come here. I read about it. I found that there are some leaders, I would say, in our country who got their higher education from this university, especially the educational [faculty], so I made that decision at that time and then I applied and just I came.

Being influenced by alums who were friends or faculty was common. Marwan asked a friend who had "graduated from MRU [and] he suggested that is a good university to study and the environment here and the atmosphere [are] supportive to anyone to study here.” Marwan also had a recommendation from Saudi faculty, "back home at my work one of the professors in the college of education he graduated from special education department and he advised me to study here."

While three of the women and four of the men had close family members earn degrees in the U.S. generally, four of these participants had family members who were alumni of MRU. As Fahd explained,

At the beginning, my brother-in-law came here, he was searching for universities and some of his friends recommended MRU for him and then he came here and spent like six months. After that he called me and asked me about if I wanted to come with my wife and he recommended this university and my wife applied here, too. 
Given the pattern of mobility and scholarship funding for Saudi students, many of these participants' undergraduate faculty or current colleagues in Saudi Arabia obtained their graduate degrees in the U.S. and specifically from this institution. For example, Essa shared that four faculty members in his department back in Saudi Arabia earned degrees from this institution. Omar echoed this by saying that he "had recommendations from [his] professor who was studying before 1980 and the end of 1970 [at this institution] and in the 1990's a lot of professors from Saudi Arabia study at MRU.”

Cultural and Religious Expectations of Family and Gender. Gender norms and family expectations created additional cultural and religious influences on choice and decision making for the participants. Saudi women are required to have a male guardian present when traveling, especially outside of the country. This requirement meant that brothers, husbands, and sometimes fathers followed some women participants and for two of the men in this study, their wives started studying after they began.

Rana explained this requirement generally and what it meant for her educational process even though her sister was already studying at this institution,

We [Saudi women] can't leave our country. Like, if I'm married, my husband has to be here with me, like, the first day and then he can go back after he settled me down and there is a house, there is a car, there is everything. There's my sister here but he stayed for seven months and then he goes back because of his job they did not let him stay for longer. So I finish my English language and I start my Masters without him and finish my Masters without him and then I took like a break from May to May, like, a year after Masters. For my $\mathrm{PhD}$, he came with me. So yeah, but I can't leave my country without a sponsor and my dad died so my husband, he's my sponsor. So there are cultural things we can't do as woman - cannot leave the country or travel anywhere without any man.

Two other women had younger brothers travel to the U.S. with them and study for their undergraduate degrees while the sisters pursued graduate education.

Omar and Saad's wives began studying for their graduate degrees at MRU after the men enrolled. For Mohanad, it was important that both he and his wife receive acceptances at the same institution and same college. Five of the male participants followed their wives to the institution because the women were accepted or started studying first. Mohanad said that he “didn't have any plans to study but because [his] wife came to America to 
study so [he] came with her and then it's like a good opportunity for [him] to study so that's why [he's] studying." As Fahd said, "I stick with my wife because she is already studying here and I cannot go there [other institutions] and leave her here alone.” For many of these Saudi students, graduate education ended up being about educating the entire family in the U.S., from spouses to brothers to children enrolled in the local k-12 system.

\section{DISCUSSION AND IMPLICATIONS}

When considering students' decisions about where to study overseas, the present study reinforces that it is necessary to consider influencers beyond the usual push-pull reasons (Mazzarol \& Soutar, 2002) or human capital (Becker, 1993). While some of the influencers in this study may echo elements of these factors, theories commonly used in international student mobility studies fail to recognize cultural and religious influences. Instead, this study shows that influences are not always best explained by either of these theoretical concepts. For example, the common narrative that the U.S. has quality and prestigious higher education is a pull factor. Participants in the study shared this; however, studying in the U.S. connected to feelings that the students did not always have a choice in their selection or decision. These Saudi students were pursuing graduate degrees abroad for external people, organizations and their country, not primarily for themselves as individuals.

Transnationalism provides an alternative explanation to the commonly used human capital theory when looking at student mobility because transnationalism acknowledges that migrants do not disconnect from their home countries by moving to another country but rather maintain relationships, connections, and spheres of influence (Schneider, 2013). The fact that the KSA or Saudi higher education institutions fund most Saudi students requires that the students maintain cross-border activity and engagement. In addition, the KASP scholarships fund yearly round trip flights home thereby ensuring personal relationships and regular physical cross-border movement. Having SACM as a mediator between KSA government officials or institutional administrators and U.S. institutions functions much differently than one-directional push or pull factors can explain.

Much of the student mobility literature discusses the decision to study abroad and the decision to study at specific institutions or in a specific discipline as an individual's choice (Chen, 2007; Lee, 2008). However, in the Saudi context, some participants expressed study abroad, institution, or program of study selection not as their choice but as a requirement of their government, SACM, or their university employer as the financial sponsor or as dictated by policies and terms of sponsorship. The participant's 
willingness to comply may reflect Saudi Arabia's collectivist societal norms that minimize the focus on individualism for the good of the greater group (Hofstede, 2003). The findings also expand understanding and conceptualizations of international student study abroad choice and decision-making.

As consistent with institutional isomorphism (DiMaggio \& Powell, 1983), many midlevel U.S. higher education institutions worry about increasing their overall ranking and type, Saudi graduate students may be willing to forgo this for quality program faculty instead and for recommendations from personal contacts. Less highly ranked institutions may want to conduct a scan of their reputation as perceived by international students and use that information to recruit for fields that already have a known reputation as opposed to trying to recruit in areas that are not ranked and do not have known quality programs or faculty. The opportunity for U.S. institutions to enroll Saudi students until 2020, presents an opportunity for mid-ranked institutions to grow Saudi student numbers by focusing on programs of reputation, quality, and uniqueness. Also related to recruiting, a collectivist society such as Saudi Arabia would value the personal relationships over the institutional or organization reputation (Hofstede, 2003); therefore, presenting an opportunity for U.S. institutions to foster Saudi alumni relationships.

Finally, while King Abdullah bin Abdul Aziz had a significant influence on expanding Saudis access to higher education and growing KSA's own system, he did so with the goal to preserve Saudi values, culture, religion, and traditions (Onsman, 2011). Saudi cultural and religious expectations or requirements clearly influenced decisions for many of the participants and influenced where a person studied and who chose to study there because of them. One dissertation found that two main reasons Saudi students study overseas were to better serve their country and to enhance their religious beliefs (Aktarkhavari, 1994). This finding has largely been absent from the research on international student mobility choice as it provides a culturally specific explanation to the influence of Muslim religion and culture for Saudi students. As family solidarity is a traditional Saudi value (Al-Banyan, 1980; Shaw, 2010), U.S. institutions could see an increase in Saudi students if they market themselves for family units and provide admissions counselors with culturally appropriate language and understanding.

Further, a better understanding of the familial focus of Saudi students as more communal may have potential to not only increase participation of Saudi students, but also provide opportunities for women to be educated at an advanced level. Our participants emphasized the importance of women having a guardian traveling with them until they are settled and the situation of a wife traveling with her husband who is a 
student. The decision for any trailing family member to also attend higher education demonstrates the transnational and non-linear decision making process. Acknowledging these values, U.S. institutions could seek to accommodate the temporary stay of a husband, brother or other male relative in their housing options or provide a potential "family deal" should more than one family member decide to study at the host institution. Or could actively reach out to the wives of male students. While our participants shared a few pieces on the gender differences related to travel and accommodations this study did not seek to focus on gender difference beyond understanding that gender played a role as to how a Saudi student began their study on a U.S. campus.

This study on Saudi graduate students reconceptualizes the homogenous perspectives on international student mobility to demonstrate that decisions are not made from just push-pull or economic factors. These Saudi students made study abroad choices based on culturally specific social processes involving various actors, both in and beyond their home country as well as intermediaries such as SACM who functions on behalf of KSA within the U.S. borders.

\section{REFERENCES}

Aktarkhavari, N. B. (1994). The perceptions of education and satisfaction of Saudi graduates: A comparative study of Saudi graduates from American and Saudi universities. (Doctoral dissertation). Retrieved from ProQuest, UMI Dissertations Publishing.

Al-Banyan, A. S. (1980). Saudi students in the United States: A study of crosscultural education and attitude change. London: Ithaca Press.

Al-Nusair, D. M. (2000). An assessment of college experience and educational gains of Saudi students studying at U.S. colleges and universities (Doctoral dissertation). Retrieved from The George Washington University, ProQuest, UMI Dissertations Publishing. (9955796).

Altbach, P. G. (2004). Higher education crosses borders. Change, 36(2), 18-24.

Becker, G. S. (1993). Human capital: A theoretical and empirical analysis, with special reference to education (3rd ed.). Chicago, IL: UCP.

Becker, R., \& Kolster, R. (2012). International student recruitment: Policies and developments in selected countries. The Hague, the Netherlands, Nuffic.

Bista, K., \& Dagley, A. (2015). Higher education preparation and decision making trends among international students. College \& University, 90(3), 2-11. Available at: http://works.bepress.com/bista/45/

Broido, E. M., \& Manning, K. (2002). Philosophical foundations and current theoretical perspectives in qualitative research. Journal of College Student Development, 43 (4), 434-445.

Brooks, R., \& J. Waters. (2011). Student mobilities, migration and the internationalization of higher education. Basingstoke: Palgrave Macmillan. doi:10.1057/9780230305588. 
Chen, L. H. (2007). East-Asian students' choice of Canadian graduate schools. International Journal of Educational Advancement, 7(4), 271-306.

Creswell, J. W. (2014). Research design: Qualitative, quantitative, and mixed methods approaches ( $4^{\text {th }}$ ed.). Thousand Oaks, CA: Sage Publications Inc.

Denman, B. D., \& Hilal, K. T. (2011). From barriers to bridges: An investigation on Saudi student mobility (2006-2009). International Review of Education, 57(3-4), 299-318.

DiMaggio, P. \& Powell, W. (1983). The iron cage revisited: Institutional isomorphism and collective rationality in organizational fields. American Sociological Review, 48(2), 147-160.

Eder, J., Smith, W. W., \& Pitts, R. E. (2010). Exploring factors influencing student study abroad destination choice. Journal of Teaching in Travel \& Tourism, 10(3), 232-250. doi: 10.1080/15313220.2010.503534

Elyas, T. (2008). The attitude and the impact of the American English as a global language within the Saudi education system. Novitas-ROYAL, 2(1), 28-48.

Gargano, T. (2009). (Re)conceptualizing international student mobility: The potential of transnational social fields. Journal of Studies in International Education, 13(3), 331-346.

Gibbs, G. (2007). Analyzing qualitative data. Thousand Oaks, California: Sage Publications Inc.

Hagedorn, L. S., \& Zhang, L. Y. (2011). The use of agents in recruiting Chinese undergraduates. Journal of Studies in International Education, 15(2), 186202. Doi: $10.1177 / 1028315310385460$

Hall, T. R. (2013). Saudi male perceptions of study in the United States: An analysis of King Abdullah scholarship program participants. (Unpublished doctoral dissertation). Western Kentucky University, Bowling Green, Kentucky.

Heyn, M. E. (2013). Experiences of male Saudi Arabian international students in the United States. (Doctoral dissertation). Retrieved from Proquest. (3572541).

Higher Education Council in Saudi Arabia. (1997). The regulations of scholarship and training for employees of universities. Retrieved from http://sponsorships.kau.edu.sa/Content.aspx?Site_ID=303\&lng=EN\&cid=2 301

Hofer, J. V. (2009). The identification of issues serving as barriers to positive educational experiences for Saudi Arabian students studying in the state of Missouri. (Doctoral dissertation). Available from ProQuest Dissertations and Theses database.

Hofstede, G. (2003). Culture's consequences: Comparing values, behaviors, institutions and organizations across nations. Thousand Oaks, CA: Sage Publications

Institute of International Education. (2015). Open doors data: Fact sheet by country 2015. Retrieved from http://www.iie.org/ /media/Files/Corporate/OpenDoors/Fact-Sheets-2015/Countries/Saudi-Arabia-Open-Doors-2015.pdf.

Jones, S. R., Torres, V., \& Armino, J. (2006). Negotiating the complexities of qualitative research in higher education: Fundamental elements and issues. New York, NY: Routledge.

King Abdullah Scholarships Program. Retrieved from Portal of the Saudi Ministry of Higher Education: http://www.mohe.gov.sa/ar/studyaboard/KingAbdulla-hstages/Pages/NinthStage.aspx 
Lee, E. (1966). A theory of migration. Demography, 3(1), 47-57. doi: $10.2307 / 2060063$

Lee, J. J. (2008). Beyond borders: International student pathways to the United States. Journal of Studies in International Education,12(3), 308-327. doi: 10.1177/1028315307299418

Lincoln, Y. S., Lynham, S. A., \& Guba, E. G. (2011). Paradigmatic controversies, contradictions, and emerging confluences, revisited. In N. K. Denzin and Y. S. Lincoln (Eds.), The Sage Handbook of Qualitative Research (pp. 97128). Thousand Oaks, CA: Sage.

Maxwell, J. A. (2004). Qualitative research design: An interactive approach. Thousand Oaks, CA: Sage.

Mazzarol, T., \& Soutar, G. N. (2002). "Push-pull” factors influencing international student destination choice. The International Journal of Educational Management, 16(2), 82-90. Doi: 10.1108/09513540210418403

Merriam, S. B. (2009). Qualitative research: A guide to design and implementation (2nd ed.). San Francisco, CA: Jossey-Bass.

Onsman, A. (2011). It is better to light a candle than to ban the darkness: Government led academic development in Saudi Arabian universities. Higher Education, 62(4), 519-532. Doi: 10.1007/s10734-010-9402-y

Onsman, A. (2012). Distributing the future evenly: English as the lingua franca in the Saudi Arabian higher education sector. Higher Education Policy, 25, 477-491. doi 10.1057/hep.2012.8

Patton, M. Q. (2001). Qualitative research and evaluation methods, 3rd ed. Thousand Oaks, CA: Sage Publications.

Paulsen, M. B. (2001). The economics of the public sector: The nature and role of public policy in the finance of higher education. In M. B. Paulsen \& J. C. Smart (eds.), The finance of higher education: Theory, research, policy, and practice (pp. 95-132). New York: Springer.

Perna, L. W., Orosz, K., Gopaul, B., Jumakulov, Z., Ashirbekov, A. \& Kishkentayeva, M. (2014). Promoting human capital development: A typology of international scholarship programs in higher education. Educational Researcher, 43(2), 63-73. doi 10.3102/0013189X14521863

Perna, L. W., Orosz, K., Jumakulov, Z., Kishkentayeva, M., \& Ashirbekov, A. (2015). Understanding the programmatic and contextual forces that influence participation in a government-sponsored international studentmobility program. Higher Education, 69(2), 173-188. doi 10.1007/s10734014-9767-4

Pimpa, N. (2003). The influence of peers and student recruitment agencies on Thai students' choices of international education. Journal of Studies in International Education, 7(2), 178-192. doi $10.1177 / 1028315303007002005$

Rasheed, M. A. (1972). Saudi students in the United States: A study of their perceptions of university goals and functions. Dissertation Abstracts International, 33, 6135.

Saudi Arabian Cultural Mission. (n.d.) Saudi Students Guide. Retrieved from http://www.sacm.org/pdf/studentsguide_english.pdf.

Saudi Arabian Cultural Mission (n.d.). Advancement of Saudi Women. Retrieved 
from Saudi Arabian Cultural Mission web site: http://www.sacm.org/ArabicSACM/pdf/women_front_web.pdf.

Schneider, C. (2013). Researching transnationalisation and higher education in the context of social mechanisms. Journal of Contemporary European Studies, 21(4), 480-495.

Shanka, T., Quintal, V., \& MEdMan, R. T. (2006). Factors influencing international students' choice of an education destination: A correspondence analysis. Journal of Marketing for Higher Education, 15(2), 31-46.

Shaw, D. (2010). Bridging differences: Saudi Arabian students reflect on their educational experiences and share success strategies. Dissertation Abstracts International, 71(4-A), 1192.

Urias, D., \& Yeakey, C. C. (2009). Analysis of the U.S. student visa system: Misperceptions, barriers, and consequences. Journal of Studies in International Education, 13(1), 72-109. doi 10.1177/1028315307308135

Wei, H. (2013). An empirical study on the determinants of international student mobility: A global perspective. Higher Education, 66(1), 105-122. doi 10.1007/s10734-012-9593-5

Wilkins, S., \& Huisman, J. (2011). International student destination choice: the influence of home campus experience on the decision to consider branch campuses. Journal of Marketing for Higher Education, 21(1), 61-83. doi 10.1080/08841241.2011.573592

Yakaboski, T. (2013). The rest of they story: A qualitative study of Chinese and Indian women's graduate education migration. NASPA Journal About Women in Higher Education, 6, 166-184. doi: 10.1515/njawhe-2013-0012.

Zhou, J. (2015). International students' motivation to pursue and complete a Ph.D. in the U.S.Higher Education, 69(5), 719-733. doi 10.1007/s10734-0149802-5

TAMARA YAKABOSKI, Ph.D., is an Associate Professor in Higher Education and Student Affairs Leadership at the University of Northern Colorado. She researches and teaches graduate seminars on student affairs, women's issues, and international higher education and the internationalization of universities. Email: Tamara.Yakaboski@unco.edu

KARLA PEREZ-VELEZ, is a Ph.D. candidate in Higher Education and Student Affairs Leadership at University of Northern Colorado. Email: pere0670@bears.unco.edu

YOUSEF ALMUTAIRI, is a Ph.D. candidate in Higher Education and Student Affairs Leadership at University of Northern Colorado. Email: almu4680@bears.unco.edu 
Peer-Reviewed Article

ISSN: 2162-3104 Print/ ISSN: 2166-3750 Online

Volume 7 Number 1 (2017), pp. 113-135

(C) Journal of International Students

http://jistudents.org/

\title{
Three Levels of Push-Pull Dynamics Among Chinese International Students' Decision to Study Abroad in the Canadian Context
}

\author{
Jun Mian Chen \\ Brock University, Canada
}

\begin{abstract}
The extant literature on student migration flows generally focus on the traditional push-pull factors of migration at the individual level. Such a tendency excludes the broader levels affecting international student mobility. This paper proposes a hybrid of three levels of push-pull dynamics (micro-individual decision-making, meso-academic marketing, and macro-national marketing) to paint a more accurate picture of student migration flows. A case study of 15 semi-structured interviews with Chinese international students at a Canadian university was conducted to illuminate the underresearched reality that universities and Canada as a nation offer additional incentives, in conjunction with individual/familial reasons, for study abroad. The paper concludes with recommendations for new research directions arising from the present study.
\end{abstract}

Keywords: Canadian university, Chinese international students, macromarketing, meso-marketing, micro-marketing, study abroad

China is the world's leading provider of international students, with the United States being the international hub for students studying abroad. With over 974,000 international students in 2014/15 fiscal year, of whom over 304,000 are from China (Institute of International Education, 2016), United States continues to attract the greatest number of international students worldwide (UIS, 2016). In comparison, Canada ranks among top seven in the world, with Chinese students comprising the greatest segment (over 110,000 in 2014) of international student population (CBIE, 2016). However, the latest national survey of international students reveals that more than half $(53 \%)$ of the 5,925 students surveyed chose Canada as their 
first-choice country for study abroad, while only $25 \%$ preferred the United States (CBIE, 2009).

The population of international students present in Canada is at an all-time high, and it has increased from 159,425 in 2003 to 293,503 in 2013 (CIC, 2013, 2014a). The numbers of international students from CIC (Citizenship and Immigration Canada) is available up to year 2013; newer data is currently unavailable. In $2014,43 \%$ of all international students in Canada were studying in Ontario, followed by $28.9 \%$ in British Columbia (CBIE, 2016). Pertinently, 58\% of the international student population are enrolled in university-level programs, as opposed to other post-secondary (i.e., college, trades) and secondary or elementary levels (CBIE, 2016). Clearly, Canadian universities, those in Ontario in particular, have experienced tremendous growth in international student enrollment in the last decade.

The recent growth in the number of international students in Canada can be examined at three different yet interrelated levels: micro (individual decision-making processes), meso (academic marketing), and macro (national marketing). At the micro-level, Fama (2011) argued that the demand for education in Canada has sparked an increase in the number of international students who have enrolled at Canadian universities in recent years. Owing to this widely held premise, extant studies at the micro-level (e.g., Mazzarol \& Soutar, 2001; Chen, 2008) have typically examined the decision-making process and students' motivation to study abroad. Nonetheless, the exploration of academic marketing, which constitutes just one aspect of the complex meso-level dynamics, is gradually growing in prominence. Meso-level studies (e.g., Çetin, 2003; Pimpa, 2005; Wilkins \& Huisman, 2013) point to the reality of decreased government funding, which in turn creates the need for universities to increasingly compete for the international student market, as the panacea for individual institutions' financial slump. As a case in point, in 2008, the University of Toronto reported a loss of $\$ 1.3$ billion, while York University lost $19 \%$ of its $\$ 300$ million endowment fund (Canadian Federation of Students-Ontario, 2010). These large amounts of money exemplify the seriousness of the financial difficulties experienced by even some of the most reputable universities in Canada. Finally, studies that have explored this phenomenon at the macrolevel, while limited, tended to focus on the role of the Government of Canada in explaining the recent growth in the international student population.

\section{THEORETICAL FRAMEWORK}

The push-pull theory of international migration is a classic model that is commonly used to explain student migration, as it allows identifying push 
and pull factors that work in conjunction to affect student decision-making (Mazzarol \& Soutar, 2002). Push factors are the social, political, and economic forces within the home country that initiate a student's decision to pursue education overseas, such as high levels of student competition for university entrance due to overpopulation (Bodycott \& Lai, 2012, p. 254). Pull factors, on the other hand, are those that induce students to choose one particular country over another, such as the knowledge and awareness of an institution's reputation, recommendations by peers and relatives, and ability to work in the host country (Mazzarol, Soutar, \& Thein, 2001). The value of the push-pull theory stems from its ability to explicate student migration flows. The model has some drawbacks, one of which is the fact that it does not clearly distinguish between country characteristics (e.g., ability to work) and characteristics within the country (e.g., an institution's reputation, which may not correlate to the host country's appeal).

Moreover, most extant studies on international student migration flows focus on one level of analysis, such as examining push-pull factors influencing students' decision to study overseas (e.g., Mazzarol \& Soutar, 2002), or marketing strategies employed by individual institutions (e.g., Mazzarol, Soutar, Smart, \& Choo, 2001) for the purpose of international student recruitment. Such approach implicitly neglects the fact that students' choice to study overseas is affected by numerous, complex, and often interrelated factors that operate at several levels. For instance, the push-pull model tends to treat pull factors as immutable and clearly apparent to the students. Canada has recently started following the example of United States and Australia, where aggressive international marketing strategies have been employed, with the aim of increasing the number of international students within its borders (Michael, 1990; Mazzarol \& Hosie, 1996). This paper contributes to the literature by examining these complex phenomena. In particular, it synthesizes the micro, meso, and macro levels of analysis, which are all interconnected. It also uncovers the rationales and the broader context within which Chinese students are choosing to study in Canada.

\section{LITERATURE REVIEW}

\section{English-Speaking Countries}

The US, the UK, and Australian literature on international students - and English-speaking countries more generally-have plentiful studies that focus on students' adjustment to the host country and the needs of international students in higher education (e.g., Hanassab \& Tidwell, 2002; Bartram, 2007; Campbell \& Li, 2008; Zhou \& Todman, 2009; Andrade, 2010; Campbell, 2012; Cheng \& Erben, 2012), as well as on migration patterns (e.g., Pan, 2010; Bodycott \& Lai, 2012; Wilkins, Balakrishnan, \& Huisman, 2012). Such studies are predominantly 
conducted in the United States and the United Kingdom because these two countries have the greatest number of international students studying at their higher education institutions (UIS, 2014). Their popularity is also likely influenced by the fact that a significant number of the highest ranked universities are located in the United States followed by several prominent universities from the UK (Shanghai Ranking Consultancy, 2014). As the number of international students in Canada continues to climb, the body of research on the international student population is also likely to expand (e.g., Zhang \& Zhou, 2010).

Nonetheless, given that the international mobility of students follows a distinct geographical pattern, it is no coincidence that Canada continuously receives significant numbers of international students. According to Waters (2008), the vast majority of international students choose specific English-speaking countries for their studies, such as the US, the UK, Australia, Canada, and New Zealand.

\section{Micro-level Factors Affecting Student Mobility: Decision-making and Motivation to Study Abroad}

Given that the paper aims to draw more attention to the meso- and macro-level factors influencing student migration, only a brief review of the micro-level factors will be given. Essentially, every decision to study abroad is made by the individual student, often with input from his/her immediate family (Mazzarol \& Soutar, 2001; Bodycott, 2009; Bodycott \& Lai, 2012). The role of parents in a Confucian society, such as mainland China, is especially important because Confucianism is the cornerstone of traditional Chinese culture, upon which the decision to study abroad is in part based on. In mainland China, a strict parent-child relationship prevails and even adult children must respect and obey their parents (Bodycott, 2009). Thus, most of the decision-making involves parents and other relatives. When deciding to study internationally, most students would go through four distinct stages: clarifying the intention to study internationally, choice of country in which to study, the selection of an institution, and the choice of the city (Mazzarol \& Soutar, 2001).

\section{Macro-level Factors Affecting Student Mobility: National Marketing for International Students}

National marketing in Canada is a more recent development than academic marketing. Education in Canada is primarily the responsibility of each province, while immigration visas (often referred to as Canada Green Cards by people outside of Canada), foreign affairs, and international trade are the responsibility of the federal government. The affairs of international students thus fall under the remit of both the provincial and federal government. Until recently, international students were typically recruited 
by individual institutions without "a coordinated marketing effort" (Chen, 2008, p. 8) between individual institutions and Canada as a nation. In recognition of this shortcoming, the Government of Canada recently developed strategies to increase the international student intake.

\section{Canada's International Education Strategy}

The Government of Canada recognizes the vital role of international education in creating jobs, economic growth, and long-term prosperity in Canada (FATDC, 2014). Thus, Canada's International Education Strategy, launched in January 2014 by the Harper government, as the most recent initiative to capitalize on international education, will allow Canada to stay competitive in the global market (as a part of Canada's Global Markets Action Plan). As noted in the final report-International Education: A Key Driver of Canada's Future Prosperity - issued by the Advisory Panel on Canada's International Education Strategy, "The overarching goal of an international education strategy is to brand Canada internationally as a choice destination for talented people from around the world for studying, conducting research and potentially immigration" (FATDC, 2012, p. 48, emphasis added). Here, the meta-message or the latent objective in the goal statement reveals attempts to link international education (i.e., international students) to immigration by retaining international students post-graduation. The immediate target, however, is to increase the number of international students from 239,131 in 2011 to more than 450,000 by 2022 (FATDC, 2014). In order to achieve the stated strategy goals, as set out in Canada's International Education Strategy, the Government of Canada acknowledged a number of aims, some of which are: to strengthen cooperation to leverage scholarships for international students, to build strategic partnerships with key countries, to work with online educators to foster greater uptake by international students, and to increase the number of international students opting to remain in Canada as permanent residents after graduation (FATDC, 2014).

\section{Canadian Experience Class (CEC)}

Both Canadian Government and individual institutions use the Canadian Experience Class (CEC) as a selling feature to attract and recruit international students for whom permanent residency status in the host country is a desired goal. The Canadian Government created the CEC in 2008 to specifically target international students and migrant workers. The CEC program enables individuals in these groups who have work experience in Canada to move from temporary to permanent residency. Valiani (2013) explained, "The CEC offers the 'carrot' of permanent residency to international students and internationally trained workers of various skilled categories following the completion of, respectively, twelve 
or twenty-four months of work in Canada, on the basis of a temporary work authorization" (p. 62). As of January 1, 2015, those interested in applying to the CEC must go through the Express Entry system.

A recent change that was instated on May $1^{\text {st }}, 2014$, which caps the total number of new CEC applications to 8,000, is in part a response to the introduction of the Express Entry, launched in January 2015 (CIC, 2014b). Express Entry is a system that manages applications for permanent residence under three federal economic immigration programs: the Canadian Experience Class, the Federal Skilled Worker Program, and the Federal Skilled Trades Program. With the Express Entry in operation, provinces are able to select the most qualified candidates and ensure that these receive immigration status (CIC, 2014c). This policy change exemplifies Altbach and Knight's (2007) point that, while students generally migrate from south to north, it is the north (in the present case Canada) that largely controls the process, as it produces the conditions upon which students' decisions to study overseas are in part based on. These policy changes are clear examples of how Canada strategically adjusts its immigration policy to offer permanent migration as an option, thus creating a significant pull factor. In other words, Canada actively facilitates the flow of international students, by adjusting conditions through immigration policy changes.

Available evidence also suggests presence of a link between choice of country in which to study and the likelihood of obtaining permanent residency upon graduation (see, for example, Baas, 2006). Thus, marketing of international education is increasingly being integrated into the migration marketing strategies, such as those pertaining to permanent residency (Baas, 2007). Put differently, the increased flow of tertiary students to Canada may not be solely based on the international education quality alone; rather, the prospect of securing a permanent residency status may in part influence international student mobility.

\section{The Broader Financial Context of International Education in Canada}

Given the factors discussed above, an important question arises: what are the conditions under which a country may want to offer, or at the very least ease the process of obtaining, permanent residency status to international students? The answer lies in the economic value of international students. International education is a multi-billion dollar industry (FATDC, 2012). According to the 2012 federal government report commissioned by the Department of Foreign Affairs and International Trade Canada (FATDC), estimates pertaining to 2010 reveal several positive economic impacts of international students in Canada. In particular, the findings reveal that international students spent over $\$ 7.7$ billion on tuition, accommodation, and discretionary spending; created over 81,000 jobs; and generated more than $\$ 445$ million in government revenue (Roslyn Kunin \& 
Associates, Inc., 2012). The report further estimates that, in 2010, international students in $\mathrm{K}-12$ and university-level education contributed over $\$ 763$ million and $\$ 4$ billion to the Canadian economy, respectively (Roslyn Kunin \& Associates, Inc., 2012). Given that international tertiarylevel students are the major contributors to the economy, the Government of Canada has ample economic reasons and motives to increase the intake of international students.

\section{Meso-level Factors Affecting Student Mobility: Academic Marketing for International Students}

The Economic Impact of International Students on Individual Institutions. International students are also highly sought commodity for universities that are undergoing transformative changes brought on by neoliberal policies, whereby university agendas are increasingly aligning with corporate interests (Magnusson, 2000; Scott, 2000; Sidhu, 2006). In addition, institutions are increasingly under pressure to internationalize and diversify their campuses, with the main rationale that this shift would ensure that graduates are internationally knowledgeable and thus competitive beyond their borders (AUCC, 2007; Hudzik, 2010). Neoliberalism is a rather broad concept pertaining to an economic and political model of society that has risen to prominence in the 1980s (Harvey, 2005). While acknowledging several ways to interpret neoliberalism (Springer, 2012), the focus of this paper is on the policy and program framework.

Decreases in government funding have led universities to assume greater autonomy in devising methods to secure operating funds, and most have adopted increasing tuition fees as the main strategy (Magnusson, 2000; Godard, 2010). However, many also strive to increase the number of international students (Oplatka \& Hemsley-Brown, 2010), and have thus started offering language programs to assist with this process. This creates an environment in which universities compete with each other to attract and retain students in order to maximize their competitiveness in the global market and to achieve a worldwide reputation as an excellent and renowned higher education institution (Oplatka \& Hemsley-Brown, 2010; Newson, Polster, \& Woodhouse, 2012). Hence, the competition for international students among universities characterizes the meso-level of internal competition within Canada.

University Funding in Decline: A Brief History. Many universities have become corporate organizations that seek to generate profit, rather than to focus on producing and disseminating knowledge for the betterment of society (Maringe, 2010). Academic internationalization is one means through which revenue can be generated in an effort to offset financial 
concerns of the institution. This is becoming increasingly important for Canadian universities that are no longer receiving the funds they once did. In the 1960s, government funding for higher education increased, which ensured that universities could focus on education, rather than seeking to maximize revenue (Godard, 2010). From 1977 through 1996, postsecondary educational institutions, along with Canada's healthcare system, were still largely funded by the federal government through Established Programs Financing (EPF) (Teeple, 2000). The EPF was a financial program in which the federal government provided funds according to a formula based on growth of the Gross National Product (GNP) and population (Teeple, 2000). However, the decline of the Canadian welfare state since the mid-1980s has changed the formula, resulting in reduced annual funding for post-secondary education (Teeple, 2000).

Federal funding for post-secondary education significantly changed yet again in 1996, with the introduction of the Canada Health and Social Transfer (CHST). In force from 1996 to 2003, the CHST was an amalgamation of the EPF and the federal Canada Assistance Plan (CAP) into one block fund (Department of Finance Canada, 2011). While the EPF largely subsidized healthcare and post-secondary education, the CAP subsidized social assistance (Metcalfe, 2010). Although the CHST provided financial assistance to provincial and territorial governments in support of healthcare, post-secondary education, social assistance, and social welfare, owing to the system of block transfer payments, funding to post-secondary education declined.

Since 2004, the CHST has been segregated into two streams: the Canada Health Transfer (CHT) and the Canadian Social Transfer (CST), with the latter serving as the conduit for post-secondary education funding, separating it from healthcare. However, the federal lump sum transfer under the CST conceals the amount designated for post-secondary education. Moreover, the funds are now awarded (e.g., based on research merit) rather than allocated, as has been the case in the past (Metcalfe, 2010). This is one of the ways in which neoliberalism manifests itself through policies and programs.

The Case of University- $X$. This case study examines the increased number of international students studying at a small, liberal arts university in Southwestern Ontario (henceforth referred to as University-X), contextualized against the backdrop of increasing body of international students present in Canada. University-X serves over 17,000 undergraduate and graduate students. The university has secured a positive reputation among locals, as well as internationally via branding, and it provides one of Canada's largest Business co-op program. Like many other universities, University-X actively recruits international students, particularly from 
China, via academic marketing. Kotler and Fox (1985) defined applying the concept of marketing to education as "the analysis, planning, implementation, and control of carefully formulated programs designed to bring about voluntary exchanges of values with target markets, to achieve institutional objectives" (p. 7). According to them, "Marketing involves designing the institution's offerings to meet the target market's needs and desires, and using effective pricing, communication, distribution to inform, motivate, and service the markets" (p. 7).

Kotler and Fox's framework of marketing elucidates the rationale behind University-X's effective promotion of its Business program to international students (as well as locals), which has resulted in the majority of its international students enrolling in that program.

University-X also markets its language program as much more than just an English requirement. The language program offers courses that focus on academic English and on equipping students with English skills in essay writing and reading academic texts, among others. Students also engage in sociocultural activities as a way to experience Canadian culture, such as field trips to Niagara Falls, food festivals, potlucks, and bowling, to name a few. University- $X$ uses the language program to advertise opportunities for international students to interact with English-speaking locals. The language program constitutes one aspect of University-X's internationalization efforts (Knight, 2004), which serve two main purposes. First, it helps to recruit international students by offering academically qualified students a conditional offer into University-X's program upon completion of the language program; second, it constitutes an important stream of revenue for the university.

The purpose of the present study is to explore why Chinese international students choose to study abroad, specifically at University-X. Chinese international students are selected for this investigation because they comprise the majority of the international students at University-X, as well as worldwide. The study is guided by the research question-what factors influence international students' decision to pursue international education? The present study contributes to the extant literature in the field by examining a case example within the Canadian context to demonstrate the effect of three levels of push-pull dynamics on international migration among Chinese students looking to study abroad.

\section{RESEARCH METHOD}

The ability to understand the perspective of students as closely as possible in regards to their decision-making processes is of vital importance for the present study. According to Yin (2014), a case study design is appropriate when the focus of the study is to answer "how" and "why" questions, and to 
uncover contextual conditions relevant to the phenomenon under study. Yin (2014) defines case study as "an empirical inquiry that investigates a contemporary phenomenon (the 'case') in depth and within its real-world context” (p. 16). As well, a qualitative approach was selected, given its advantage over quantitative inquires when it comes to capturing a deeper understanding of students' narratives (Denzin \& Lincoln, 2003).

\section{Procedures}

The present study is a pilot case study with 15 Chinese international undergraduate students studying at University-X. The study participants were chosen via two recruitment strategies. The primary recruitment initiative took place through class solicitation in one of University-X's North American Studies classes. This particular course is designed to provide international degree-seeking and exchange students an introduction to Canadian society, culture, politics, history, and geography, among other important aspects. This particular course was deemed an ideal platform for recruitment, as it is open to first- and second-year international degreeseeking and exchange students only. Students' interest in the study was very high and interviews started on the day of the in-class recruitment.

The second recruitment strategy comprised of snowball sampling. At the end of each interview participants were asked if they knew of any Chinese international students whom they thought might have been interested in the study. The snowball method proved to be effective because this population of students is typically difficult to locate (Amit \& Riss, 2007). To qualify for participation in the study, students had to be undergraduate degree-seeking international students, rather than exchange students, from China. To satisfy this condition, participants self-declared at the beginning of each interview.

\section{Research Instruments and Participants}

Two data collection instruments were used to gather the information required to meet the study aims. The first involved questionnaires, which solicited demographic information from the participating students. Each participant completed a questionnaire just prior to starting the one-on-one interview. The main research instrument comprised of individual in-depth, semi-structured, and audio-recorded interviews. Interviews were conducted in English, using a set of interview questions, and lasted 52 minutes on average. In addition, stress was minimized by not using a translator as it might have caused some students to feel slightly uncomfortable. The principal investigator of the study conducted all 15 interviews. Pseudonyms were used to ensure confidentiality.

The cohort consisted of two males and thirteen females, all of whom were interviewed from April 3rd to April 16th, 2013. At the time of the 
study, all participants were 18 to 20 years old and all but one was first year students. The majority of the students were studying either Bachelor of Business Administration (BBA) or Economics. The only two exceptions were a student pursuing a double major in BBA and Financial Math, and a first-year Biology major student. All but two students finished University$\mathrm{X}$ 's language program prior to studying at the university.

\section{Qualitative Descriptive Research Design}

The present study examines students' decision-making processes through the symbolic interactionist framework, or the perspective that students construct their own actions, which are deliberate and intentional, as a result of social interaction with others as well as their environment (Handberg, Thorne, Midtgaard, Nielsen, \& Lomborg, 2015). Adopting a qualitative descriptive research design ensured that a comprehensive understanding of reasons that motivated students to study in Canada, and specifically University-X, could be obtained. According to Sandelowski (2000), qualitative descriptive studies are best suited when the aim is to present a comprehensive summary of the data in everyday language, rather than interpret events and meanings in other terms.

\section{Data Analysis}

Data analysis follows a bottom-up approach, otherwise known as inductive analysis. Inductive analysis refers to the generation and emergence of categories, themes, and patterns that come directly from the data (Denzin \& Lincoln, 2003). The first step in the data analysis was open coding, resulting in common themes, which were subsequently refined and narrowed into central themes (van den Hoonaard, 2012). These themes led to several sensitizing concepts, including competition, pressure, disappointment, reputation, English, friends, homestay, and Canadian culture.

A sensitizing concept refers to a construct developed by the participant and through the perspective of the participant, using his or her own language or expression, to convey the meaning of that construct (van den Hoonaard, 1997). From this standpoint, sensitizing concepts helped capture the meanings that the students attached to the world around them. Sensitizing concepts also complement the inductive approach to analysis because they stem from the data rather than from preconceived ideas held by the researcher (van den Hoonaard, 2012). With each sensitizing concept, a general direction was followed along which to look deeper (Blumer, 1954, as cited in van den Hoonaard, 1997, p. 2). For this reason, sensitizing concepts were quite useful, as they suggested possible areas to be analyzed, and guided the direction of the analysis. 


\section{Reliability and Validity}

Validity and reliability are important concepts in qualitative research. To help safeguard validity during the research process, Kvale (1996) recommended that studies of this type undergo seven stages comprised of thematizing, designing, interviewing, transcribing, analyzing, validating, and reporting. In the transcribing stage, for example, the researcher should choose a linguistic style that best translates the oral interviews into written form. In the analyzing (or interpreting) stage, the researcher should assess whether the analysis is sound and whether it answers the research question. The validating (or verifying) stage progresses throughout the research process. In particular, the researcher validates his/her own work by discussing the validity of the research project with others (e.g., supervisors, colleagues). Kvale's seven stages were useful guidelines to ensure the validity of the present research.

The reliability of a research project is increased by adopting methods that are consistent, dependable, and accurate. In other words, reliable measurements are those that produce the same result when repeated under similar circumstances (Gleason, Harris, Sheean, Boushey, \& Bruemmer, 2010). The present study ensures reliability by maintaining consistency throughout the interviewing process, as well as in the transcription phase and data analysis.

\section{Limitations}

Although the present study has reached its aims of identifying and uncovering the rationales behind Chinese students' decisions to study abroad, and specifically choosing University-X, it is affected by some unavoidable limitations. Because of the gender composition of the sample, the findings are heavily skewed towards female perspective. Similarly, it is the perspective of students from University-X's Business program which are represented, due to the participant recruitment method employed. Despite these limitations, the current study contributes to the limited literature on student migration in a Canadian context by accentuating three levels of push-pull dynamics.

\section{FINDINGS}

\section{(Micro) Push-Pull Factors in the Decision to Study Abroad}

The decision-making process to study internationally is complex and factors affecting its outcome are multifaceted. Most students envision studying abroad before they commence high school. One of the study participants explained that high school in China lasts three years, covering grades 10 to 12. After middle school, comprising of grades 7 to 9 , students are streamed into either traditional high schools, where they will have to 
take the daunting university entrance exam, or international high schools, for those who are planning to pursue further education overseas. All students who took part in the present study see the former option as highly competitive and stressful and the latter as an alternative to the pressure and competition in China. According to them, attending international high schools reduces the pressure of studying for and taking the university entrance exam at the end of high school, which is the conventional route.

The participants in this study unanimously expressed concern about the university entrance exam, which constitutes a major push factor recognized by both students and their parents in their decision to study abroad. In Chinese Confucian culture, parents take on an active role in the education of their children. Myla recalled,

When I was in middle school, my parents decided to send me to international school, like English education system. So, I was there for three years high school study and then my dad didn't want me to take the Chinese university entrance exam 'cause it was really, really hard and then that exam decides your whole life. So, my dad really didn't want me to get stressed out, so he just want to send me abroad and then I was really interested in studying English, so I chose to come to Canada.

A detailed analysis of the interview transcripts revealed some variations in the onset of the decision-making process. More specifically, while eight students indicated that their parents initiated the idea of studying abroad, six interviewees stated that the idea was their own and they had to convince and persuade their parents to support it. Only one student specified that it was a mutual decision right from the outset. Despite these differences, all participants concurred that the final decision to study abroad was reached by mutual consent.

While academic streaming, high competition levels among students in China, and the pressure of the university entrance exam all constitute push factors, their effect on the students' decision to study abroad is highly interrelated with the pull factors of their target country. When asked what prompted the students to study abroad, interviewees cited expectation of new life experiences, ability to learn and improve English language skills in an English-speaking country, and a desire to make new friends from different countries, all of which coincide with pull factors at the macro and meso level.

\section{(Macro) Push-Pull Factors in Selecting the Country of Destination}

The participants all had a desire to improve their English language skills, and only Canada and the United States were highlighted as the most 
suitable countries for that purpose. There was no mention of other English speaking countries. The students reveal that Canada's perceived quality of education was not a strong factor in their decision to study in the country. Instead, most students contrasted what they knew about life in Canada and the United States with that they could expect life to be if they remained in China. In Ayame's assessment,

Canada is safe; it's safer than America. And there's less people, not like China there's a lot of people and it's quiet and it's good for our study. It's a good country for study. . . . They [parents] think, you know, North American countries are always providing a lot of opportunities for you and for you to discover. Not like China, you know.

As Ayame revealed, perceived opportunity is a key pull factor in selecting the country of destination. The discourse of the American Dream, or the Canadian Dream, within immigrant populations is principally associated with the idea of opportunities. Both Canada and the United States are believed to hold opportunities for those willing to work to achieve their goals. This system in both countries is perceived as based on meritocracy. Sora provided yet another example of how the popular discourse functions by implanting these ideas into the minds of prospective students:

I love Biology but Biology does not have a beautiful future in China; so I think North America will be better for me, easier for me to find a job, or do the lab thing.

The data analysis revealed that all participants took the notion of attainability of the American/Canadian Dream for granted without questioning whether meritocracy applies in Canadian and the US societies practice.

Although both Canada and the United States are envisioned as a land of opportunities, the former is perceived to be a much safer place for one to study and live. Thus, while the lack of opportunities in China is a major push factor, the perception that favorable life chances are abundant in Canada is a strong pull factor in choosing Canada as the destination of choice.

In addition, the ability to work in Canada and to potentially gain immigration status is a highly attractive option. When asked about her plans, Myla responded, 
I'm thinking to work here for like two or three more years after I graduate so then I can immigrate. . . I kinda want to get that Canadian citizen[ship]. I wanna stay permanently here and then bring my parents here.

Because of the recent policy changes, international students are now allowed to work on- and off-campus without a work permit. This is another incentive to study in Canada, as international students can gain valuable experience as well as lessen the financial burden on their parents.

Furthermore, students reason that being bilingual, and as fluent in English as possible, will serve them well in the job market, whether in China or in Canada, should they stay post-graduation. In fact, in China, students start learning English at a very young age. Formal instruction commences in primary school (around grade 3, depending on the province), as English is a compulsory subject, along with Chinese and Math. However, several students expressed that the English they learn in China was not very useful. Aeris described the practicality of English classes in China:

You have to learn it [English], but I don't think it's useful. We just learn the vocabulary and we learn the skills that the Canadian people won't use now; so, actually it's just like, we won't learn how to speak and how to communicate. We just learn something on paper.

Aeris alluded to the reality that students in China learn English by way of rote-memorization. Simply learning English without engaging in natural dialogue to practice language skills hinders one's ability to communicate in a natural context in which it is used. Zanar was more explicit,

. . . they [referring to students in China] just do the paperwork, memorizing the vocabulary, and maybe pay more focus attention on grammar; but honestly, we don't practice a lot on speaking and listening. That's why lots of Chinese students, including me, the first time come here, are afraid of speaking, open our mouth to the English speaking people . . . because we don't have experience to talk, to listen in English, just read.

In brief, all participating students stated that their desire for social interaction with native English-speaking students in an English-speaking country was one of the main reasons for choosing to study in Canada. In their view, this is the ideal way to learn and improve their English skills. 


\section{(Meso) Push-Pull Factors in Selecting University-X as the Study Destination}

The English that students learn in China does not equip them well for academic study abroad, especially at the university level. In particular, it does not prepare them well for social/conversational interactions with English-speakers, justifying the need for attending language programs at individual institutions once students are admitted into the country of study. As Aeris explained,

... you know, like we study in university, we learn how to write essays and we didn't learn before so it's kind of difficult for us to learn now.

Aeris alluded to the reality that, she experienced learning difficulties as a result of not having learned the essential writing skills early on. Thus, the lack of proper English training and the desire to study in an Englishspeaking country, where one has a chance to study among native Englishspeakers, constitute a key pull factor to studying overseas, particularly in Canada. Upon admission to University- $X$, as is the case with many other universities, international students must meet the university's language proficiency requirement. Thus, those that do not successfully pass the TOEFL or IELTS tests are required to complete the university's language program. The fact that 13 out of 15 participants finished University-X's language program confirms that English studied in China was not sufficient.

When it comes to selecting the university, the findings of the present study revealed that parents have more say on their child's decision to study abroad than they do on the choice of university. This decision is generally left to the student. When asked about her parent's involvement in the decision to choose University-X, Sango noted,

... [when] I came to Canada and entered [University-X], my Dad's friends asked where did your daughter go and my Dad said, "Oh I don't know which university she goes to." My Dad completely does not know where I am; just know, "Oh, my daughter is in Canada right now," that's it.

While the push factors in choosing University-X were mostly personal in nature, the pull factors are numerous and diverse. Majority of the study participants contrasted the institutional ranking and status of the Chinese institutions with those of various Canadian universities. They confirmed the widely held view that graduating from a reputable international school is important for future career and life prospects. In their 
individual interviews, students also explained that they gauged reputation of various institutions by looking at rankings in magazines and websites.

Both the University of Toronto and University of Waterloo are referred to by the students as internationally famous universities. On the other hand, University-X does not appear in the Shanghai Ranking (Shanghai Ranking Consultancy, 2014) as a top national university and is thus not well known in China. This appears to be highly relevant in the university choice, as noted by Aeris, when asked if Chinese employers value Canadian degrees more than their Chinese equivalents,

It depends if the university is more famous. Like, if you do the Tsinghua University in China, if you graduate from Tsinghua University and you, or another one graduated from [University-X], maybe they'd prefer the student in Tsinghua University.

Tsinghua University is nationally recognized as a top university in Beijing, China. Yet, despite this prevalent view, the study participants still felt that gaining a degree abroad would give them advantage upon returning to China. Hence, the majority of the students are studying Business at University-X, a program for which the university has gained an international reputation.

While University-X is not considered very well known in China, there is a consensus among the students that University-X has a strong and reputable Business school. Ayame elaborated on her rationale for choosing University-X,

I hear that [University-X's] business school is awesome. My first choice was York University, but I heard that the area is kind of . . . it's pretty dangerous 'cause there's many news, like gunshots and it happened in their university; and I can't say often, but sometimes it is. Sometimes, I think it's really a big problem so I didn't choose that school, although they sent me an offer. [University-X] is not big like University of Toronto, but I like small university; it makes me feel safer.

Even though some of the participating students felt that gaining a degree at a more reputable university, such as the University of Toronto or York University, would give them a greater advantage in life, these universities are perceived to be situated in undesirable locations. Thus, it is important to have a safe environment to study and live. In other words, University-X's location emerges as a pull factor mainly in response to an aversive factor pertaining to another university. 


\section{DISCUSSION AND IMPLICATION}

The findings of the present study indicated that the four-stage process of student migration may not be as linear as posited by Mazzarol and Soutar's (2001) findings. The results challenge the prevalent view that students generally decide to study overseas first, after which they identify their preferred country, followed by an institution in which to study, and finally the city. In fact, the present study revealed that, while some students' decision-making processes did follow Mazzarol and Soutar's (2001) linear model, some participants made their decisions differently. In this particular sample, which was mostly comprised of young females, the city in which a university is situated seemed to take precedence over an institution. Given that the reputation of a university is a major criterion in selecting school, these findings suggest that the linear model may undergo further shifts in the future, as internationally reputable universities must consider their location as well, if they are to attract sufficient number of overseas students. This discernment highlights the shortcoming of focusing on the traditional microlevel aspects of the push-pull model to the exclusion of macro- and mesolevel decision-making. Conversely, accounting for all three levels of pushpull dynamics to explain students' decision to study abroad will reveal nuanced details, including the difference between country characteristics (e.g., ability to work/immigrate) and characteristics within the country (e.g., the reputation of an institution).

The study findings also revealed that students' choice of country is based upon popular discourses (e.g., the American/Canadian dream, recommendations from relatives and friends both at home and from abroad), rather than on current policy changes pertaining to international education and immigration in Canada. None of the students interviewed for this study considered Canadian policy changes when making their decision to enroll at University-X. However, it is also likely that these issues were not revealed because the interview questions did not specifically address the meso- and macro-level factors. These limitations should be addressed in further research focusing on Canada, as well as other countries. In-depth assessment of the effects that macro-level processes have on the decision to study abroad would provide a more comprehensive picture of the international student migration dynamics. Exploring this unique area may reveal new kinds of pull factors that a particular country creates, as well as aversive factors that would deter prospective international students. This research direction would extend and challenge the classical push-pull model by adding the possibility that there may be aversive kinds of push factors within a country that has been traditionally viewed as mainly creating pull factors. 
The present study also offers implications for universities wishing to expand their academic marketing, which typically focuses on the benefits of their academic/language programs and campus environment. Given the findings reported here, it is evident that greater emphasis should be placed on marketing the university location and the way of life students can expect upon arrival. As well, University-X and other universities generally employ micro-marketing strategies that target a precisely defined student population (e.g., students with an interest in University-X's Business program). It is highly recommended that these be complemented by macro-marketing strategies, focusing on promoting the university image more broadly.

\section{REFERENCES}

Altbach, P. G., \& Knight, J. (2007). The Internationalization of Higher Education: Motivations and Realities. Journal of Studies in International Education, 11(3-4), 290-305.

Amit, K., \& Riss, I. (2007). The Role of Social networks in the Immigration

Decision-making Process: The Case of North American Immigration to Israel. Immigrants \& Minorities, 25(3), 290-313.

Andrade, M. S. (2010). Increasing Accountability: Faculty Perspectives on the English Language Competence of Nonnative English Speakers. Journal of Studies in International Education, 14(3), 221-239.

Association of Universities and Colleges of Canada (AUCC). (2007). Internationalizing Canadian campuses: Main themes emerging from the 2007 Scotiabank-AUCC workshop on excellence in internationalization at Canadian universities. Retrieved from http://www.aucc.ca/wpcontent/uploads/2011/05/scotiabank-internationalization- workshop2007.pdf

Baas, M. (2006). Student of Migration: Indian Overseas Students and the Question of Permanent Residency. People and Place, 14(1), 8-23.

Baas, M. (2007). The Language of Migration: The Education Industry versus the Migration Industry. People and Place, 15(2), 49-60.

Bartram, B. (2007). The Sociocultural Needs of International Students in Higher Education: A Comparison of Staff and Student Views. Journal of Studies in InternationalEducation, 11(2), 205-214.

Bodycott, P. (2009). Choosing a higher education study abroad destination:

What mainland Chinese parents and students rate as important. Journal of Research in International Education, 8(3), 349-373.

Bodycott, P., \& Lai, A. (2012). The Influence and Implications of Chinese

Culture in the Decision to Undertake Cross-Border HigherEducation. Journal of Studies in International Education, 16(3), 252-270.

Campbell, N. (2012). Promoting intercultural Contact on Campus: A Project to Connect and Engage International and Host Students. Journal of Studies in International Education, 16(3), 205-227.

Campbell, J., \& Li, M. (2008). Asian Students' Voices: An Empirical Study of Asian Student's Learning Experiences at a New Zealand University. Journal of Studies in International Education, 12(4), 375-396. 
Canadian Bureau for International Education (CBIE). (2009). Canada First: The 2009 Survey of International Students.

Canadian Bureau for International Education (CBIE). (2016). Facts and Figures: Canada's performance in international education, 2015. Retrieved from http://www.cbie.ca/about-ie/facts-and-figures/

Canadian Federation of Students-Ontario. (2010). The Impact of Government Underfunding On Students. Retrieved from http://cfsontario.ca/ downloads/CFS- Underfunding\%20Factsheet.pdf

Çetin, R. (2003). Planning and Implementing Institutional Image and Promoting Academic Programs in Higher Education. Journal of Marketing for Higher Education, 13(1-2), 57-75.

Chen, L.-H. (2008). Internationalization or International Marketing? Two Frameworks for Understanding International Students' Choice of Canadian Universities. Journal of Marketing for Higher Education, 18(1), 1-33.

Cheng, R., \& Erben, A. (2012). Language Anxiety: Experiences of Chinese Graduate Students at U.S. Higher Institutions. Journal of Studies in International Education, 16(5), 477-497.

Denzin, N. K., \& Lincoln, Y. S. (2003). Strategies of Qualitative Inquiry (2nd ed.). Thousand Oaks, CA: Sage

Citizenship \& Immigration Canada (CIC). (2013). Facts and Figures 2012 Immigration overview: Permanent and temporary residents. Retrieved from http://www.cic.gc.ca/english/resources/statistics /facts2012/teporary/16.asp

Citizenship \& Immigration Canada (CIC). (2014a). Retrieved from http://www.cic.gc.ca/english/resources/statistics/facts2013preliminary/08.asp

Citizenship \& Immigration Canada (CIC). (2014b). Express Entry. Retrieved http://www.cic.gc.ca/english/immigrate/express/express- entry.asp

Citizenship \& Immigration Canada (CIC). (2014c). Retrieved from http://www.cic.gc.ca/english/immigrate/cec/applications-accepted.asp

Department of Finance Canada. (2014). Retrieved from http://www.fin.gc.ca/fedprov/his-eng.asp

Fama, M. (2011). A New Era for Canada's International Student Program. Canadian Diversity, 8(5), 11-14.

Foreign Affairs, Trade and Development Canada (FATDC). (2012). International Education: A Key Driver of Canada's Future Prosperity. Retrieved from $\mathrm{http} / / / \mathrm{www}$. international.gc.ca/education/assets/pdfs/ies_report_rapport_se i-eng.pdf

Foreign Affairs, Trade and Development Canada (FATDC). (2014). Canada's International Education Strategy. Retrieved from http://international.gc.ca/global-markets-marchesmondiaux/assets/pdfs/overview-apercu-eng.pdf

Gleason, P. M., Harris, J., Sheean, P. M., Boushey, C. J., \& Bruemmer, B. (2010). Publishing Nutrition Research: Validity, Reliability, and Diagnostic Test Assessment in Nutrition-Related Research. Journal of the American Dietetic Association, 11(3), 409-419.

Godard, B. (2010). Chapter 3: The Risk of Critique: Voices across the Generations. In J. Newson and C. Polster (Eds.), Academic callings: The University We 
Have Had, Now Have, and Could Have (pp. 26-34). Toronto, Canada: Canadian Scholars' Press.

Hanassab, S., \& Tidwell, R. (2002). International Students in Higher Education: Identification of Needs and Implications for Policy and Practice. Journal of Studies in International Education, 6(4), 305-322.

Handberg, C., Thorne, S., Midtgaard, J., Nielsen, C. V., \& Lomborg, K. (2015). Revisiting Symbolic Interactionism as a Theoretical Framework Beyond the Grounded Theory Tradition. Qualitative Health Research, 25(8), 10231032.

Harvey, D. (2005). A Brief History of Neoliberalism. New York, NY: Oxford University Press.

Hudzik, J. K. (2010). The Economy, Higher Education, and Campus Internationalization. International Educator, May/June, 96-102.

Institute of International Education. (2016). Fast Facts Open Doors 2015. Research and Publications: Open Doors. Retrieved, http://www.iie.org/en/Researchand-Publications/Open-Doors/Data/Fast-Facts\#.Vy-Susv2YdV

Knight, J. (2004). Internationalization Remodeled: Definition, Approaches, and Rationales. Journal of Studies in International Education, 8(1), 5-31.

Kotler, P., \& Fox, K. F. A. (1985). Strategic Marketing for Educational Institutions. Englewood Cliffs, CA: Prentice Hall.

Kvale, S. (1996). InterViews: An introduction to qualitative research interviewing. Thousand Oaks, CA: Sage Publications.

Magnusson, J.-L. (2000). Examining Higher Education and Citizenship in a Global Context of Neoliberal Restructuring. Canadian Ethnic Studies/Etudes ethniques au Canada, 32(1), 72-88.

Maringe, F. (2010). The Meanings of Globalization and Internationalization in HE: Findings from a World Survey. In F. Maringe \& N. Foskett (Eds.), Globalization and Internationalization in Higher Education: Theoretical, Strategic and Management Perspectives (pp. 17-34). London, New York: Continuum International Publishing Group.

Mazzarol, T., \& Hosie, P. (1996). Exploring Australian higher education: future strategies in maturing market. Quality Assurance in Education, 4(1), 37-50.

Mazzarol, T., \& Soutar, G. N. (2001). Push-Pull Factors Influencing International Student Destination Choice. CEMI Discussion Paper Series, DP 0105, Centre for Entrepreneurial Management and Innovation. Retrieved from http://www.cemi.com.au/sites/all/publications/CEMI\%20DP0105\%20Maz zarol\%20and $\% 20$ Soutar\%202001.pdf

Mazzarol, T., Soutar, G. N., Smart, D., \& Choo, C. (2001). Perceptions, information and choice: Understanding how Chinese students select a country for overseas study. Australian Education International: Department of Education, Training and Youth Affairs, i-96.

Mazzarol, T., Soutar, G. N., \& Thein, V. (2001). Critical Success Factors in the Marketing of an Educational Institution: A Comparison of Institutional and Student Perspectives. Journal of Marketing for Higher Education, 10(2), 39-57.

Mazzarol, T., \& Soutar, G. N. (2002). "Push-pull” factors influencing international student destination choice. The International Journal of Education Management, 16(2), 82-90. 
Metcalfe, A. S. (2010). Revisiting Academic Capitalism in Canada: No Longer the Exception. The Journal of Higher Education, 81(4), 489-514.

Michael, S. (1990). Marketing Educational Institutions: Implications for Administrators. International Journal of Education Management, 4(5), 2330.

Newson, J., Polster, C., \& Woodhouse, H. (2012). Toward an alternative future for Canada's corporatized universities. English Studies in Canada, 38(1), 5170.

Oplatka, I., \& Hemsley-Brown, J. (2010). The Globalization and Marketization of Higher Education: Some Insights from the Standpoint of Institutional Theory. In F. Maringe \& N. Foskett (Eds.), Globalization and Internationalization in Higher Education: Theoretical, Strategic and Management Perspectives (pp. 65-80). London, New York: Continuum International Publishing Group.

Pan, S.-Y. (2010). Changes and Challenges in the Flow of International Human Capital: China's Experience. Journal of Studies in International Education, 14(3), 259-288.

Pimpa, N. (2005). Marketing Australian Universities to Thai Students. Journal of Studies in International Education, 9(2), 137-146.

Roslyn Kunin \& Associates, Inc. (RKA, Inc.). (2012). Economic Impact of International Education in Canada. Accessed from http://www.international.gc.ca/education/assets/pdfs/economic_impact_en. pdf

Sandelowski, M. (2000). Whatever Happened to Qualitative Description? Research in Nursing \& Health, 23(4), 334-340.

Scott, P. (2000). Globalisation and Higher Education: Challenges for the 21st Century. Journal of Studies in International Education, 4(1), 3-10.

Shanghai Ranking Consultancy. (2014). Academic Ranking of World Universities. Retrieved from http://www.shanghairanking.com/aboutarwu.html

Sidhu, R. (2002). Educational Brokers in Global Education Markets. Journal of Studies in International Education, 6(1), 16-43.

Sidhu, R. K. (2006). Universities and Globalization: To Market, To Market. Mahwah, India: New Jersey.

Springer, S. (2012). Neoliberalism as discourse: between Foucauldian political economy and Marxian poststructuralism. Critical Discourse Studies, 9(2), 133-147.

Teeple, G. (2000). Chapter 16: The Decline of the Canadian Welfare State: Policies and Implications of Retrenchment. In B. S. Bolaria (Ed.), Social Issues and Contradictions in Canadian society (3rd ed., pp. 434-468). Toronto, Canada: Harcourt Canada Ltd.

UNESCO Institute for Statistics (UIS). (2016). Global Flow of Tertiary-level Students. Retrieved from http://www.uis.unesco.org/Education/ Pages/international-student-flow-viz.aspx

Valiani, S. (2013). Shifting Landscape of Contemporary Canadian Immigration Policy. In L. Goldring \& P. Landolt (Eds.), Producing and Negotiating Non-Citizenship: Precarious Legal Status in Canada (pp. 55-70). Toronto, Canada: University of Toronto Press. 
van den Hoonaard, W. C. (1997). Working with Sensitizing concepts: Analytical Field Research. Thousand Oaks, CA: SAGE Publications, Inc.

van den Hoonaard, D. K. (2012). Qualitative Research in Action: A Canadian Primer. Don Mills, UK: Oxford University Press.

Waters, J. L. (2008). Education, Migration, and Cultural Capital in the Chinese Diaspora: Transnational Students between Hong Kong and Canada. New York, NY: Cambria Press.

Wilkins, S., Balakrishnan, M. S., \& Huisman, J. (2012). Student Choice in Higher Education: Motivations for Choosing to Study at an International Branch Campus. Journal of Studies in International Education, 16(5), 413-433.

Wilkins, S., \& Huisman, J. (2013). Student Evaluation of University Image Attractiveness and Its Impact on Student Attachment to International Branch Campuses. Journal of Studies in International Education, 17(5), 607-623.

Yin, R. K. (2014). Case Study Research Design and Methods (5 $5^{\text {th }}$ ed.). Thousand Oaks, CA: Sage.

Zhang, Z., \& Zhou, G. (2010). Understanding Chinese International Students at a Canadian University: Perspectives, Expectations, and Experiences. Canadian and International Education / Education canadienne et internationale, 39(3), 43-58.

Zhou, Y., \& Todman, J. (2009). Patterns of Adaptation of Chinese Postgraduate Students in the United Kingdom. Journal of Studies in International Education, 13(4), 467-486.

JUN MIAN CHEN, MA, teaches at Conestoga College and is a MEd candidate at Brock University. His interdisciplinary research interests fall within and around the area of student migration and immigration, international student experience, internationalization of higher education, philosophy of education, and philosophy of race. Email: jchen@conestogac.on.ca 
Peer-Reviewed Article

ISSN: 2162-3104 Print/ ISSN: 2166-3750 Online

Volume 7 Number 1 (2017), pp. 136-153

(C) Journal of International Students

http://jistudents.org/

\title{
The Cultural Elements of Academic Honesty
}

\author{
LaNette W. Thompson \\ Baylor University, USA \\ Janet H. Bagby \\ Baylor University, USA \\ Tracey N. Sulak \\ Baylor University, USA \\ Janet Sheets \\ Baylor University, USA \\ Tonya M. Trepinski \\ Texas A\&M International University, USA
}

\begin{abstract}
We examined the impact of a workshop on Asian international graduate students' understanding of a U. S. American university's concept of academic honesty. The workshop, taught from a cultural perspective, explained the U.S. American university's expectations to 19 participants. Data was obtained from a workshop post-test and from subsequent interviews of three workshop participants who relayed their views of textual practices in their home countries. Sixty-seven graduate students from the general graduate student population completed the workshop post-test without benefit of the workshop. Trends in the data supported the workshop's effectiveness and pointed to the importance of helping international students understand their host university's expectations.
\end{abstract}

Keywords: Asian international students, graduate students, academic honesty workshop 
Students in higher education are becoming increasingly mobile. Worldwide, in 2000, approximately 2 million students were enrolled in institutions of higher education outside their own countries. That figure doubled to more than 4.5 million by 2012 (OECD, 2014). In the United States, for the 2013/2014 school year, approximately 886,000 international students enrolled in U. S. American schools. Of that number, more than 530,000 students came from Asian countries (Institute of International Education, 2015).

The growing enrollment of international students in the United States is receiving prominent attention as the media highlights the financial benefits of foreign students willing to pay out-of-state tuition to universities struggling with budget cuts (Lewin, 2012). Increasing international student populations on campus also foster concerns for the challenges of meeting their needs. Lipson (2008) advised international students intent on studying in the United States and Canada that other than English proficiency, the two issues international students face that affect their success in North American academics are understanding the freedom to express their own opinions in class and knowing what constitutes academic honesty at their host universities. For students from a society where individualism is frowned upon and students may study by copying information from experts, academic honesty as defined by a host institution may be a difficult concept to grasp (Gu, 2010; Kim, 2011; Leki, 2006; Liao \& Tseng, 2010; Sato \& Hodge, 2009; Shi, 2006).

Universities and institutions of higher learning differ in how they address plagiarism, who is responsible for enforcing policies, and which learning practices are considered academically dishonest (Gallant, 2008; Jamieson, 2008; Pecorari, 2008). International students may arrive in their host country with little knowledge of concepts or the unwritten practices of their new academic culture (Chen \& Van Ullen, 2011; Holmes, 2004). Though students may be familiar with the copyright laws of their own countries, they may not be familiar with the laws of their host country or the plagiarism policies of the university they are attending (Craig, Federici, \& Buehler, 2010). When international students come from an educational system where they are expected to quote their teacher's opinions or where knowledge content has received more emphasis than knowledge delivery, complications may arise (Gu, 2010; Song-Turner, 2008). If international students have had limited experience writing in English, they may need special help to avoid plagiarism and its consequences (Amsberry, 2010a; Chen \& Van Ullen, 2011; Pecorari, 2008).

This study began from a desire to provide the Asian graduate participants an opportunity to increase their knowledge of their host university's concept of academic honesty since graduate students are not required to complete an academic integrity tutorial at the research site. By 
assessing the influence of an academic honesty workshop that was taught from a cultural perspective, this study responded to a gap in the literature concerning the benefits of cultural workshops in helping Asian international students understand their host university's concept of academic honesty. This study also contributed to our knowledge concerning the importance of helping international students understand their host university's expectations.

\section{LITERATURE REVIEW}

According to the Merriam-Webster (2015) dictionary, the word "plagiarism" means "the act of using another person's work or ideas without giving credit to that person." The Oxford (2016) dictionary includes two acts in its definition of plagiarism, not only taking the words or ideas of another, but also "passing them off as one's own." This latter definition points out a conflict in the use of the term "plagiarism" to refer to all incidents of textual borrowing. Some authors are questioning the use of one term to describe those who intend to deceive and those who are simply unfamiliar with acceptable writing practices (Amsberry, 2010b; Holmes, 2004; Pecorari, 2008).

In a study examining plagiarism policies, Pfeuffer-Scherer (2010) noted that all of the universities studied had posted plagiarism policies on their websites, but the universities differed as to where the information was located. Some universities included plagiarism information in the academic conduct code whereas some listed it within student affairs policies. Although the universities that were studied generally agreed on definitions, they differed in how infractions were treated. Within a university, acceptable learning practices may differ from department to department. It may be assumed that students will collaborate in the math department, for example, but collaboration in other departments such as the humanities is considered academically dishonest (Gallant, 2008). International students must therefore understand each discipline's practices since acceptable learning practices may differ from department to department (Day, 2008; Hu \& Lei, 2012).

Universities throughout the world also differ in how they educate their students on academic honesty topics. After studying graduate students' understanding of plagiarism at universities in Pakistan, Ramzan, Munir, Siddique, and Asif (2012) called for universities to publish their academic honesty policies as well as hold workshops and seminars to help students better understand the concept of plagiarism.

Multiple researchers have stressed the importance of helping international students understand their host university's academic policies and concept of plagiarism (Abasi, Akbari, \& Graves, 2006; Abasi \& Graves, 2008; Amsberry, 2010a; Chen \& Van Ullen, 2011; Duff, Rogers, \& Harris, 
2006; Holmes, 2004; Mundava \& Chaudhuri, 2007; Song \& Cadman, 2013; Song-Turner, 2008). In her study of academic writing and plagiarism, Pecorari (2008) noted that it is possible that limited opportunities to practice citation skills or a lack of English proficiency may sometimes lead to plagiarism even though the student had no intention to deceive. Instead of assuming that every act of plagiarism is a moral problem, Robillard and Howard (2008) suggested that each incident be examined from the standpoint of the identities and social contexts of those involved.

Even if students are proficient in English, studies with international students in the United Kingdom revealed that knowing how to write in another language goes beyond understanding grammar to understanding how knowledge is constructed (Gow, 2014; Gu \& Brooks, 2008). Focusing solely on writing skills without a discussion of language terms and cultural views of knowledge may be inadequate for students to comprehend an institution's concept of academic honesty. In Holmes' (2004) research with Chinese students at a university in New Zealand, she observed that differing cultural views of knowledge, the failure of teachers to help students understand what constitutes plagiarism in their discipline, and the use of a language-learning strategy that involves students emulating the words of an expert may inadvertently lead to plagiarism.

Understanding English words does not mean one understands the concept behind the word. In an Asian Studies course developed for Chinese speakers at an Australian university, professors sought to meet the needs of the students by designing an interactive course which they conducted bilingually in English and Chinese (Song \& Cadman, 2013). As part of the course, the students and professors discussed research terms and clarified concepts. The professors found it necessary to demystify "often 'secret' terms associated with the Western academy" (p. 263) such as research, primary and secondary data, and logic. The students discussed their experiences with the various terms, engaged in activities, and reached a consensus on the meaning of the terms. The students were then given assignments to demonstrate their awareness and proficiency in the use of the terms.

Researchers at the University of Albany (Chen \&Van Ullen, 2011) designed and conducted two workshops for international students, one on the research process and another on plagiarism. Most of the study participants were graduate students. The researchers gave pre-tests and posttests in each workshop to discern students' understanding. The workshop post-tests showed a statistically significant increase in the students' understanding of both the research process and plagiarism. Because Asian students were the largest group of international students and composed more than $75 \%$ of the study participants, the researchers compared their scores with those of the non-Asian participants. They found no statistical difference 
between the scores of the two groups. Because of the emphasis in research in doctoral programs, the authors were surprised that there was also no statistical difference between the masters students' and the doctoral students' scores. The authors noted, however, that most of the doctoral students were in their first year in the United States and "were at the same level of academic experience" (p. 122) as the masters students.

As noted previously, training on plagiarism and academic honesty policies offered to all students differs from university to university and also differs based on whether one is an undergraduate or a graduate student (Jamieson, 2008; Pecorari, 2008). In their study, Voelker, Love, and Pentina (2012) found little difference between undergraduate and graduate students in the students' understanding of plagiarism. They concluded that many low-performing students may have heard about plagiarism and understand the consequences but "genuinely do not understand what plagiarism means" (p. 40). In the university where the current study was conducted, in order to register, all freshmen undergraduates and transfer students are required to have a perfect score in an online academic integrity tutorial. There is no similar requirement for graduate students though plagiarism and academic honesty are mentioned in graduate orientation. Howard (2008) noted that in the educational model where knowledge passes from the professor to the student, it may be assumed that graduate students already know the rules. Howard observed that for faculty, plagiarism among graduate students often "takes on intensified force" (p. 92) because faculty mentor graduate students, see them as future colleagues, and may collaborate or coauthor articles with them.

\section{RESEARCH METHOD}

For this study, the workshop format for sharing knowledge was chosen because previous research has indicated the efficacy of workshops in assisting international students to better understand their host university's expectations (Chen \& Van Ullen, 2011; Craig et al., 2010). Scenarios were used in the post-test to examine the participants' understanding of the concepts that were presented (Song \& Cadman, 2013). The quantitative data obtained from the workshops served as a starting point for the qualitative portion of the study. The research questions were: (a) Does an academic integrity workshop that is taught from a cultural perspective influence Asian graduate students understanding of a U.S. American university's concept of academic integrity and plagiarism? (b) How do Asian graduate students' cultural perception of knowledge influence their understanding of a U.S. American university's concept of academic integrity and plagiarism?

An explanatory sequential mixed methods research design was chosen in which the quantitative study of the workshop's effectiveness was 
to be followed by a qualitative case study investigating selected participants' academic experiences in their home and host cultures. A University Research Grant was obtained from the university site, approval was received from the Institutional Review Board, and a research team was assembled. After a thorough examination of the literature, the team developed workshop objectives with an expectation that the workshop would equip the participants to understand the university's perspective concerning:

- Academic dishonesty including plagiarism and self-plagiarism.

- The concept of common knowledge.

- Paraphrasing, including improper paraphrasing and patchwriting.

- Proper and improper citation practices.

- Acceptable research practices and practices that put one in danger of being academically dishonest.

- The consequences of committing plagiarism.

- The concept of intellectual property, including code of ethics, patents, copyrights, and trade secrets.

The research team prepared the workshop and a power point presentation that would meet the workshop objectives, entitling the workshop, "Making Good Decisions (MGD).”

The research team constructed a summative test to assess the workshop's effectiveness. Most of the questions were scenario-based and asked the respondent to identify whether or not the action in the scenario was allowable or would put the student at risk of being academically dishonest. Initially, 90 questions were developed, tested, and discussed. The final test was composed of 55 scenario-based questions and eight multiplechoice questions for a total of 63 questions. Pilot testing showed that the test required from 30 to 40 minutes to complete. The test was put into Qualtrics, an online survey site, for workshop participants to complete online following the workshop.

An invitation to participate was sent to the more than 200 Asian graduate students enrolled at the university through the International Education Office. The invitation offered each student a $\$ 25$ gift certificate to a local grocery store for his or her participation. Response was minimal. In further email communications, more details about the workshop were communicated, assuring confidentiality and focusing on the research team's desire to increase cross-cultural understanding. Investigations revealed that some students were confused about the research process and were concerned that findings might put them in a negative light. In spite of the small response, it was decided to continue the investigation as a basis for further studies.

The MGD workshop was offered three times and was conducted in the university library computer lab by the member of the research team with 
the most cross-cultural experience. A total of 19 Asian graduate students participated in the workshops though only 17 completed the post-test in the allotted 40-minute time following the workshop. It was decided that demographic data would not be requested because of the students' reluctance to engage in the research project and their fear of having responses traced to them. All 19 students responded to questions at the end of the post-test about their perception of the workshop's effectiveness in increasing their understanding of academic honesty, plagiarism, and intellectual property.

For the qualitative portion of the study, twelve of the MGD workshop participants were contacted and asked to participate. Ultimately, only three students agreed to be interviewed. None of the students with the lower scores agreed to be interviewed. The three participants, one male and two females, were from India, Bangladesh, and South Korea. The two females were in doctoral programs, one in the School of Education and the other in the School of Arts and Sciences and both had received their undergraduate and master's degrees in their home countries. The male was in a dual master's program in the Social Sciences and had completed his undergraduate degree in his home country. The three participants were interviewed using a semi-structured format, a data analysis procedure typical to basic qualitative study where researchers are interested in discovering the meaning that individuals ascribe to their realities (Merriam, 2009). The interviews for the three participants were audio recorded and were conducted by the research team member who conducted the MGD workshops. The recordings were transcribed, and the transcriptions were approved by the participants.

The interview transcripts were read several times and comments were divided into those comments that pertained to the participants' home countries and those that pertained to their experiences in the United States. The two groupings were divided into categories and further coded (Creswell, 2013) as themes emerged. It was decided, following approval from the Institutional Review Board, to move to a multi-phase research design. The purpose of the second phase was to obtain more data in order to answer the first research question concerning the workshop's effectiveness by asking volunteers from the general graduate student population to take the test without having the workshop. The Graduate School and various Graduate Student Association representatives advertised this opportunity for graduate students at the university. A $\$ 15$ gift card to a coffee shop was given to those who chose to participate. A convenience sample of 68 graduate students took the online test. One student stopped the test midway after missing several questions resulting in a total of 67 participants who completed the test. As the demographic questions were at the end of the test, it is not known if the student who stopped taking the test were an 
international student. Seven of the 67 participants self-identified as international students. Five of those seven were from Asian countries.

\section{Participants}

The Asian international graduate student population was not chosen because of an assumed difference between their responses and those of other international graduate students (Chen \& Van Ullen, 2011). Asians were the largest group of international graduate students at the research site and because the workshop was to be conducted from a cultural perspective, it was thought that choosing this population, even though varied, would reduce variables.

\section{RESULTS}

It is unfortunate that there were not enough participants to conduct the study as planned as an analysis of the test results suggested interesting trends that warrant further investigation. Participants' test scores were calculated on a possible 100 points. The lowest test score (63.5) was made by a student who did not participate in the MGD workshop but who took the test as part of the general graduate student population. This student self-identified as Asian but not as an international student. There were 1 Chinese, 3 Korean, and 1 student from Nepal who self-identified as international students for a total of 5 Asian students who took the test that was offered to all graduate students without benefit of the MGD workshop. The test mean of 88.7 for all of the graduate students who took the test without benefit of the MGD workshop was the same as that of the Asian graduate students who attended the MGD workshop. However, the mean score of the five Asian graduate students who took the test without benefit of the workshop was 80.3 with a range of 74.6 to 90.5 compared to a range of 77.7 to 100 for those Asian graduate students who took the MGD workshop. The only participant in all groups to correctly answer all of the test items was a student who attended the MGD workshop.

One portion of the test examined the participants' knowledge of acceptable paraphrasing. In this portion comprising 11 questions, participants were given a reference for an article. They were then given a one-sentence direct quotation from the article as well as a paraphrase of the sentence and were asked to identify whether the paraphrase were acceptable or if it put the writer at risk of committing plagiarism. Participants who did not take the workshop struggled more on this portion of the test than those students who took the workshop. Paraphrase examples from the test that participants said were acceptable but are not, are given below. The following is the APA reference given to the participants for the paraphrase questions. 
Barnard-Brak, L., Bagby, J. H., Jones, N., \& Sulak, T. (2011). Teaching post 9/11 student-veterans with symptoms of PTSD: The influence of faculty perceptions and self-efficacy. Journal of Vocational Rehabilitation, 35, 29-36. doi: 10.3233/JVR-2011.0551

Quotation \#1: "With large numbers of student veterans returning to higher education due to the reauthorization of the GI Bill, faculty and staff's ability to serve the needs of these students becomes a salient issue.”

Paraphrase \#1: With great numbers of student veterans returning to college due to the reauthorization of the GI Bill, professors' ability to serve the needs of these student veterans becomes an important issue (BarnardBrak, Bagby, Jones, \& Sulak, 2011).

Patchwriting is the process of substituting vocabulary or phrases for words in an original sentence, often leaving the structure of the original sentence intact. None of the workshop participants said that Paraphrase \#1, an example of patchwriting, was acceptable whereas $31 \%$ of those participants who did not take the workshop incorrectly said Paraphrase \#1 was acceptable.

Paraphrase \#2: Barnard-Brak, Bagby, Jones, and Sulak (2011) note that with the increasing student veteran population, faculty and staff's ability to serve the needs of these students becomes a salient issue.

From those taking the MGD workshop, 2 of the 17 participants, $12 \%$, incorrectly said Paraphrase \#2 was acceptable whereas 23 of the 67 students who only took the test, $34 \%$, incorrectly said Paraphrase \#2 was acceptable.

Quotation \#2: "We surveyed 596 faculty members as to their views of serving in the military, the United States' involvement in the Iraq/Afghanistan wars and perceptions of their ability or self-efficacy to address the special needs of combat veterans in the classroom."

Paraphrase \#3: Barnard-Brak, Bagby, Jones, and Sulak (2011) surveyed 596 faculty members as to their views of serving in the military, the United States' involvement in the Iraq/Afghanistan wars and perceptions of their ability or self-efficacy to address the special needs of combat veterans in the classroom.

Although Paraphrase \#3 is almost exactly the same as the quotation, two of the 17 workshop participants (12\%) and 20 of the 67 graduate 
students who only took the test (30\%) incorrectly said Paraphrase \#3 was acceptable and would not put the student in danger of committing plagiarism.

The MGD workshop participants used a 5-point Likert-type scale to respond to questions concerning how they perceived the MGD workshop. Sixty-three percent of the participants agreed or strongly agreed that their understanding of the issues surrounding academic integrity and plagiarism were greater following the workshop.

The three graduate students from India, Bangladesh, and South Korea who had participated in the MGD workshop agreed to be interviewed on condition of anonymity. In spite of the wide cultural differences between the three countries represented, the participants' responses (P1, P2, and P3) were surprisingly similar. Specific participant descriptions linking participants to their comments will not be given in order to preserve confidentiality. The following seven themes emerged from the interviews.

\section{Theme 1: Participants' home population's view of sharing knowledge.}

All of the participants spoke of the importance of sharing knowledge, whether it be sharing knowledge freely with family or others of the same social status or impressing others with ones' knowledge. In communal societies they noted that knowledge is to be shared, and it is not necessary to attribute knowledge to a specific individual. P3: "Knowledge is a much freer concept .... . If an old man dies with knowledge that he did not teach to someone else, it would be quite shameful."

Though this concept of knowledge may be the general public's view, students are expected to have specialized knowledge pertinent to their field. In educational systems where students may choose a profession when they begin high school, students often study only topics relevant to that field. According to one participant, students accustomed to specialized knowledge may have difficulty understanding the goals of a liberal arts education in the United States and may turn to plagiarism when required to take courses that do not appear to contribute to the student's main career goals and in which the student has little background.

\section{Theme 2: Participant's home population's view of copyright.}

All of the participants conceded that while there were copyright laws in their countries, they were difficult, if not impossible, to enforce.

P3: "The concept of selling books doesn't arise. ... [my people] are quite voracious readers but they have no problem photocopying books.”

In the more impoverished countries, a lack of resources drove students and faculty alike to find materials wherever they could. 
Theme 3: Students' higher education experiences in their home countries and attitudes toward academic honesty and plagiarism.

The participants painted a picture of an educational system in their homelands where teachers and older people are respected for their knowledge, and students are expected to be respectful receivers of that knowledge.

P1: "The teacher being authoritative and the student being deferential is still quite strongly in place. . . .It has become a little more relaxed over the last 10 or 15 years."

P2: "It is hard to get close . . . the teacher and student. They are different.”

P3: "There are countless sayings, old proverbs like, "Worship your teacher." There is always the concept that the teacher is the smarter person because they are the ones doing the teaching. Nothing can change that."

None of the three participants had been asked to do research until they attended university. With limited access to academic databases or outdated library resources, faculty were often lenient.

P1: "Definitely they [students] will sometimes take a paper from somewhere whether it's online or a book or get someone else to write it or take an old paper from a sibling or a friend and they will pass it off. The consequences will really vary. A lot of teachers don't even check to see if it were plagiarized. And for those who do, I don't think that anyone really turns a blind eye entirely, but the severity of the punishment varies."

P2: "As a freshman, I would always copy and paste, copy and paste. In college, the professors did not check. In graduate school, however, a professor said we could not do that."

Theme 4: Participants' orientation experiences concerning academic honesty and plagiarism issues prior to and upon arrival at a U. S. American university.

The participants' experiences varied concerning their orientation to academic honesty issues in their host countries. The South Korean participant talked about the prevalence of guidebooks that discussed the issue, guidebooks which prospective students and their parents habitually read. The other participants received no orientation but "picked up" information about academic honesty once they arrived in the United States if their professors happened to discuss the issue when going over the syllabus. One participant learned about plagiarism "the hard way."

Theme 5: Participants' perceptions of fellow international students' attitudes toward the emphasis North American universities place upon academic honesty issues. 
Two of the participants mentioned the students' frustration, feeling the emphasis that North American universities placed on the issue was extreme. One participant's frustration arose from believing there was little new knowledge, especially in the area of textual criticism. Feeling that the responsibility of researching others' work, just to be sure that what the student was writing and thought to be original had not been written before, was an oppressive burden. The student feared that without such research, an expert in the field who was familiar with others' writings may believe that the student had plagiarized another's ideas, even if the student's work were original.

Another participant believed that plagiarism was not an issue of unfamiliarity with English but was more unfamiliarity with liberal arts curriculum where international students in a particular study track who had studied biology, for example, since high school suddenly found themselves thrust in a U.S. history course where they had no background and little interest. Plagiarism often made sense to them in those instances where all they cared about was getting through the course as quickly as possible so they could spend their time in their chosen field.

Theme 6: Participants' suggestions of how they would approach the topic of plagiarism if orienting international students from their home countries.

All of the participants said they would stress the consequences of committing plagiarism as well as emphasizing the hard work involved in learning the academic skills so students would not be tempted to plagiarize. They also mentioned the importance of developing an academic community.

P1: "I would probably also talk a little bit about pride in one's work, so that I'm not approaching it, right from the beginning, with negativity but also telling students why, in general, it's just nice if you've done your own work and not just depended on someone else. Especially because a lot of them are spending money to be here, they're trying to get an education, so why not get the full experience and have something they can call their own?"

P3: "Explain the concept of stealing and compare it to real stealing - and this is real stealing, in the academic culture, that is universal, I think. But compare it to what is a tangible thievery in their own culture ... . Yes, knowledge is free, and yes, anyone could have spent the time - maybe - and gotten it, but this is years of study so it belongs to someone. So, if you take it, you've stolen it, unless you give them credit.”

Theme 7: Participants' beliefs concerning what administration in North American institutions of higher education need to know about the topic of international students and plagiarism. 
The participants agreed that it was necessary to have plagiarism workshops and orientation for newcomers, especially graduate students who did not do their undergraduate work in a North American institution. Their suggestions included not assuming that plagiarism is a moral or ethical issue but more of an issue of ascribing different cultural meaning to the practice of using others' ideas. When asked what university administration needed to know, one participant spoke candidly.

P1: "I think they definitely need to know that ... this is how it is in other countries .... it really almost has no importance in a lot of other countries. “

The participant continued by saying that in countries where copyright laws are difficult to enforce, academic authors "put books together" to help the students without an expectation of royalties.

P1: In some ways it [putting books together] is good, and in some ways it is bad . . . it's like it's good that people would now only put a book together because of the good it would do for students who are going to use it. That is also, I think, kind of holding some people back from doing any hard work because they know, there isn't going to be a lot of money in this.”

\section{DISCUSSION AND CONCLUSIONS}

The purpose of this study was to assess the influence of a workshop, taught from a cultural perspective, on Asian international graduate students' perceptions of a U. S. American university's concept of plagiarism and academic honesty and to learn about the participants' concepts of textual practices in their home countries. Though there were not enough participants to conduct the study as initially envisioned, moving to two phases and examining the process provided insight into the dynamics involved when addressing academic honesty issues cross-culturally.

Many Asian graduate students were reluctant to participate in the study. It is not known whether their reluctance is indicative of sensitivity to the topic, a lack of familiarity with the research process, or simply the result of busy schedules typical of graduate students. Research in the area of survey nonresponse suggests that in cultures where the communication style includes understanding the context of a message, people may look for hidden motives if the interviewer is not a member of the in-group (Johnson, O’Rourke, Burris, \& Owens, 2002). In one study in Hong Kong, interviewers used focus groups when interviewing students because students were "usually scared” when interviewed individually (Kwong, Ng, Kai-Pan, \& Wong, 2010, p. 344).

The first research question was: Does an academic integrity workshop that is taught from a cultural perspective influence Asian graduate 
students understanding of a U.S. American university's concept of academic integrity and plagiarism? In spite of a reluctance to participate, 63\% of those students who took the workshop agreed or strongly agreed that their understanding of plagiarism and academic honesty were greater following the workshop. Sixty-eight percent stated that they had a greater understanding of paraphrasing. Participants from the qualitative portion of the study reported limited orientation concerning plagiarism before they left their home countries with one learning about the topic "the hard way" following arrival. Though these results cannot be generalized to the larger population of international graduate students, the participants' experiences illustrate the danger of assuming incoming international graduate students understand their host university's expectations when it comes to academic dishonesty and plagiarism.

Research has shown that international students studying in a foreign language need practice in knowing how to paraphrase correctly (Liao \& Tseng, 2010). Because the test was offered to graduate students who did not take the workshop, unforeseen results revealed confusion in the general graduate student population concerning acceptable paraphrasing practices. It may be beneficial for universities to provide all graduate students with information on correct paraphrasing, especially concerning the unacceptability of patchwriting.

The second research question was: How do Asian graduate students' cultural perception of knowledge influence their understanding of a U.S. American university's concept of academic integrity and plagiarism? In the qualitative portion of the study, though there are distinct differences in how the three Asian cultures represented view knowledge, the students from these cultures all agreed that in their home cultures, knowledge is seen as something that needs to be shared. They described people in their countries as sometimes being more interested in obtaining knowledge than worrying about respecting others' supposed rights of ownership. They noted the "extreme" views they found in the U. S. where it sometimes appeared as if university leadership were more interested in catching perpetrators than in offering training. This finding agrees with that of Awdry and Sarre (2013) when they noted that "tutors should focus less on the detection and punishment of plagiarism and more on the value of students completing their own work and valuing their own integrity” (p. 43). University leadership needs to be sensitive to this perception by showing their willingness to provide training on the academic literacy necessary to succeed in their environment (Song \& Cadman, 2013).

The primary limitation of this study was the small participant sample. With an insufficient number of willing participants, the results of this study cannot be generalized to larger Asian international graduate student populations. Also, all of the participants were drawn from the same 
research university in the Southwest of the United States. Participants in other academic settings may have responded differently.

\section{IMPLICATIONS}

With students in higher education becoming more mobile, there is an increasing need for better intercultural communication between students and university faculty or staff, especially on topics such as academic integrity and plagiarism which are often influenced by cultural values. People's views of whether knowledge should be shared or can be owned may influence their attitudes toward these topics. Making value judgments without proper orientation to cultural differences discourages students and faculty alike and can lead to adversarial positions. International students can benefit from training that discusses academic honesty issues from a cultural perspective as they are led to understand and adhere to their host university's policies.

There may be an assumption among higher education leadership that all students who enter graduate programs already understand an institution's expectations when it comes to academic honesty and plagiarism. This assumption may be false, however, especially when students completed their undergraduate education at other universities. Institutions of higher education must provide adequate orientation programs to all incoming graduate students, domestic students as well as international students, especially if there is confusion about such issues as acceptable paraphrasing practices.

In these days of continuing internationalization of higher education, exploring the cultural elements of academic honesty and meeting the need of the entire graduate student population to develop paraphrasing skills will also help international students understand expectations and will assist universities to address academic honesty concerns on campus.

Research is needed to study the issues that emerged in this study. Research might reveal how university faculty and administration can be more culturally sensitive in addressing academic honesty concerns with international students. If international students are reluctant to address the topic, they may not be taking advantage of an institution's efforts to help them. Research is also needed to explore whether providing workshops that address academic integrity issues from a cultural perspective are more effective than general workshops that discuss the mechanics of plagiarism.

\section{REFERENCES}

Abasi, A. R., Akbari, N., \& Graves, B. (2006). Discourse appropriation, construction of identities, and the complex issue of plagiarism: ESL students writing in graduate school. Journal of Second Language Writing, 15(2), 102-117. doi: 10.1016/j.jslw.2006.05.001 
Abasi, A. R., \& Graves, B. (2008). Academic literacy and plagiarism: conversations with international graduate students and disciplinary professors. Journal of English for Academic Purposes, 7, 221-233. doi: 10.1016/j.jeap.2008.10.010

Amsberry, D. (2010a). Deconstructing plagiarism: International students and textual borrowing practices. The Reference Librarian, 51, 31-44. doi: $10.1080 / 02763870903362183$

Amsberry, D. (2010b). Plagiarism and the nontraditional student: Challenges and perspectives. In V. B. Cvetkovic \& K. E. Anderson (Eds.), Stop plagiarism: A guide to understanding and prevention (pp. 107-116). New York, NY: Neal-Schuman Publishers.

Awdry, R., \& Sarre, R. (2013). An investigation into plagiarism motivations and prevention techniques: Can they be appropriately aligned? International Journal for Educational Integrity, 9(2), 35-49.

Chen, Y.-H., \& Van Ullen, M. K. (2011). Helping international students succeed academically through research process and plagiarism workshops. College and Research Libraries, 72(3), 209-235.

Craig, P. A., Federici, E., \& Buehler, M. A. (2010). Instructing students in academic integrity. Journal of College Science Teaching, 40(2), 50-55.

Creswell, J. W. (2013). Qualitative inquiry research design: Choosing among five approaches (3rd ed.). Thousand Oaks, CA: Sage.

Day, K. (2008). Time is not on our side: Plagiarism and workload in the community college. In R. M. Howard \& A. E. Robillard (Eds.), Pluralizing plagiarism (pp. 43-61). Portsmouth, NH: Boynton/Cook Publishers.

Duff, A. H., Rogers, D. P., \& Harris, M.D. (2006). International engineering students - avoiding plagiarism through understanding the Western academic context of scholarship. European Journal of Engineering Education, 31(6), 673-681. doi: 10.1080/03043790600911753

Gallant, T. B. (2008). Academic integrity in the twenty-first century: A teaching and learning imperative. San Francisco, CA: Wiley Bass.

Gow, S. (2014). A cultural bridge for academic integrity? Mainland Chinese master's graduates of UK institutions returning to China. International Journal for Educational Integrity, 10, 70-83.

$\mathrm{Gu}$, Q. (2010). Variations in beliefs and practices: Teaching English in crosscultural contexts. Language and Intercultural Communication, 10, 32-53. doi: 10.1080/14708470903377357

Gu, Q., \& Brooks, J. (2008). Beyond the accusation of plagiarism. Science Direct System, 36, 337-352. doi: 10.1016/j.system.2008.01.004

Holmes, P. (2004). Negotiating differences in learning and intercultural communication - Ethnic Chinese students in a New Zealand university. Business Communication Quarterly, 67(3), 294-307. doi: 1080569904268141

Howard, R. M. (2008). Plagiarizing (from) graduate students. In R. M. Howard \& A. E. Robillard (Eds.), Pluralizing plagiarism (pp. 92-100). Portsmouth, NH: Boynton/Cook Publishers.

Hu, G., \& Lei, J. (2012). Investigating Chinese university students’ knowledge of and attitudes toward plagiarism from an integrated perspective. Language learning, 62(3), 813-850. doi: 10.1111/j.1467-9922.2011.00650.x 
Institute of International Education (2015). Open doors report 2014 fast facts. Retrieved from http://www.iie.org/opendoors

Jamieson, S. (2008). One size does not fit all: Plagiarism across the curriculum. In R. M. Howard \& A. E. Robillard (Eds.), Pluralizing plagiarism (pp. 7791). Portsmouth, NH: Boynton/Cook Publishers.

Johnson, T. P., O’Rourke, D., Burris, J., \& Owens, L. (2002). Culture and survey nonresponse. In Groves, R. M., Dillman, D. A., Eltinge, J. L. \& Litle, R. J. (Eds.), Survey nonresponse (55-70). New York, NY: Wiley.

Kim, H. Y. (2011). International graduate students’ difficulties: Graduate classes as a community of practices. Teaching in Higher Education, 16, 281-292. doi: 10.1080/13562517.2010.524922

Kwong, T., Ng, H.-M., M. Kai-Pan, \& Wong, E. (2010). Students’ and faculty’s perception of academic integrity in Hong Kong. Campus-Wide Information Systems, 27, 341-355.

Leki, I. (2006). Negotiating socioacademic relations: English learners’ reception by and reaction to college faculty. Journal of English for Academic Purposes, 5, 136-152.

Lewin, T. (2012, February 5). Taking more seats on campus, foreigners also pay the freight. The New York Times, pp. 1, 21.

Liao, M.-T., \& Tseng, C.-Y. (2010). Students' behaviors and views of paraphrasing and inappropriate textual borrowing in an EFL academic setting. Journal of Pan-Pacific Association of Applied Linguistics, 14, 187-211.

Lipson, C. (2008). Succeeding as an international student in the United States and Canada. Chicago: The University of Chicago Press.

Merriam, S. B. (2009). Qualitative research: A guide to design and implementation. San Francisco, CA: Jossey-Bass.

Mundava, M., \& Chaudhuri, J. (2007). Understanding Plagiarism. College \& Research Libraries News, 68, 170-173. Retrieved from http://crln.acrl.org/content/68/3/170.full.pdf+html

OECD. (2014). Education at a glance 2014: OECD indicators. OECD Publishing. Retrieved from http://dx.doi.org/10.1787/eag-2014-en

Pecorari, D. (2008). Academic writing and plagiarism: A linguistic analysis. New York, NY: Continuum.

Pfeuffer-Scherer, D. (2010). Plagiarism: University reaction and subsequent action. In V. B. Cvetkovic \& K. E. Anderson (Eds.), Stop plagiarism: A guide to understanding and prevention (pp. 95-106). New York, NY: NealSchuman Publishers.

Plagiarism. (2016). In Oxford Dictionaries online. Retrieved from http://www.oxforddictionaries.com/us/definition/american_english/plagiari $\mathrm{sm}$

Plagiarism. (2015). In Merriam-Webster dictionary online. Retrieved from http://www.merriam-webster.com/dictionary/plagiarism

Ramzan, M., Munir, M. A., Siddique, N., \& Asif, M. (2012). Awareness about plagiarism amongst university students in Pakistan. Higher Education, 64, 73-84. doi: 10.1007/s10734-011-9481-4

Robillard, A. E., \& R. M. Howard (2008). Introduction: Plagiarisms. In R. M. Howard \& A. E. Robillard (Eds.), Pluralizing plagiarism (pp. 1-7). Portsmouth, NH: Boynton/Cook Publishers. 
Sato, T., \& Hodge, S. R. (2009). Asian international doctoral students' experiences at two American universities: Assimilation, accommodation, and resistance. Journal of Diversity in Higher Education, 2, 136-148. doi: $10.1037 / \mathrm{a} 0015912$

Shi, L. (2006). Cultural backgrounds and textual appropriation. Language Awareness, 15, 264-282. doi: 0965-8416/06/04 0264-19

Song, X., \& Cadman, K. (2013). Education with(out) distinction: beyond graduate attributes for Chinese international students. Higher Education Research \& Development, 32, 258-271. doi: 1080/07294360.2012.673573

Song-Turner, H. (2008). Plagiarism: Academic dishonesty or 'blind spot' of multicultural education? Australian Universities’ Review, 50(2), 38-50.

Voelker, T. A., Love, L. G., \& Pentina, I. (2012). Plagiarism: What don't they know? Journal of Education for Business, 87, 36-41. doi: 10.1080/08832323.2011.552536

LANETTE W. THOMPSON, PhD, is the Assistant Director for Student Life Assessment and Planning at Baylor University. Her research interests include assessment, adult learning, and intercultural communication. Email: lanette_thompson@baylor.edu

JANET H. BAGBY, $\mathrm{PhD}$, is a Senior Lecturer for the Educational Psychology Department at Baylor University. Besides teaching, she mentors students and researches non-traditional students' effective transitions to academia. Email: janet_bagby@baylor.edu

TRACEY N. SULAK, PhD, is a Clinical Assistant Professor in educational psychology at Baylor University. Her research and teaching interests include school climate and teacher education. Email: Tracey_Sulak@baylor.edu

JANET SHEETS, MLS, is an Associate Professor Emerita from the Baylor University Libraries where she was the Liaison Librarian for the School of Education. Email: Janet_Sheets@baylor.edu

TONYA M. TREPINSKI, PhD, is an adjunct professor at Texas A \& M International University. She teaches special education and behavior analysis courses. She also works as a college adviser at a private school. Email: tonya.trepinski@tamiu.edu

Manuscript submitted: August 11, 2015 Manuscript revised: January 24, 2016 Accepted for publication: May 5, 2016 
ISSN: 2162-3104 Print/ ISSN: 2166-3750 Online

Volume 7 Number 1 (2017), pp. 154-159

(C) Journal of International Students

http://jistudents.org/

\title{
But I Don't Understand You: One Faculty's Observations of the Challenges Facing International Healthcare Students
}

\author{
Cheryl O. DuBose \\ Arkansas State University, Jonesboro, USA
}

\begin{abstract}
International students face many challenges when pursuing a degree in higher education. Communication and cultural differences are typically cited as the most challenging aspects of any study abroad program. Students attempting to complete a healthcare program face sometimes insurmountable issues, as communication, cultural differences, and discrimination play a large role in providing quality patient care. This paper is a commentary on my experiences as a faculty member with various international students enrolled in healthcare programs in the southeastern United States.
\end{abstract}

Keywords: communication, cultural differences, discrimination, healthcare, international students

When I hear that international students are interested in my program, I experience both excitement and trepidation. From which countries have they traveled? What have they seen? What are their native languages? How well can they communicate in English? How long have they lived in the South? What are their religious backgrounds? Do they plan to remain here in the States, or return to their homeland?

While the answers to these questions do not affect student admittance into the healthcare program, the answers do affect my teaching and the culture in the classroom. Some will argue that it shouldn't, that my teaching should be the same regardless of the origin of the student. My rebuttal to this argument is effect size: my classroom size (population) is small enough that each student affects the dynamic and culture of the learning environment. As an instructor in a relatively homogeneous area in 
the rural South, my classrooms typically consist of Caucasian males or females who were born and raised in the Bible-Belt region. Their siblings, parents, grandparents, and great-grandparents live nearby and attend the same Christian-based church every Sunday. This homogeneity makes teaching easy, if somewhat boring.

Now let us introduce an "outsider." Someone who will challenge the status quo; who will introduce diversity and new ideas. Someone who has traveled a great distance to study abroad and experience new things. Someone with the courage to leave the "known" for the "unknown," abandoning family and friends in the search for life-changing experiences. Someone who is open to new ideas and perspectives. International students are to be admired for their tenacity and willingness to pursue unique learning experiences. But what if I don't understand them?

According to the Institute of International Education, there were 974,926 international students studying in the United States in 2014-2015 (Institute, 2016). Of these, 33,399 majored in the health professions. Of the top 10 countries of origin, only one (Canada) could be considered similar in language and culture to the United States. Other countries within the top 10 included: China, India, South Korea, Saudi Arabia, Brazil, Chinese Taipei, Japan, Vietnam, and Mexico. These countries have varying primary languages and extremely diverse cultures. Not only is it challenging for international students to acclimate to coursework here in the United States, but it is a challenge for faculty to meet the individual needs of these students (Mantzourani, Courtier, Davies \& Bean, 2015).

\section{COMMUNICATION CHALLENGES}

Communication issues are, by far, the biggest hurdle for international students in a healthcare program. Not only is English the primary (and usually only) language spoken in the southeastern United States, but the local accents can make it difficult for any non-locals to understand. A classic example of this can be seen by the use of subtext during an episode of the highly controversial show, Here Comes Honey Boo-Boo, a reality television series which follows the life of a family in rural Georgia (Cavalcante, 2014). The use of subtext implies that even the English speaking public cannot understand the rural southeastern dialect. Now, imagine that English is your second language. Comprehension and communication becomes even more difficult as the English taught during their primary education years does not align with the English actually used by their teachers, fellow classmates, and patients.

While English comprehension in the southeast is challenging, the anxiety created by the language barrier drastically increases when students 
are asked to participate in formal oral discussions (Bista, 2012). However, research has shown that informal conversations, such as those found with patients and peers in clinical practice, can greatly increase communication skills (Lee, 2016; Mesaroli et al, 2015). A study by Mesaroli et al (2015) found that international students believed their interactions with patients enhanced their overall communication skills and "improved their ability to use short, direct questions" (p.388).

We cannot discuss communication challenges in healthcare programs without discussing medical terminology, an additional language of words and phrases used to describe various human anatomy and physiologic processes (based on the languages of Greek and Latin). International students, as well as domestic students, are tasked with learning another language to correctly interpret physician orders or patient history. Without a comprehensive understanding of medical terminology, quality patient care will suffer. This challenge is easily remedied by requiring all students to use proper medical terminology during classroom discussions and journaling, reinforcing textbook learning of medical terminology and improving overall communication skills in the clinical environment.

To further combat various communication issues, faculty should pay special attention to student participation levels during group discussions or patient interactions. Although international students typically study English for years prior to studying abroad, many are apprehensive and reluctant to participate in discussions due to their perceived (or realistic) shortcomings (Bista, 2012). However, studies show that communication skills greatly increase with extended use, so students should be encouraged to practice these skills (Lee, 2016; Mesaroli et al, 2015). To optimize student learning, a classroom environment safe from derision or condescension should be created.

\section{CULTURAL DIFFERENCES}

The second challenge for international students involves the inherent cultural differences that exist between the southeastern U.S. and the student's native country. A former international healthcare student once stated that:

In Nigeria, looking straight into the eyes of someone above you in age, education, and skills is considered disrespectful and daring. On the contrary, here in the United States, it is expect that you look into someone's face/eyes whenever you speak to the person.

Trust between the patient and healthcare providers is imperative, and in the U.S., a lack of eye contact may be interpreted by the patient or 
public as disrespectful or breeding distrust. This student claims to have a non-assertive nature, which has been misinterpreted as being scared, eroding the patient's or clinical instructor's trust in his abilities to successfully complete his healthcare duties. He found that to be successful as a student in a U.S. healthcare program, he had to be louder, more assertive, and had to "look at people straight in the eyes."

While this information is not necessarily new, it is still relevant in today's educational programs. It may take several years for international students to assimilate to a new culture, affecting their academic and clinical performances. Healthcare programs in these modern times may stress cultural awareness for faculty and students, but what about our clinical settings? Are they adequately prepared for the challenges facing international students? Are clinical preceptors receiving training prior to teaching these students? An affirmation of cultural training for personnel who assist educational programs at the hospital or outpatient clinical setting will reduce misunderstandings and provide a better experience for the clinical site and the student.

The clinical setting can be a stressful environment, and international students may have a difficult time expressing related challenges or issues. Many healthcare programs encourage reflection to help students process their feelings about events occurring during clinical rotations. Some international students claim that using various reflection activities (e.g. journaling or debriefing with instructors or peers) help them develop an insight into their personal strengths and biases, as well as internalize the importance of understanding the local culture and values (Mesaroli et al, 2015). This reflection improves communication with the local population, reduces anxiety associated with unknown cultural challenges, and improves the overall educational experience for the student.

\section{DISCRIMINATION}

Finally, experience has shown that human bias and discrimination still exists in society and the classroom. Stories abound of students with perceived or actual slights based on their cultural differences or inferior language skills. While a low score for a poor essay may be justifiable to some professors, it is unacceptable to discriminate on clinical performance based solely on cultural differences. For example, one student narrative described the failure of a practicum exam because an injured hand was angled 41 degrees instead of the traditional 45 degrees for visualization. However, a domestic student examined the wrong body part and still passed the practicum. Perhaps there is a worthy explanation for the apparent grading bias, or perhaps discrimination was on display. 
Discrimination is not limited to the classroom, but may also be seen during clinical experiences. Difficulties arising from communication issues and cultural differences lend themselves to decreased quality clinical experiences, as some healthcare employees avoid the student simply because it is more difficult to communicate. While cultural sensitivity and training at the healthcare setting is an ideal solution, international students can overcome many of these issues with patience. One student from Nigeria shared his experience by stating that, "there was one [who was] not friendly at first, but eventually things became better." This same student also shared with me a triumphant story: the healthcare worker who was originally discriminatory would later present him with a gift following the birth of his son.

Repeated experience has shown that time breeds familiarity, increasing the comfort and acceptance levels for many international students in the healthcare setting. This should be considered when placing international students in clinical assignments. The longer the student is allowed to stay in each rotation, the easier it may be to improve communication skills and reduce discrimination.

\section{CONCLUSION}

Despite the challenges faced by international students, the majority with whom I have interacted appear to appreciate their time spent learning in the United States. Of those students entering my healthcare program, all agree that English proficiency is the single most important factor for success. As an instructor, communication is my primary concern when discussing admittance to an international student. Once admitted into the healthcare program, there is little time to spend on significant improvements of oral or written English competency. However, international students have repeatedly demonstrated an improvement in oral communication skills throughout the program. Students should also be prepared for cultural differences and open to learning the best methods to connect with their patients and peers. No matter the chosen profession, healthcare providers interact on a daily basis with their peers and the public. Quality patient care is the global standard, and international students are a contributing factor to our success.

\section{REFERENCES}

Bista, K. (2012). Silence in teaching and learning: Perspectives of a Nepalese graduate student. College Teaching, 60, 76-82. doi: $10.1080 / 87567555.2011 .633943$ 
Cavalcante, A. (2014). You better 'Reneckognize'!: Deploying the discourses of realness, social defiance, and happiness to defend Here Comes Honey Boo Boo on Facebook. Reality Television: Oddities of Culture, 39-58.

Institute for International Education (2016). Project Atlas: United States. International students in the United States. Accessed on March 31, 2016 from http://www.iie.org/Services/Project-Atlas/ United-States/International-Students-In-US.

Lee, E. (2016). International and American students' perceptions of informal English conversations. Journal of International Students, 6(1); 14-34.

Mantzourani, E., Courtier, N., Davies, S., and Bean, G. (2015). Perceptions of faculty in health care and social sciences on teaching international students. Currents in Pharmacy Teaching and Learning, 7(5); 635-644. doi: 10.1016/j.cptl.2015.06.018. .

Mesaroli, G., Bourgeois, A., McCurry, E., Condren, A., Petropanagos, P., Fraser, M., and Nixon, S. (2015). Enhanced patient-centred care: Physiotherapists' perspectives on the impact of international clinical internships on Canadian practice. Physiotherapy Canada, 67(4); 385-392. doi: 10.3138/ptc. 2014-57GH.

CHERYL O. DUBOSE, EdD, is the Program Director and Assistant Professor for the Magnetic Resonance Imaging program at Arkansas State University. Her research interests include social media use in higher education, generational differences, communication, and all things in medical imaging. Email: cdubose@astate.edu. 
Book Review

ISSN: 2162-3104 Print/ ISSN: 2166-3750 Online Volume 7 Number 1 (2017), pp. 160-162

(c) Journal of International Students http://jistudents.org/

\section{Exploring the Social and Academic Experiences of International Students in Higher Education Institutions}

Bista, K., \& Foster, C. (2016). Exploring the social and academic experiences of international students in higher education institutions. Hershey, PA: IGI Global, pp. 363; \$185.00 (hardback), ISBN13: 978-14666-9749-2

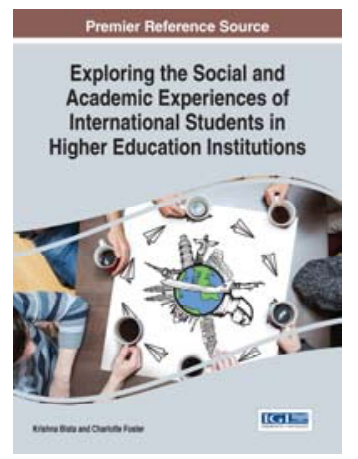

Reviewed by

Sherrie Lee, University of Waikato, New Zealand

This edited book explores the multifaceted experiences of international students in higher education. With an increasing presence of international students in universities across the globe, there is a need for a greater awareness of such a diverse student population. Although the studies in this book are mostly based in North American educational settings, the range of topics reflects important ongoing and emerging issues.

Academic acculturation is a major theme that is addressed throughout the book. In particular, several chapters focus on the experiences of groups of undergraduate or postgraduate students. Chapter One examines the experiences of eight postgraduate students in a US university, while Chapter Three investigates the experiences of 20 undergraduates in a New Zealand university. The interview studies of these chapters reveal how inadequate English proficiency and cultural differences hamper international students' learning opportunities and their ability to form meaning relationships with their domestic peers. In Chapter Ten, focus group discussions revealed a need for ESL curriculum to be discipline-specific, as well as to support students' communicative competence in social settings. Chapter Nine examines international teaching assistants in relation to mentoring efforts and strategies provided by their departments. The authors found that many teaching assistants desired explicit mentoring approaches, 
especially when they were not familiar with cultural norms and teaching methods.

Other chapters explore the dynamics of intercultural interactions between international and domestic students. Chapter Two focuses on the dynamics of intercultural interactions among international and domestic postgraduate students at a Canadian university. Through in-depth interviews with ten students, the authors found a lack of interest among domestic students about their international classmates. In response, international students sought solidarity and support from fellow international students. Chapter Fourteen describes a two-year ethnographic study which tracked the study experiences of two Japanese students enrolled in the same teaching training program. The combination of observations, multiple interviews and reflective field notes produce a compelling narrative of how faculty members had low academic expectations of the students. As a result, faculty failed to address students' academic weaknesses and limited their professional development. The author also showed that cultural dominance and White superiority impacted teaching practices in this study.

Race, ethnicity and identity are prominent themes that emerged in this text. While racial discourses are frequent in the US, international students often have different ways of understanding the concepts of race, ethnicity and identity, and how these concepts apply to them. Chapter Four explores how students' conceptions of racial terms such as 'Black' and 'White' were experienced in their home countries and how they perceived and experienced these racial concepts in a US educational institution. Chapter Five deals with a similar topic but focuses exclusively on the experiences of African students and how they negotiate the racial identity of 'Black', in particular, Black racial solidarity. The authors found that the African students shared the perspective of the common fate for Black people but nonetheless perceived themselves as distinct from native-born Blacks in the US.

The theme of racial discourse is further explored through the topics of neo-racism and racial stereotypes. Chapter Eleven focuses on participants from sub-African and Caribbean countries. Using the lenses of selfdetermination theory and neo-racism, the authors found that while students had high levels of motivation to succeed academically, their domestic peers did not readily recognize those strengths, potentially because of negative media coverage of the countries from where the students came from. Chapter Eight examines East Asian students' racial stereotypes and experiences in their social relations. The authors found that students had a strong notion of racial hierarchy in which 'White' people were at the top, followed by 'East Asian', 'Latino', African-Americans' and 'Southeast Asian'. While there were instances of positive interactions with domestic 
students, racial prejudices and limited interactions with other racial groups were predominant.

An important but neglected aspect of the international student experience is the experience of their partners. While partners are a valuable source of social and emotional support to international students, they themselves face adjustment issues. Chapters Six and Seven focus on the experiences of the partners of international students at North American universities. The authors show how structural factors such as visa conditions and institution policies contribute to the partners' sense of isolation and a lack of purpose in life. The authors also recommend changes and policies and practices that increase recognition and support for students' partners.

The remaining chapters in the book focus on the use of large-scale survey data to inform institutional support of international students. Chapter Twelve reviews how the International Student Barometer, a US campuswide survey regarding student satisfaction and students' overall experience, has been used with other sources of data to initiate changes in institutional practices and ultimately improve internationalization efforts to benefit all students. Chapter Thirteen examines the differences in academic achievements of different cohorts of US undergraduates - first-time freshmen, exchange visitors, and international transfer undergraduates from community colleges. Such demographic data is useful for informing admission policies and targeting increased student support at appropriate groups of students.

Finally, Chapter Fifteen provides a multi-institutional large-scale survey showing how international students' participation in high-impact educational practices was positively associated with their academic engagement and academic skills development. There is no doubt about the complexities and challenges of enhancing international students' experiences as illustrated throughout the preceding chapters. Nonetheless, the final chapter signals a positive and forward-looking attitude towards successful intervention and support.

The book provides a variety of perspectives to understand the diversity of the experiences of international students. Faculty, researchers, administrators and policy makers will find this book a useful resource for guiding institutional changes and future research.

SHERRIE LEE is a $\mathrm{PhD}$ candidate at the Faculty of Education at the University of Waikato. Her research focuses on academic learning practices of international students using an ethnographic approach. She completed her Master of Arts in Teaching (TESOL) at the University of Southern California and was formerly a business communications lecturer at a polytechnic in Singapore. E-mail: csl15@students.waikato.ac.nz 